\title{
Updates to Finnish aphyllophoroid funga (Basidiomycota): new species and range extensions
}

\author{
Kunttu $\mathbf{P}^{1^{*}}$, Juutilainen $\mathrm{K}^{2}$, Helo $\mathrm{T}^{3}$, Kulju $\mathrm{M}^{4}$, Kekki $\mathrm{T}^{5}$ and Kotiranta $\mathbf{H}^{6}$ \\ ${ }^{I}$ World Wide Fund for Nature, Lintulahdenkatu 10, FI-00500 Helsinki. \\ ${ }^{2}$ Department of Biological and Environmental Science, P.O. Box 35, FI-40014 University of Jyväskylä. \\ ${ }^{3}$ Erätie 13 C 19, FI-87200 Kajaani, Finland. \\ ${ }^{4}$ Biodiversity Unit P.O. Box 3000, FI-90014 University of Oulu, Finland. \\ ${ }^{5}$ Jyväskylä University Museum, Natural History Section, P.O. BOX 35, FI-40014 University of Jyväskylä, Finland. \\ ${ }^{6}$ Finnish Environment Institute, P.O. Box 140, FI-00251 Helsinki, Finland.
}

Kunttu P, Juutilainen K, Helo T, Kulju M, Kekki T, Kotiranta H 2018 - Updates to Finnish aphyllophoroid funga (Basidiomycota): new species and range extensions. Mycosphere 9(3), 519564, Doi 10.5943/mycosphere/9/3/7

\begin{abstract}
The knowledge of Finnish aphyllophoroid funga has increased substantially in recent years. In this article we present six species new to Finland: Cristinia (cf.) rhenana Grosse-Brauckm., Hyphodontiella hauerslevii K.H. Larss. \& Hjortstam, Leptosporomyces montanus (Jülich) Ginns \& M.N.L Lefebvre, Osteina obducta (Berk.) Donk, Sebacina helvelloides (Schwein.) Burt, and Tulasnella brinkmannii sensu lato Bres. The finding of Osteina obducta is the first record in Northern Europe. The article also contributes new records of 56 nationally rare species (maximum ten previous records in Finland). Additionally, we list 110 regionally new species, found for the first time from a certain subzone of the boreal vegetation zones in Finland. Every record is enclosed with notes on the substrate. Furthermore, the ecology and distribution of rare species are discussed.
\end{abstract}

Key words - aphyllophorales - biogeography - clavarioids - corticioids - polypores - woodinhabiting fungi

\section{Introduction}

Aphyllophoroid fungi are a non-gilled, ecological form group of the Basidiomycota. They comprise of morphologically varied fungal sub-groups, such as corticioids, polypores, clavarioids and tremelloids. These groups are taxonomically highly diverse and polyphyletic (Hibbett et al. 2014). In Finland, $87 \%$ of the aphyllophoroid fungal species grow in various kinds of forests, and $75 \%$ of the species are decayers (Kotiranta et al. 2009). In addition to wood decayers, aphyllophoroid fungi also include litter decayers, ectomycorrhizal species, parasitic fungi and mycoparasites (Kotiranta et al. 2009).

The aphyllophoroid fungi, as wood-decaying fungi in general, play the key ecological role in forest ecosystems. Through decomposition processes they are responsible for the carbon and nutrient cycles of the forest ecosystem (Boddy et al. 2008). Fungi also provide microhabitats and nutrition for wide range of invertebrates, slime moulds and parasitic fungi (Jonsell et al. 2001, Dudka \& Romanenko 2006, Schigel 2009). Due to their often narrow substrate requirements, the 
aphyllophoroid fungi are also used as indicators of ecological value in boreal forests (e.g. Kotiranta \& Niemelä 1996, Nitare 2000).

The Finnish aphyllophoroid funga comprises 1034 species. The majority of the species are corticioids and polypores (Kotiranta et al. 2009, Kunttu 2016, Niemelä 2016). A large body of knowledge of aphyllophoroid species' occurrence and distribution has been accumulated after the first Finnish checklist (Kotiranta et al. 2009), especially on polypores and corticioids, but some also on clavarioids (e.g. Juutilainen et al 2011, Kunttu et al. 2011, 2015, 2016a, Kotiranta \& Shiryaev 2013, Kunttu 2016, Juutilainen 2016, Niemelä 2016).

However, the occurrence and distribution of many aphyllophoroid species are still inadequately known in Finland. Thus, there are large gaps in knowledge of their ecology, biogeography, substrata and habitat requirements. The main reasons behind this gap are timeconsuming sampling, inconspicuous basidiomata which are tricky to find, narrow ecological niches (substratum), unstable taxonomy and challenges in species identification.

In this article we present new records of aphyllophoroid fungi in Finland. We consider three kinds of records: species new to Finland, rare or seldom collected species with maximum ten previous records in Finland, and species which are new to certain subzone (section) of the boreal vegetation zone in Finland.

\section{Materials \& Methods}

The records in this article were mainly obtained during the years 2015 to 2017 but include some older records as well. The majority of the records derive from field studies conducted in different parts of Finland, but also sporadic records were included. The inventory methods varied to some extent.

Many records were made in nature conservation areas in species diversity inventories. Some records were made along with other outdoor activities or nature inventories as a result of random sampling of species, like inventories for the Finnish Atlas of Fungi (http://www.sieniatlas.fi) or nature inventories for the planning in the Kainuu region. Also surveys of species assemblages or biogeographical research were carried out in certain areas. Some records were made in PallasYllästunturi National Park during a BioBlitz nature inventory event in August 2016. For 24 hours a group of scientists and volunteers conducted an intensive field work to record species from the National Park area. An often-used inventory method was opportunistic sampling of species (Stokland \& Sippola 2004), but for example on the island of Örö in the Baltic Sea, the inventory method was a systematic survey of certain number of drift wood logs.

The collections of K.J. are part of a large dataset published e.g. in Juutilainen et al. (2011, 2014). A novel and thorough inventory method was used to collect fungal data from four coniferous and three deciduous boreal forest types. The hierarchical sampling method comprised of three $10 \times$ $10 \mathrm{~m}$ sampling plots inside of witch four smaller $2 \times 2 \mathrm{~m}$ corner plots were established. All dead wood material with the minimum diameter of $2 \mathrm{~cm}$ was inventoried from the whole sampling plot. Additionally, from each corner plot also minor branches, twigs, and conifer cones - basically every dead wood unit larger than a coniferous needle - was counted and inspected for fungal fruit bodies. A more detailed description of the sampling method can be found in Juutilainen (2016).

In presented records, we use three levels for the names of the sites: a municipality, a village / large nature conservation area and a topographical name. For coordinates, we use the Finnish National Uniform Coordinate System (UCS, $27^{\circ}$ E) according to Heikinheimo \& Raatikainen (1981). The biogeographical provinces (at the beginning of each record) are according to Knudsen $\&$ Vesterholt (2008), the Latin province names are presented on the website of the Finnish Museum of Natural History (Anonymous 2014). The map showing the forest vegetation zones and their subzones (Fig. 1) was modified from Rassi et al. (2010). In accordance with the above-mentioned sources, the names of the subzones are presented in English (e.g. Ostrobothnia), contrary to the Latin names of the biogeographical provinces (e.g. Ostrobottnia).

Followed taxonomy and nomenclature are mainly according to Hjortstam \& Ryvarden (2009), Kotiranta et al. (2009), Niemelä (2016), but in case of some species Bernicchia \& Gorjón (2010) 
were used. The Finnish national red-list evaluation of the IUCN standard is according to Kotiranta et al. (2010). The decay stage classification (1-5) of dead wood is according to Renvall (1995), where stage 1 means hard dead wood and stage 5 means completely decayed wood. The diameter of dead wood was measured at breast height if the trunk was complete, and from the middle if the trunk was broken. We use the term "kelo" referring to dead and old-growth trunks of Scots pine (Pinus sylvestris L.) with a grey and decorticated surface. Scots pine can become kelo trees mainly in dry and barren forest habitats (Leikola 1969, Niemelä et al. 2002).

The material was collected, identified and confirmed by several researchers mentioned in the record details. The most often mentioned researchers are referred to the following abbreviations: $\mathrm{TH}$ = Teppo Helo, KJ = Katja Juutilainen, TK = Tapio Kekki, HK = Heikki Kotiranta, MK = Matti Kulju and PK = Panu Kunttu. The collector is also the identifier unless otherwise stated. The code after the collector's name or abbreviation is a personal sampling number of the specimen. In some cases, also the reference number of the herbarium is given. Voucher specimens are deposited in the herbaria of the universities of Helsinki (H), Oulu (OULU), Turku (TUR), and/or in the private reference herbarium of Teppo Helo (T.H.), Pekka Helo (P.H.), Katja Juutilainen (K.J.) or Heikki Kotiranta (H.K.).

The following abbreviations are used for spores: $\mathrm{L}=$ mean spore length, $\mathrm{W}=$ mean spore width, $\mathrm{Q}=$ quotients of the mean spore length and mean spore width (L/W ratio).

\section{Results}

Cristinia (cf.) rhenana Grosse-Brauckm., Hyphodontiella hauerslevii K.H. Larss. \& Hjortstam, Leptosporomyces montanus (Jülich) Ginns \& M.N.L Lefebvre, Osteina obducta (Berk.) Donk, Sebacina helvelloides (Schwein.) Burt, Tulasnella brinkmannii s.l. Bres. are presented from Finland for the first time. New records (localities) of 56 rare or infrequently collected species (in total 108 records). The second Finnish record derived the following species: Aphanobasidium cf. subnitens, Athelia singularis, Botryobasidium ellipsosporum, Crustoderma efibulatum, Hyphoderma incrustatum, Tulasnella deliquescens, Tulasnella fuscoviolacea, Xenasma pruinosum, and Xenasmatella insperata.

Altogether, 129 records of 110 species are reported as new to a certain subzone (section) of the boreal forest vegetation zone in Finland. The numbers of records new to subzones are: Hemiboreal, oak zone (1b) 1; Southern boreal, Southwestern Finland and Southern Ostrobothnia (2a) 1; Southern boreal, lake district (2b) 38; Middle boreal, Ostrobothnia (3a) 15; Middle boreal, Northern Carelia - Kainuu (3b) 48; Middle boreal, Southwestern Lapland (3c) 6; Northern boreal, Kuusamo district (4a) 7; Northern boreal, North Ostrobothnia (4b) 7; Northern boreal, Forest Lapland (4c) 6.

The species presented here divide into following red-listed categories: Critically Endangered (1 species), Endangered (4), Vulnerable (4), Near Threatened (6), Data Deficient (3), and Not Evaluated (2). If status of the species is Least Concern, it is not mentioned.

\section{List of species}

Species are listed in alphabetic order.

Amylostereum laevigatum (Fr.) Boidin

Specimen examined: Ostrobottnia kajanensis, Sotkamo, Parkua, Känttäjä, UCS 7103379:3547232, on dead branch of Juniperus communis (diam. $3 \mathrm{~cm}$, decay stage 1) in juniper stand next to meadow, 21 Sep 2015, leg. Pekka Helo 2826 (P.H.), det. TH.

New to Middle boreal, Northern Carelia - Kainuu (3b). Several collections have been made after this record and this species seems to be common, but its host tree Juniperus communis has not been surveyed before in the subzone $3 b$. 


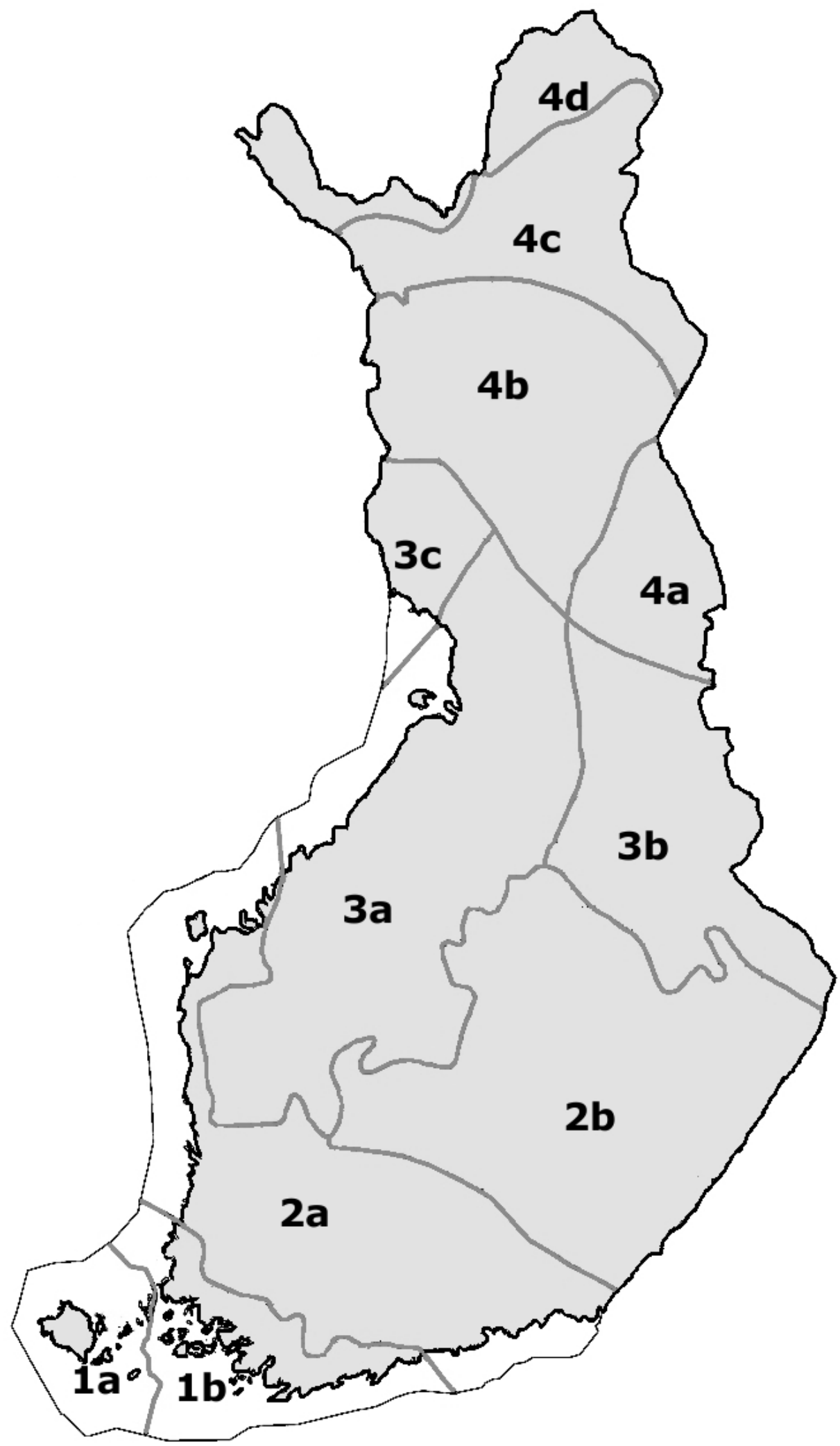

Figure 1 - Boreal forest vegetation zones (1-4) and their subzones in Finland. 1a Hemiboreal, Åland. 1b Hemiboreal, oak zone. 2a Southern boreal, Southwestern Finland and Southern Ostrobothnia. 2b Southern boreal, lake district. 3a Middle boreal, Ostrobothnia. 3b Middle boreal, Northern Carelia - Kainuu. 3c Middle boreal, Southwestern Lapland. 4a Northern boreal, Kuusamo district. 4b Northern boreal, North Ostrobothnia. 4c Northern boreal, Forest Lapland. 4d Northern boreal, Fjeld Lapland. 
Specimens examined - Tavastia australis, Jyväskylä, Korpilahti, Oittila, UCS 6870834:3433926, on unidentified hardwood branch (diam. $1.9 \mathrm{~cm}$, decay stage 2) in near natural herb-rich forest, 30 Aug 2007, leg. KJ 1013 (K.J.); Ostrobottnia kajanensis, Kajaani, Purola, Pyykönpuro UCS 71249:35334, on fallen trunk of Alnus incana (diam. $2 \mathrm{~cm}$, decay stage 3) in deciduous thicket forest with high amount of dead wood, 3 Oct 2017, leg. \& det. TH 20170038 (T.H., OULU), conf. MK, HK; Suomussalmi, Koisti, UCS 7177:3600, on fallen trunk of Pinus sylvestris (diam. $20 \mathrm{~cm}$, decay stage 2) in very old pine-dominated mesic heath forest with very high amount of dead wood, 17 Sep 2017, leg. \& det. TH 20170037 (T.H., OULU), conf. MK, HK.

These are the $7^{\text {th }}-9^{\text {th }}$ records in Finland. The previous records are from Tammisaari $(1 \mathrm{~b})$, Helsinki (1b, two sites), Kuhmoinen (2b), Toivakka (2b) and Lieksa (3b) (Kotiranta et al. 2009, Miettinen 2012).

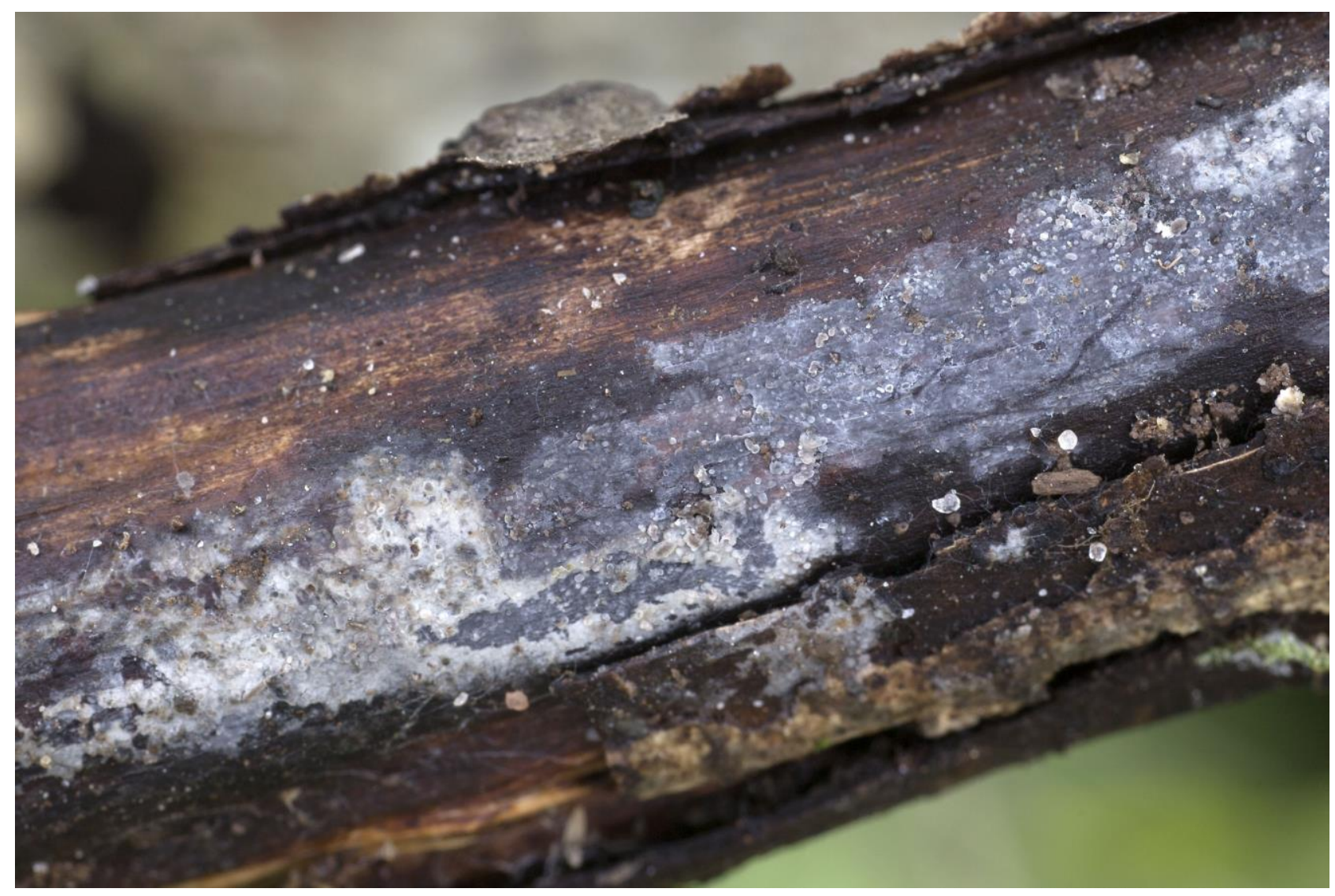

Figure 2 - Amyloxenasma allantosporum in Suomussalmi (TH 20170037). Photo: Teppo Helo

Amyloxenasma grisellum (Bourdot) Hjortstam \& Ryvarden

Specimens examined - Ostrobottnia kajanensis, Kajaani, Pöllyvaara, UCS 7126:3535, on fallen trunk of Alnus incana (diam. $40 \mathrm{~cm}$, decay stage 4) in spruce-dominated mesic heath forest, 20 Sep 2017, leg. \& det. TH 20170036 (T.H., OULU), conf. HK; Kajaani, Ensilä, Maitoniemi, UCS 71264:35344, on fallen trunk of Alnus incana (diam. $13 \mathrm{~cm}$, decay stage 3) in deciduous riverside thicket forest with high amount of dead wood, 17 Oct 2017, leg. \& det. TH 20170039 (T.H., OULU), conf. HK.

New to Middle boreal, Northern Carelia - Kainuu (3b).

Antrodia mappa (Overh. \& J. Lowe) Miettinen \& Vlasák

Fig. 3

Specimen examined - Ostrobottnia kajanensis, Sotkamo, Naulavaara, Korkeakoskenpuro, UCS 70893:35582, on fallen trunk of Populus tremula (diam. $10 \mathrm{~cm}$, decay stage 2) in moist oldgrowth spruce-dominated forest, 13 Sep 2012, leg. \& det. TH (OULU GAJ.5451), conf. MK. 
New to Middle boreal, Northern Carelia - Kainuu (3b). This is the $6^{\text {th }}$ record in Finland. The previous records are from Nauvo (1b), Korpilahti (2b) and Savonranta (2b), Puolanka (3a) and Kankaanpää (3a) (Kotiranta et al. 2009, Kunttu et al. 2011). Endangered.

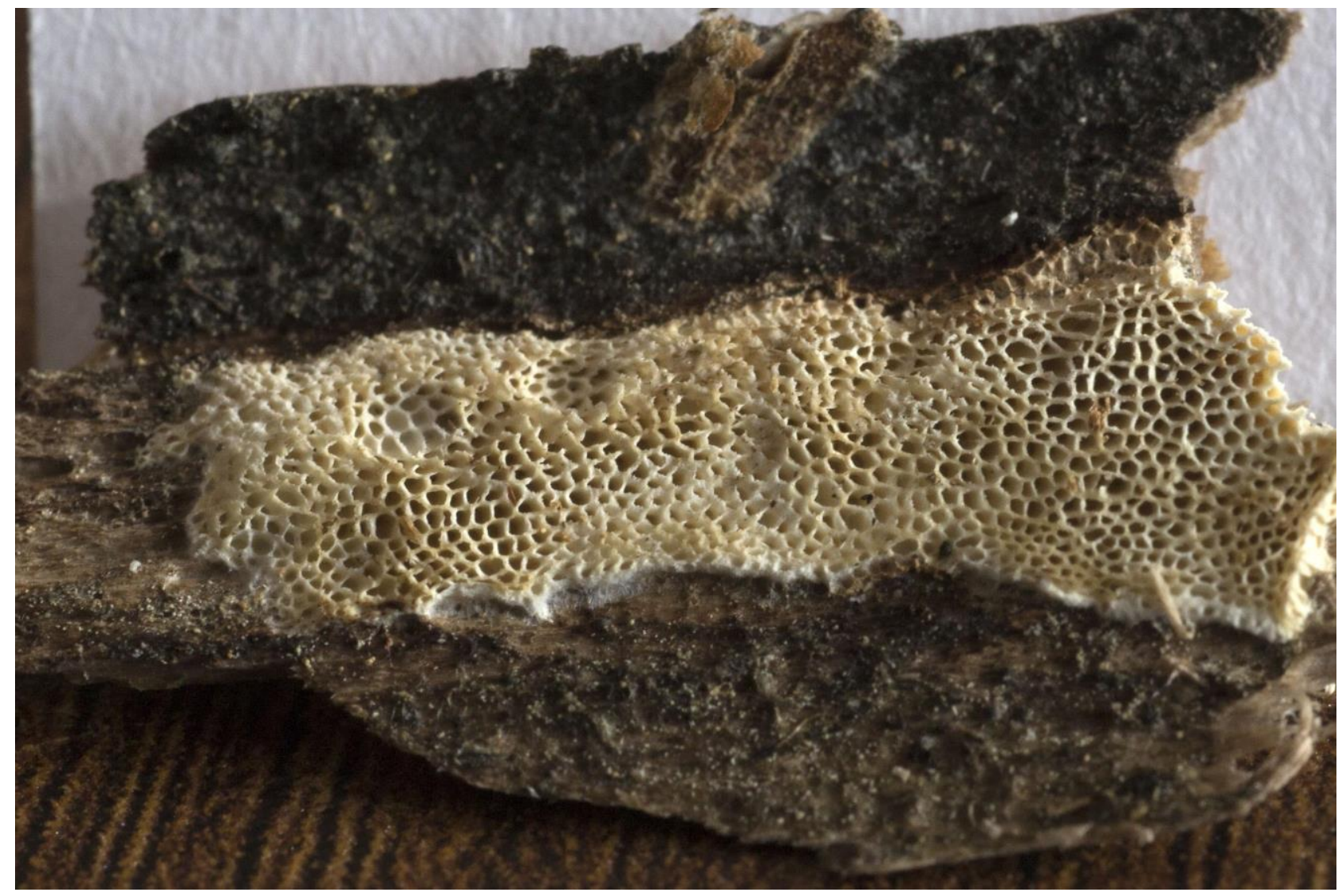

Figure 3 - Antrodia mappa in Sotkamo, ex situ. Photo: Teppo Helo

Antrodiella niemelaei Vampola \& Vlasák (Antrodiella Americana Ryvarden \& Gilb. sensu auct.)

Specimen examined - Ostrobottnia kajanensis, Kajaani, Ensilä, UCS 71265:35345, on fallen trunk of Salix caprea (diam. $8 \mathrm{~cm}$, decay stage 3) which was decayed by Hydnoporia tabacina, in deciduous riparian thicket with high amount of dead wood, 21 Oct 2016, leg. \& det. TH 20160101 (T.H.).

New to Middle boreal, Northern Carelia - Kainuu (3b). Near Threatened.

Aphanobasidium cf. subnitens (Bourdot \& Galzin) Jülich

Specimen examined - Tavastia australis, Luhanka, Onkisalo Island, Molikko, UCS 6850082:3431504, on deciduous tree twig (diam. $0.4 \mathrm{~cm}$ ) in near natural herb-rich forest, 12 Oct 2007, leg. KJ 2571 (K.J.).

This is the $2^{\text {nd }}$ record in Finland. The $1^{\text {st }}$ record is from Porvoo (2a) (Kotiranta et al. 2009). Not Evaluated.

\section{Athelicium hallenbergii Yurchenko \& Kotiranta}

Specimen examined - Tavastia borealis, Petäjävesi, Suolahti, UCS 6911151:3405740, on twig of Betula (diam. $0.4 \mathrm{~cm}$ ) in young birch-dominated afforested field, 2 Oct 2012, leg KJ 5811 (K.J.); Viitasaari, Niinilahti, Pitkämäki, UCS 6981071:3443904 and 6981203:3443835, on two Betula twigs (diam. $0.6 \mathrm{~cm}$ and $0.8 \mathrm{~cm}$ ) in young birch-dominated afforested field, 10/25 Oct 2012, leg. KJ 5957, 6224 (K.J.).

These are the $3^{\text {rd }}-4^{\text {th }}$ records in Finland. The previous records are from Lammi $(2 \mathrm{a})$ and Oulu (3a) (Kunttu et al. 2012). Not Evaluated. 
Athelia sibirica (Jülich) J. Erikss. \& Ryvarden

Specimen examined - Ostrobottnia ouluensis, Oulu, Kalimeenoja, Halosenharju, UCS 7221795:3431931, on stump of Pinus sylvestis (diam. $24 \mathrm{~cm}$, decay stage 1), 18 Oct 2016, MK 80/16 \& Esteri Ohenoja (OULU), det. MK, conf. HK.

New to Middle boreal, Ostrobothnia (3a). This is the $3^{\text {rd }}$ record in Finland. The previous records are from Lammi (2a) and Kittilä (4b) (Kotiranta et al. 2009).

\section{Athelia singularis Parmasto}

Fig. 4

Specimens examined - Ostrobottnia kajanensis, Kajaani, Pirunvaara, UCS 71270:35307, on fallen branch of Pinus sylvestris (diam. $5 \mathrm{~cm}$, decay stage 2, kelo tree) in old-growth xeric heath forest, 3 Oct 2015, leg. TH (OULU GAJ.5441), det. MK, and in the same site on fallen branch of Pinus sylvestris (diam. 3 cm, decay stage 3), 3 Oct 2016, leg. TH (OULU), det. MK; Suomussalmi, Hossa, Pahamaailma, UCS 7263:3621, on fallen trunk of Pinus sylvestris (diam. $20 \mathrm{~cm}$, decay stage 4 ) in old-growth xeric heath forest with high amount of dead wood, 16 Oct 2015, leg. TH (OULU GAJ.5458), det. MK, conf. HK.; Ostrobottnia ultima, Rovaniemi, Pisavaara Strict Nature Reserve, Teeripäri, UCS 7357885:3414533, on fallen kelo branch of Pinus sylvestris (diam. $10 \mathrm{~cm}$, decay stage 2) in dry and rocky heath forest, 19 Sep 2016, leg. \& det. MK 21/16 (OULU).

New to Middle boreal, Northern Carelia - Kainuu (3b) and Northern boreal, Kuusamo District (4a). These are the $2^{\text {nd }}-3^{\text {rd }}$ records in Finland. The record from Rovaniemi (3c) was found in the same site as the first Finnish record (Kunttu et al. 2016b).

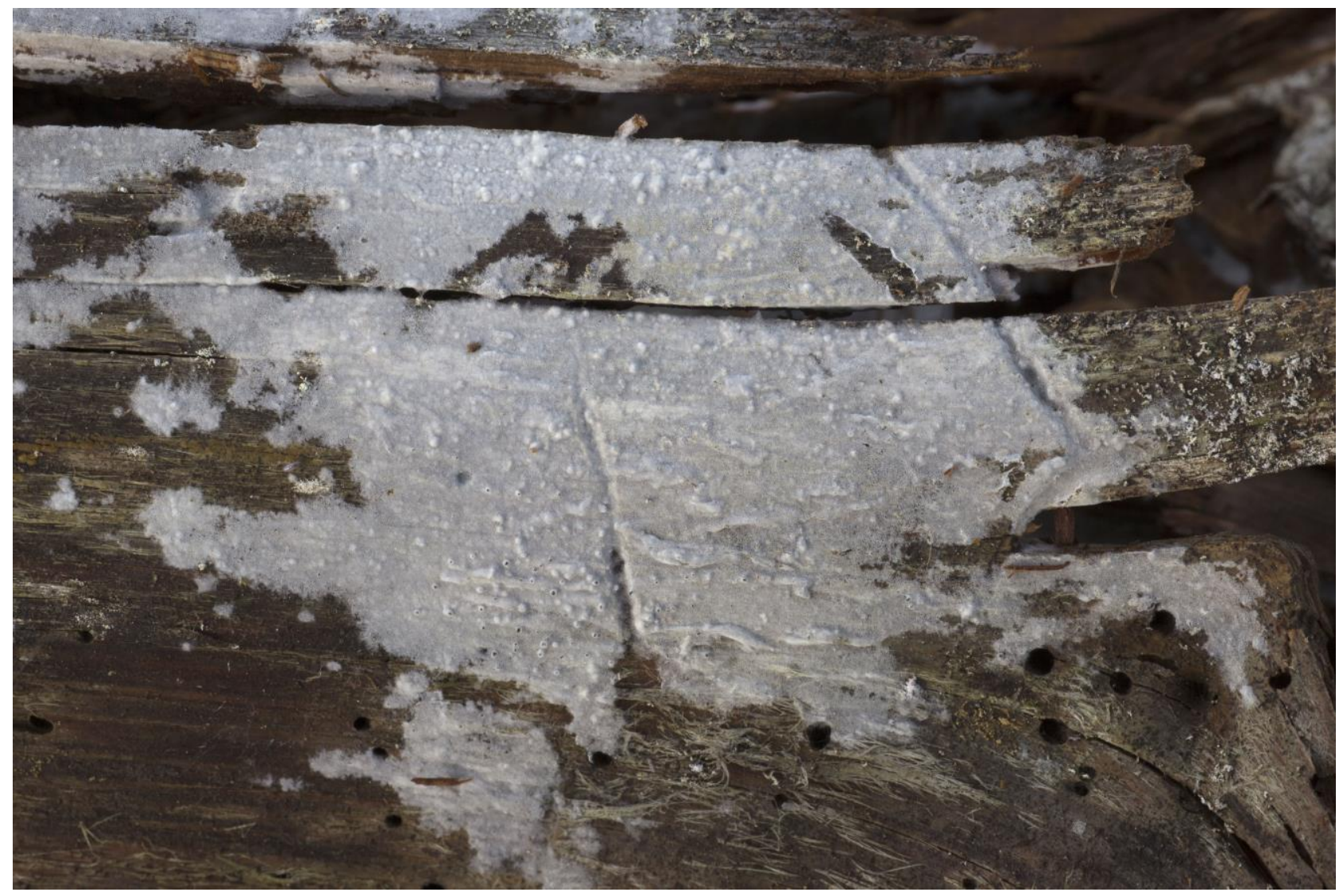

Figure 4 - Athelia singularis in Suomussalmi. Photo: Teppo Helo

Athelopsis lembospora (Bourdot) Oberw.

Specimen examined - Tavastia australis, Jyväskylä, Korpilahti, Oittila, UCS 6827097:3433861, on unidentified hardwood (diam. $2 \mathrm{~cm}$, decay stage 2) in near natural herb-rich forest, 24 Aug 2007, leg KJ 527 (K.J.).

New to Southern boreal, Lake District (2b). 
Athelopsis subinsconspicua coll. (Litsch.) Jülich

Specimen examined - Tavastia borealis, Viitasaari, Niinilahti, Pitkämäki, UCS 6981071:3443904, on Betula branch (diam. $1 \mathrm{~cm}$ ) in young birch-dominated afforested field, 10 Oct 2012, leg KJ 5965 (K.J.).

New to Southern boreal, Lake District (2b).

\section{Basidiodendron eyrei (Wakef.) Luck-Allen}

Specimens examined - Ostrobottnia kajanensis, Kajaani, Suvantola, UCS 71268:35343, on fallen branch of Betula sp. (diam. $7 \mathrm{~cm}$, decay stage 3) in riparian thicket forest with high amount of dead wood, 26 Oct 2015, leg. \& det. TH 20150101 (T.H.); Kajaani, Ensilä, UCS 71264:35344, on fallen trunk of deciduous tree (diam. $10 \mathrm{~cm}$, decay stage 3) in deciduous riparian thicket forest with high amount of dead wood, 17 Oct 2017, leg. \& det. TH 20170028 (OULU), conf. MK.

New to Middle boreal, Northern Carelia - Kainuu (3b).

Basidiodendron radians (Rick) P. Roberts

Fig. 5

Specimen examined - Ostrobottnia kajanensis, Paltamo, Kuuskanlahti, Teerivaara, UCS 71461:35142 on charred root plate of Pinus sylvestris (diam. $30 \mathrm{~cm}$, decay stage 4) in old-growth xeric heath forest with high amount of dead wood, 6 Oct 2016, leg. \& det. TH (OULU GAJ.5438), conf. MK \& HK.

New to Middle boreal, Ostrobothnia (3a). This is the $4^{\text {th }}$ record in Finland. Previous records are from Lohja (1b), Kirkkonummi (1b) and Padasjoki (2a) (Kotiranta et al. 2009).

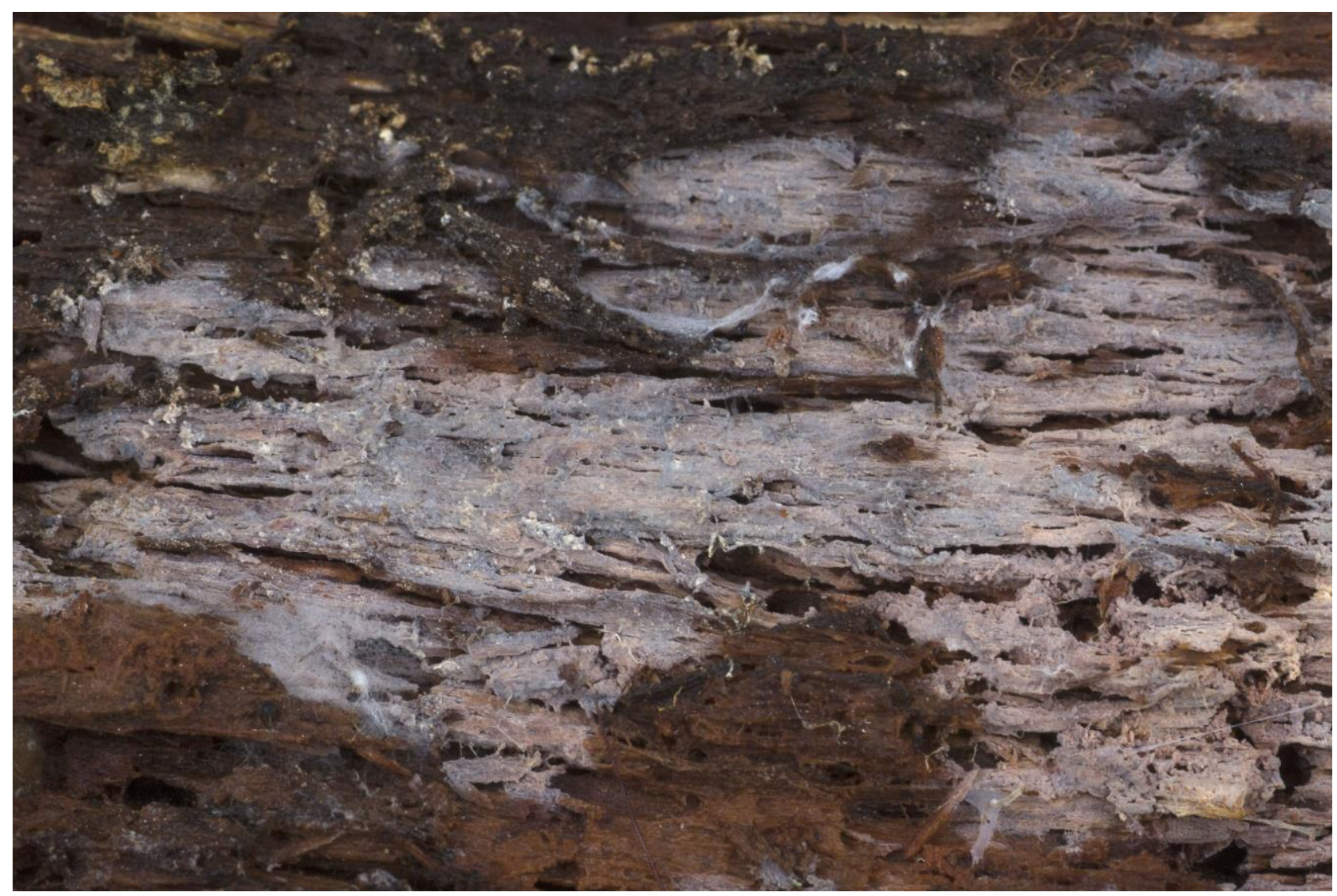

Figure 5 - Basidiodendron radians in Paltamo. Photo: Teppo Helo

Basidiodendron rimosum (H.S. Jacks \& G.W. Martin) Luck-Allen

Specimen examined - Tavastia borealis, Toivakka, Vuorilamminvuoret, UCS 6884857:3456738, on twig of Pinus sylvestris (diam. $0.2 \mathrm{~cm}$ ) in old-growth near natural sprucedominated forest, 17 Oct 2007, leg KJ 2731 (K.J.). 
New to Southern boreal, Lake District (2b). This is the $3^{\text {rd }}$ record in Finland. The previous records are from Finnström (1a), Geta (1a) and Kirkkonummi (1b) (Kotiranta et al. 2009).

Boletopsis leucomelaena (Pers.: Fr.) Fayod

Specimen examined - Lapponia kittilensis, Kolari, Äkäsjokisuu, UCS 7488292:3356921, in calciferous coniferous forest under Picea abies near river bank, 3 Sep 2016, leg. \& det. TK 2524 (H 6064737).

New to Northern boreal, North Ostrobothnia (4b). Vulnerable.

\section{Botryobasidium conspersum J. Erikss.}

Specimen examined - Ostrobottnia ouluensis, Oulu, Oinaansuo, UCS 7221016:3432115, on snag of Betula sp. (diam. 8 cm, decay stage 3) in spruce mire, 6 Sep 2017, leg. MK 93/17 \& Iita Tiusanen (OULU), det. MK.

New to Middle boreal, Ostrobothnia (3a).

Botryobasidium ellipsosporum Holubová-Jechová

Fig. 6

Specimens examined - Ostrobottnia kajanensis, Puolanka, Paljakka, Mustakumpu, UCS 71724:35506, on fallen trunk of Picea abies (diam. $7 \mathrm{~cm}$, decay stage 2) in old-growth sprucedominated moist heat forest with high amount of dead wood, 13 Oct 2017, leg. TH 20170001 (H, H.K.), det. HK, and in the same site on fallen trunk of Picea abies (diam. 15-20 cm, decay stage 12), 13 Oct 2017 Jari Julkunen 1026 (H), det. HK.

New to Middle boreal, Northern Carelia - Kainuu (3b). This is the $2^{\text {nd }}$ record in Finland. The previous record is from Lammi (2a) (Kotiranta et al. 2009). The specimen was an anamorph like the first Finnish collection.



Figure 6 - Botryobasidium ellipsosporum in Puolanka (TH 20170001). Photo: Teppo Helo 
Botryobasidium laeve (J. Erikss.) Parmasto

Specimen examined - Ostrobottnia kajanensis, Paltamo, Hakasuo, UCS 71451:35247, on fallen trunk of Alnus incana (diam. $7 \mathrm{~cm}$, decay stage 3) in alder thicket between the road and spruce-dominated mesic heath forest, 29 Aug 2017, leg. \& det. TH 20170005 (T.H.).

New to Middle boreal, Northern Carelia - Kainuu (3b).

Botryobasidium medium J. Erikss.

Specimen examined - Ostrobottnia ouluensis, Oulu, Oinaansuo, UCS 7220867:3432304, on snag of Betula sp. (diam. 5 cm, decay stage 2) in spruce mire, 6 Sep 2017, leg. MK 90/17 \& Iita Tiusanen (OULU), det. MK.

New to Middle boreal, Ostrobothnia (3a).

Byssocorticium pulchrum (S. Lundell) M.P. Christ.

Specimen examined - Ostrobottnia kajanensis, Sotkamo, Naulavaara, UCS 708637:355807, on fallen trunk of Populus tremula (diam. $10 \mathrm{~cm}$, decay stage 2) in mesic old-growth sprucedominated forest, 13. Sep 2012, leg. \& det. TH N213C (T.H.).

New to Middle boreal, Northern Carelia - Kainuu (3b).

Byssomerulius jose-ferreirae (D.A. Reid) Zmitr.

Specimens examined - Tavastia borealis, Jyväskylä, Tourujoki, UCS 6905628:3435436, on Sorbus twig (diam. 0,7 cm) in near natural herb-rich forest, 11 Oct 2007, leg KJ 2484 (K.J.), and later in the same site: UCS 6905621:3435418, on unidentified hardwood (diam. $7 \mathrm{~cm}$, decay stage 2) in near natural herb-rich forest, 18 Oct 2007, leg. KJ 2774 (K.J.) and UCS 6905570:3435388, on Salix caprea snag (diam. $25 \mathrm{~cm}$, decay stage 2) in near natural herb-rich forest, 25 Oct 2007, leg. KJ 2938b (K.J.); Toivakka, Lappila, UCS 6902242:3460412, on twig of Salix sp. (diam. $0.5 \mathrm{~cm}$ ) in young birch-dominated afforested field, 16 Sep 2013, leg. KJ 6801 (K.J.).

These are the $6^{\text {th }}-7^{\text {th }}$ records in Finland. The previous records are from Lammi (two sites, $2 a$ ), Kankaanpää (2a), Lapinlahti (2b) and Keminmaa (3c) (Kotiranta et al. 2009). Near Threatened.

Ceraceomyces tessulatus (W.B. Cooke) Jülich

Specimen examined - Ostrobottnia ouluensis, Oulu, Pikkarala, Hangaskangas, UCS 7201794:3442451, on fallen trunk of Pinus sylvestris (diam. $5 \mathrm{~cm}$, decay stage 2) in dry heath forest, 21 Oct 2016, leg. \& det. MK 86/16 (OULU); Oulu, Hietasaari, UCS 7214960:3426432, on fallen trunk of Prunus padus (diam. 4 cm), 14 Oct 2001, leg. Lassi Kalleinen (OULU), det. MK.

New to Middle boreal, Ostrobothnia (3a).

Clavaria amoenoides Corner, Thind \& Anand.

Specimens examined - Ostrobottnia ultima, Tervola, Loue, UCS 73483: 34073, on sandy dirt road near limestone quarry, 19 Aug 2016, leg. \& det. TK 2347 (OULU); Lapponia kittilensis Muonio, Pallastunturi, UCS 7550912:3381128, on dry meadow with Empetrum nigrum, 5 Aug 2016, leg Kaisa Junninen and TK 2308, det. TK (OULU).

New to Middle boreal, Southwestern Lapland (3c) and Northern boreal, Forest Lapland (4c).

Clavaria argillacea Pers.: Fr.

Specimen examined: - Lapponia sompiensis, Savukoski, Tulppio, UCS 75219: 35937, on ground in sandpit with young Pinus sylvestris, 26 Aug 2016, leg. \& det. TK. 2415 (OULU).

New to Northern boreal, Forest Lapland (4c).

\section{Clavaria incarnata Weinm.}

Specimen examined - Ostrobottnia kajanensis, Kajaani, Variskangas, Tilhitie, UCS 712378:353753, on lawn with Sorbus aucuparia, 25 Aug 2016, leg. \& det. TH (OULU GAJ.5435).

New to Middle boreal, Northern Carelia - Kainuu (3b). 
Clavulina coralloides (L.: Fr.) Schröt.

Specimen examined - Lapponia kittilensis Muonio, Pallastunturi, Pyhäjoki, UCS 7551544:3381229, on ground in mesic Picea abies dominated forest, 4 Sep 2016, leg. \& det. TK 2550 (OULU).

New to Northern boreal, Forest Lapland (4c).

\section{Clavulinopsis corniculata (Schaeff.: Fr.) Corner}

Specimen examined - Lapponia kittilensis, Kittilä, Mustavaara, UCS 7506137: 3432870, on ground in herb-rich Picea abies dominated forest, 2 Sep 2016, leg. \& det. TK 2471 (OULU).

New to Northern boreal, North Ostrobothnia (4b).

Clavulinopsis fusiformis (Sowerby.: Fr.) Corner

Specimen examined - Lapponia sompiensis, Savukoski, Tulppio, UCS 75226: 35934, on dry meadow, 26 Aug 2016, leg. \& det. TK 2414 (OULU).

New to Northern boreal, Forest Lapland (4c).

Colacogloea peniophorae (Bourdot \& Galzin) Oberw., R. Bauer \& Bandoni

Fig. 7

Specimens examined - Tavastia borealis, Jyväskylä, Tourujoki, UCS 6905570:3435388, on unidentified hardwood twig (diam. $2 \mathrm{~cm}$ ) in near natural herb-rich forest, 25 Oct 2007, leg. KJ 2923 b (K.J.); Ostrobottnia ouluensis, Oulu, Kalimeenoja, Halosenharju, UCS 7221801:3431907, on Peniophorella praetermissa, on fallen trunk of Pinus sylvestris (diam. $5 \mathrm{~cm}$, decay stage 1), 18 Oct 2016 MK 81/16 \& Esteri Ohenoja (OULU), det. MK; Ostrobottnia kajanensis, Kajaani, Ensilä, Maitoniemi, UCS 71264:35344, on fallen trunk of Alnus incana with Peniophorella pratermissa (diam. $10 \mathrm{~cm}$, decay stage 3) in deciduous riparian thicket forest with high amount of dead wood, 17 Oct 2017, leg. \& det. TH 20170006 (T.H., OULU).

New to Southern boreal, Lake District (2b), Middle boreal, Ostrobothnia (3a) and Middle boreal, Northern Carelia - Kainuu (3b). These are the $11^{\text {th }}-13^{\text {th }}$ records in Finland. All previous records are from the southwestern archipelago or the south coast (subzones 1a and 1b) (Kotiranta et al. 2009, Kunttu et al. 2009, 2012, 2015, 2016a, Miettinen 2012).

Coronicium alboglaucum (Bourdot \& Galzin) Jülich

Specimen examined - Tavastia borealis, Äänekoski, Aatula, UCS 6938588:3439737, on two Betula twigs (diam. 0.2 and $0.3 \mathrm{~cm}$ ) in birch-dominated wood-pasture, 13 Sep 2013, leg. KJ 5123, KJ 5154a (K.J.); Tavastia australis, Luhanka, Moiskala, UCS 6854041:3430819, on Betula twig (diam. $0.3 \mathrm{~cm}$ ) in birch-dominated wood-pasture, 27 Sep 2013, leg. KJ 5733 (K.J.). Additionally, corrigendum to the following record, which was published in Kotiranta et al. (2009), but the collection site was wrong there: Tavastia autralis, Muurame, Kuusimäki, UCS 6902005:3421936, on three Pinus twigs and one Betula twig (diam. 0,3-1,9 cm) in near natural old growth sprucedominated forest, 20 Sept. 2007, leg KJ 1999-2002 (K.J.).

These are the $3^{\text {rd }}-4^{\text {th }}$ records in Finland. The previous ones are from Lammi (2a) and Muurame (2b) (Kotiranta et al. 2009).

Coronicium alboglaucum (Bourdot \& Galzin) Jülich

Specimen examined - Tavastia borealis, Äänekoski, Aatula, UCS 6938588:3439737, on two Betula twigs (diam. 0.2 and $0.3 \mathrm{~cm}$ ) in birch-dominated wood-pasture, 13 Sep 2013, leg. KJ 5123, KJ 5154a (K.J.); Tavastia australis, Luhanka, Moiskala, UCS 6854041:3430819, on Betula twig (diam. $0.3 \mathrm{~cm}$ ) in birch-dominated wood-pasture, 27 Sep 2013, leg. KJ 5733 (K.J.). Additionally, corrigendum to the following record, which was published in Kotiranta et al. (2009), but the collection site was wrong there: Tavastia autralis, Muurame, Kuusimäki, UCS 6902005:3421936, on three Pinus twigs and one Betula twig (diam. 0,3-1,9 cm) in near natural old growth sprucedominated forest, 20 Sept. 2007, leg KJ 1999-2002 (K.J.). 
These are the $3^{\text {rd }}-4^{\text {th }}$ records in Finland. The previous ones are from Lammi (2a) and Muurame (2b) (Kotiranta et al. 2009).

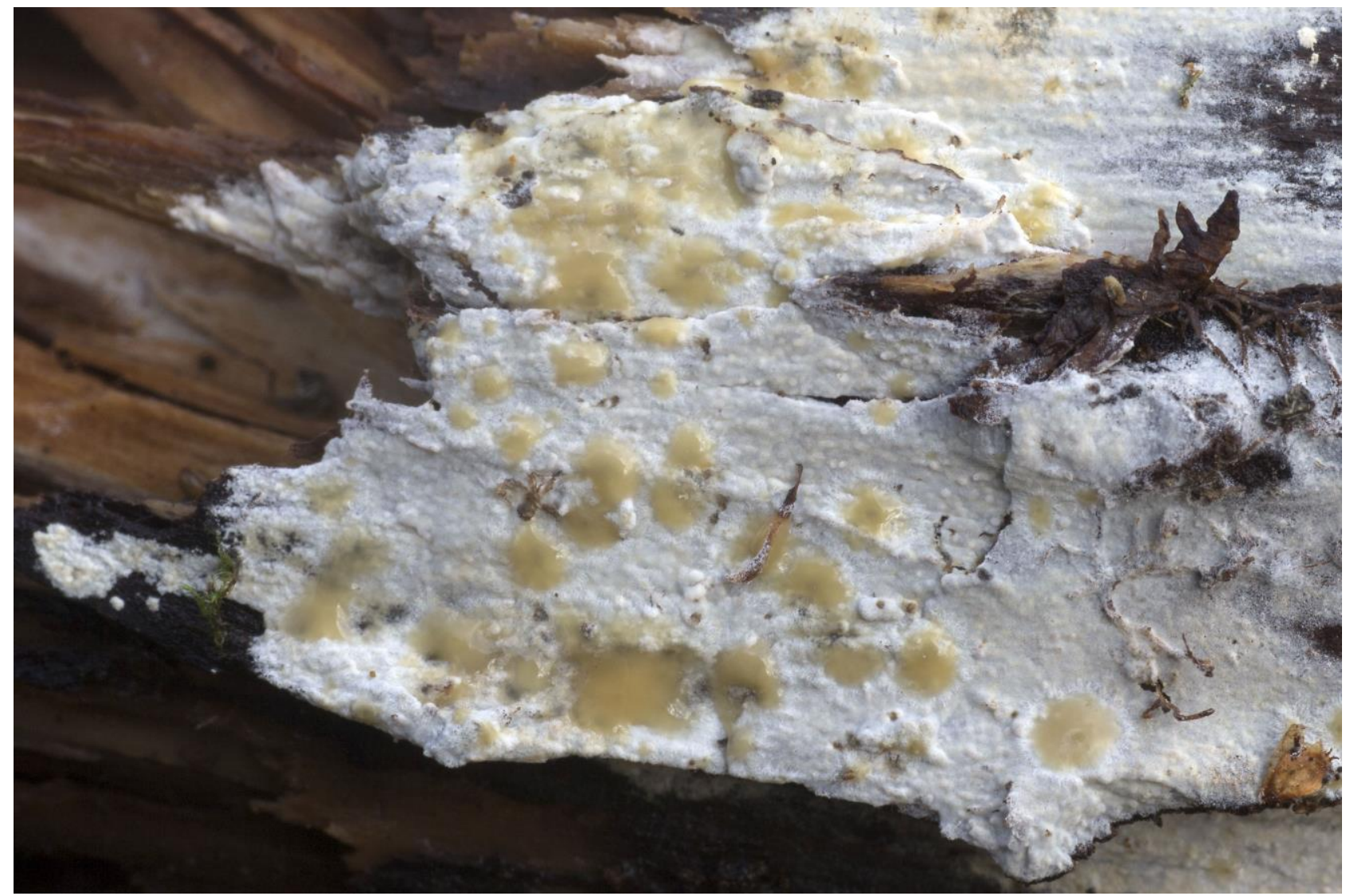

Figure 7 - Colacogloea peniophorae grew on Peniophorella pratermissa in Kajaani (TH 20170006). Photo: Teppo Helo

Craterocolla cerasi (Schumach.) Bref.

Fig. 8

Specimen examined - Lapponia kittilensis, Kolari, Äkäslompolo, Kesänkijärvi, UCS 75043:33822, on fallen Picea abies in moist coniferous forest, 6 Aug 2016, leg. Kaisa Junninen and TK 2314, det. TK (H 6064778, as C. insignis).

New to Northern boreal, North Ostrobothnia (4b).

Cristinia (cf.) rhenana Grosse-Brauckm.

Specimen examined - Tavastia australis, Jyväskylä, Korpilahti, Oittila, UCS 6827097:3433861, on unidentified hardwood (diam. $6 \mathrm{~cm}$, decay stage 2) in near natural herb-rich forest, 24 Aug 2007, leg. KJ 635 (K.J.); Luhanka, Moiskala, UCS 6854041:3430819, on fallen trunk of Alnus incana (diam. $5 \mathrm{~cm}$, decay stage 3) in birch-dominated wood-pasture, 28 Sep 2013, leg. KJ 5762 (K.J.).

New to Finland, hence new to Southern boreal, lake district (2b).

\section{Crustoderma efibulatum Kotir. \& Saaren.}

Specimen examined - Tavastia australis, Kuhmoinen, Isojärvi National Park, Lortikka, UCS 6845333:3394188, on twig of Pinus sylvestris (diam. $0.7 \mathrm{~cm}$ ) in near natural old-growth pinedominated forest, 19 Sep 2007, leg. KJ 1973 (K.J.). Deficient.

This is the $2^{\text {nd }}$ record in Finland. The $1^{\text {st }}$ one is from Porvoo (2a) (Kotiranta et al. 2009). Data 


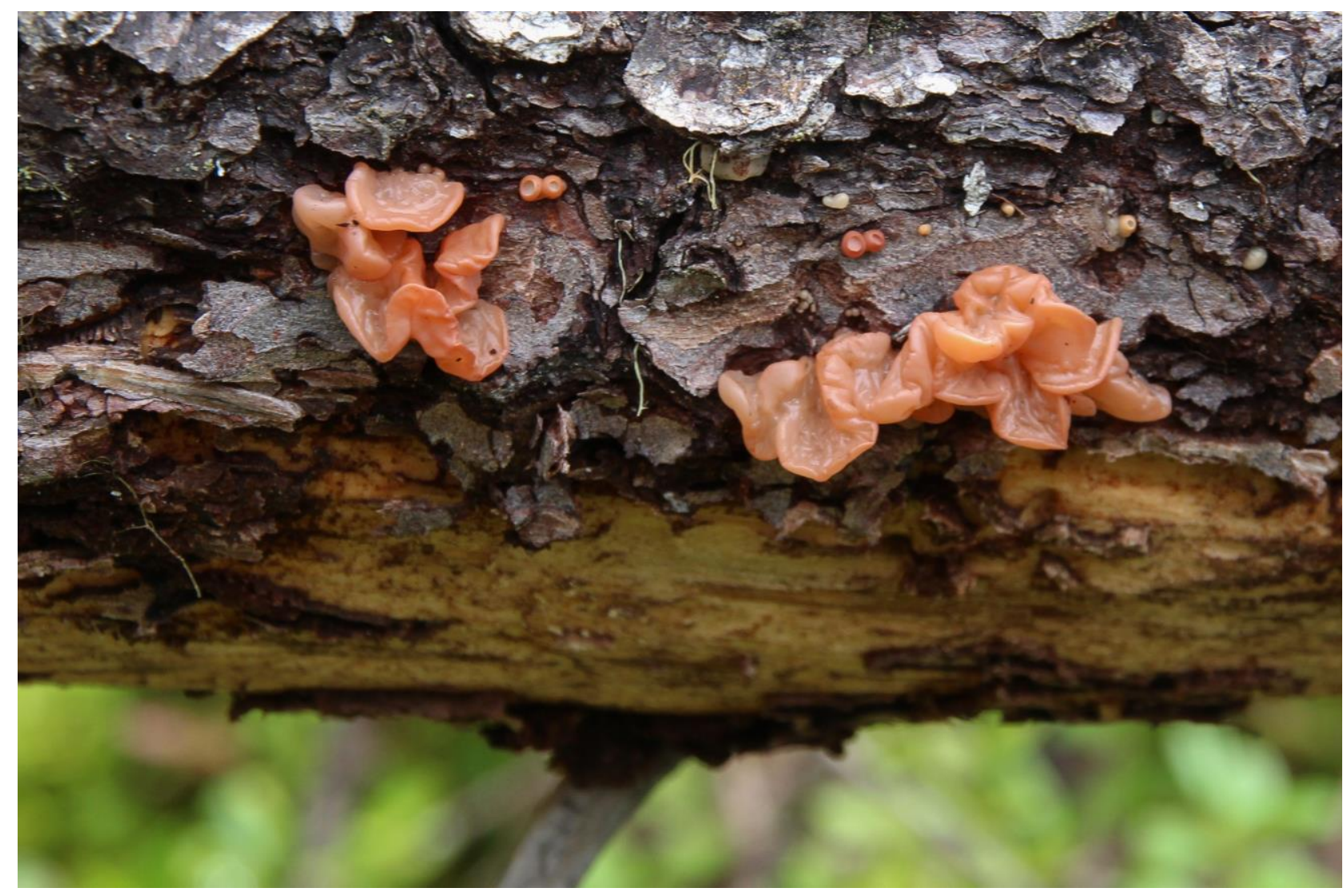

Figure 8 - Craterocolla cerasi in Kolari (TK 2314). Photo: Tapio Kekki

Dacrymyces ovisporus Bref.

Fig. 9

Specimen examined - Ostrobottnia kajanensis, Kajaani, Pöllyvaara, UCS 71263:35353, on fallen branch of Pinus sylvestris (diam. 4, decay stage 1), in spruce-dominated mesic heath forest, 13 Sep 2017, leg. \& det. TH 20170033 (T.H., OULU), conf. MK.

New to Middle boreal, Northern Carelia - Kainuu (3b). This is the $3^{\text {rd }}$ record in Finland. The previous records are from Turku (1b) and Regio kuusamoensis (4a) (Hansen \& Knudsen 1997, Kotiranta et al. 2009).

\section{Dendrothele amygdalispora Hjortstam}

Specimen examined - Tavastia borealis, Jyväskylä, Tourujoki, UCS 6905628:3435436, on fallen trunk of Salix caprea (diam. $19 \mathrm{~cm}$, decay stage 2) in near natural herb-rich forest, 11 Oct 2007, leg. KJ 2525a (K.J).

New to Southern boreal, Lake District (2b).

Exidia saccharina (Alb. \& Schwein.: Fr.) Fr.

Specimen examined - Ostrobottnia ultima, Tervola, Pisavaara Strict Nature Reserve, UCS 7354241:3412062, on fallen trunk of Picea abies (diam. $20 \mathrm{~cm}$, decay stage 1) in old-growth mesic heath forest, 26 Sep 2017, leg. \& det. MK 56/17 (OULU); Rovaniemi, Marrasjärvi, UCS 741979:342391, on trunk of Pinus sylvestris in dry heath forest, 29 May 2011, leg. \& det. TK (TUR); Rovaniemi, Apukka, UCS 738818:345688, on duckboard made of Picea abies logs in mesic coniferous forest, 18 May 2011, leg. \& det. TK (TUR)

New to Middle boreal, Southwestern Lapland (3c) and Northern boreal, North Ostrobothnia (4b).

Fibricium rude (P. Karst.) Jülich

Ostrobottnia kajanensis, Kajaani, Ilmarata, UCS 71268:35337, on fallen trunk of Picea abies 
(diam. $10 \mathrm{~cm}$, decay stage 1-2) in riparian thicket forest with high amount of dead wood, 9 Oct 2016, leg. \& det. TH GAJ.5439 (OULU), conf. MK.

New to Middle boreal, Northern Carelia - Kainuu (3b). There are several collections from Kajaani area after this by the author TH.

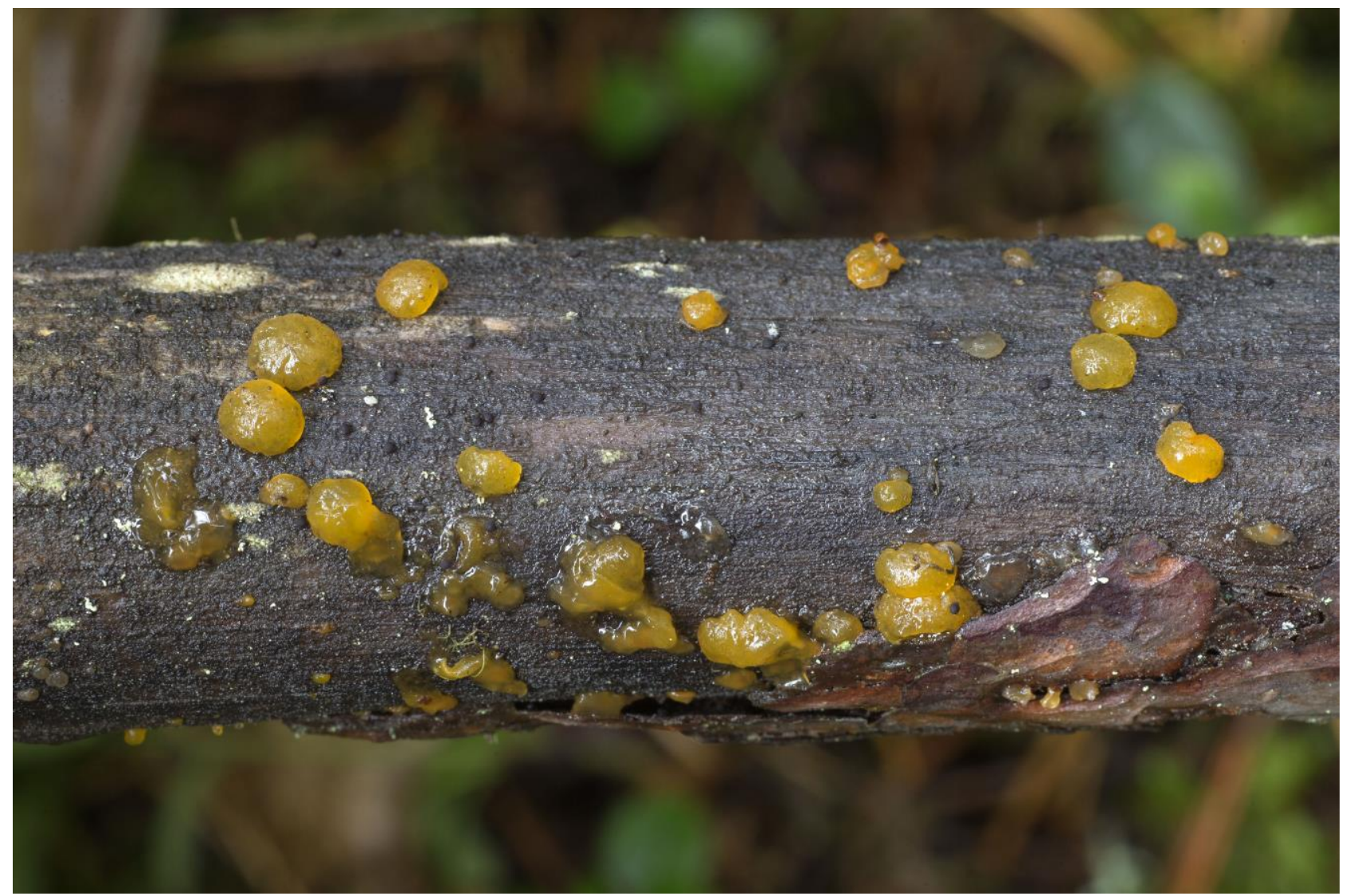

Figure 9 - Dacrymyces ovisporus in Kajaani (TH 20170033). Photo: Teppo Helo

Galzinia incrustans Parmasto

Specimen examined - Ostrobottnia kajanensis, Paltamo, Kuuskanlahti, Teerivaara, UCS 71460:35142, on fallen trunk of Betula sp. (diam. $18 \mathrm{~cm}$, decay stage 2) in old-growth sprucedominated forest, 6 Oct 2016, leg. \& det. TH (OULU GAJ.5446), conf. MK.

New to Middle boreal, Ostrobothnia (3a).

Gyrophanopsis polonensis (Bres.) Stalpers \& P.K. Buchanan

Specimen examined - Tavastia borealis, Jyväskylä, Tourujoki, UCS 6905570:3435388, on unidentified hardwood (diam. $6 \mathrm{~cm}$, decay stage 4) in near natural herb-rich forest, 25 Oct 2007, leg. KJ 2956 (K.J.).

New to Southern boreal, Lake District (2b).

Helicogloea farinacea (Höhn.) D. P. Rogers

Fig. 10

Specimens examined - Ostrobottnia kajanensis, Kajaani, Suvantola, UCS 71268:35343, on fallen branch of Prunus padus (diam. $1 \mathrm{~cm}$, decay stage 2), there are several other specimens collected close to this same site, so the number of occupied trunks is higher, in riparian thicket forest with high amount of dead wood, 24 Oct 2015, leg. \& det. TH (OULU GAJ.5464), conf. MK \& HK; Paltamo, Tololanmäki, UCS 71380:35512, on fallen branch of Populus tremula (diam. 6 $\mathrm{cm}$, decay stage 1) in moist thicket forest with high amount of dead wood, 28 Sep 2016, leg. \& det. TH 20160104 (T.H.). 
New to Middle boreal, Northern Carelia - Kainuu (3b). These are the $5^{\text {th }}-6^{\text {th }}$ records in Finland. The previous records are from Karjalohja (1b), Helsinki (1b), Lempäälä (2a), Tampere (2a) (Kotiranta et al. 2009, Kunttu et al. 2013).

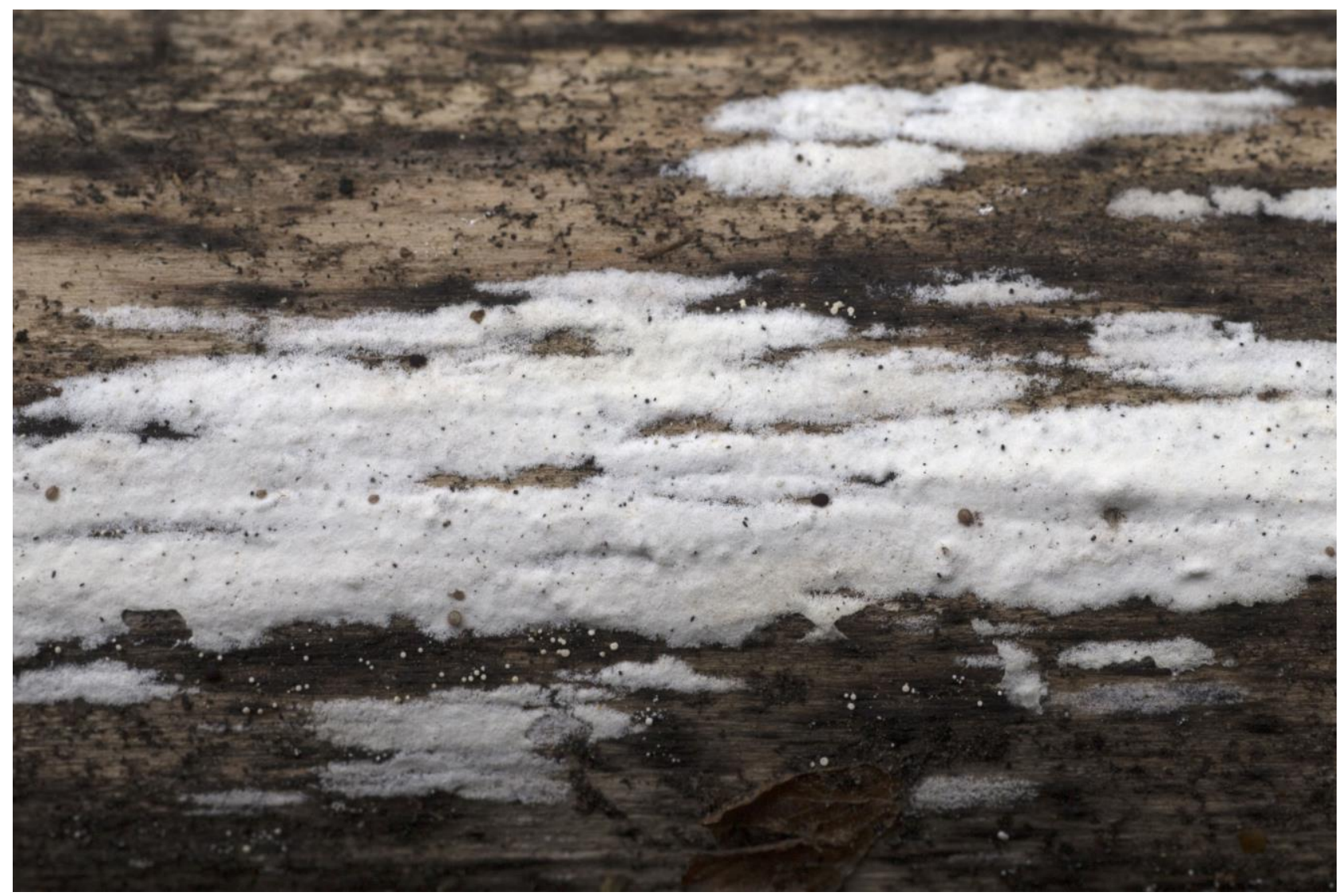

Figure 10 - Helicogloea farinacea in Paltamo (TH 20160104). Photo: Teppo Helo

Hydnellum auratile (Britz.) Maas Geest.

Fig. 11

Specimens examined - Tavastia australis, Hämeenlinna, Ahvenisto, UCS 6767571:3360233, rich Picea abies forest, 7 Oct 2007, leg. Hilkka Lahti, det. Mauri Lahti (H 6043318); Lapponia sompiensis, Pelkosenniemi, Suvanto, Kalkkivaara, UCS 7455328:3503905, south facing calcareous rocky slopes with Pinus sylvestris, 28 Aug 2016, leg. \& det. TK 2452 (H 6064744).

New to Northern boreal, North Ostrobothnia (4b). These are the $3^{\text {rd }}-4^{\text {th }}$ records from Finland. The previous records are twice from Parainen (1a) (Kotiranta et al. 2009). Endangered.

Hyphoderma crassescens Laurila ex. K.H. Larss.

Fig. 12

Specimens examined - Ostrobottnia kajanensis, Paltamo, Kuuskanlahti N, Saukkovaara, UCS 7148459:3513242, on fallen trunk of Pinus sylvestris (diam. $27 \mathrm{~cm}$, decay stage 3), 21 Oct 2012, Pekka Helo 2459 (OULU), det. HK; Paltamo, Teerivaara, UCS 7146:3514, on charred root plate of Pinus sylvestris (diam.15 cm, decay stage 4) in old-growth dry heath forest, 6 Oct 2016, leg. TH (OULU), det. MK; Karelia borealis, Lieksa, Jäkäläkangas, UCS 7024049:3688079, on charred kelo trunk of Pinus sylvestris, (diam. 40 cm, decay stage 4), 6 Sep 2016, leg. Kaisa Junninen (OULU), det. MK.

New to Middle boreal, Northern Carelia - Kainuu (3b).

\section{Hyphoderma incrustatum K.H. Larss.}

Specimens examined - Tavastia australis, Muurame, Kuusimäki, UCS 6905570:3435388, on downed Betula sp. (diam. $26 \mathrm{~cm}$, decay stage unknown) in near natural old-growth sprucedominated forest, 29 Aug 2007, leg KJ 945; Jyväskylä, Korpilahti, Oittila, UCS 6870834:3433926, 


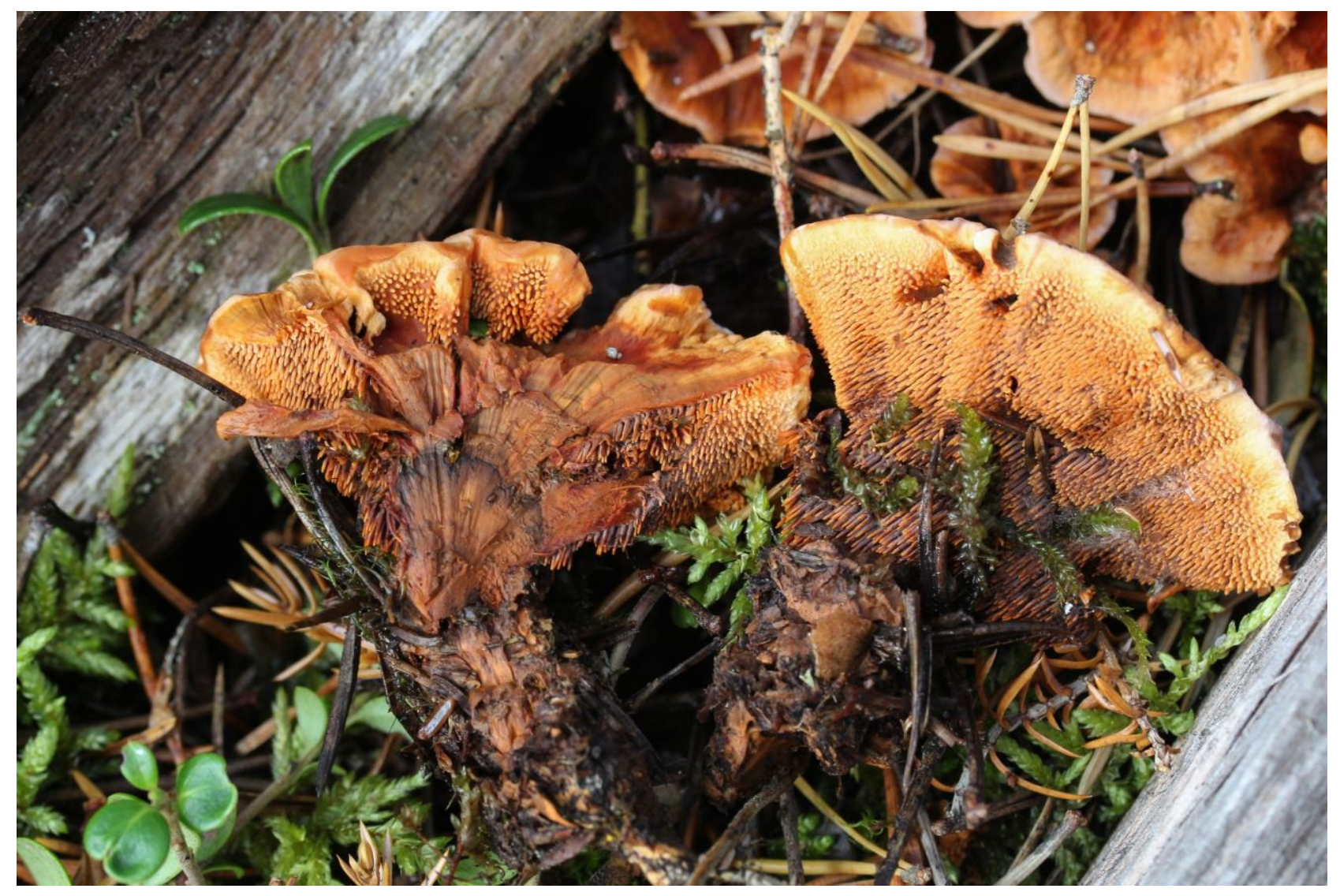

Figure 11 - Hydnellum auratile in Pelkosenniemi (TK 2452). Photo: Tapio Kekki

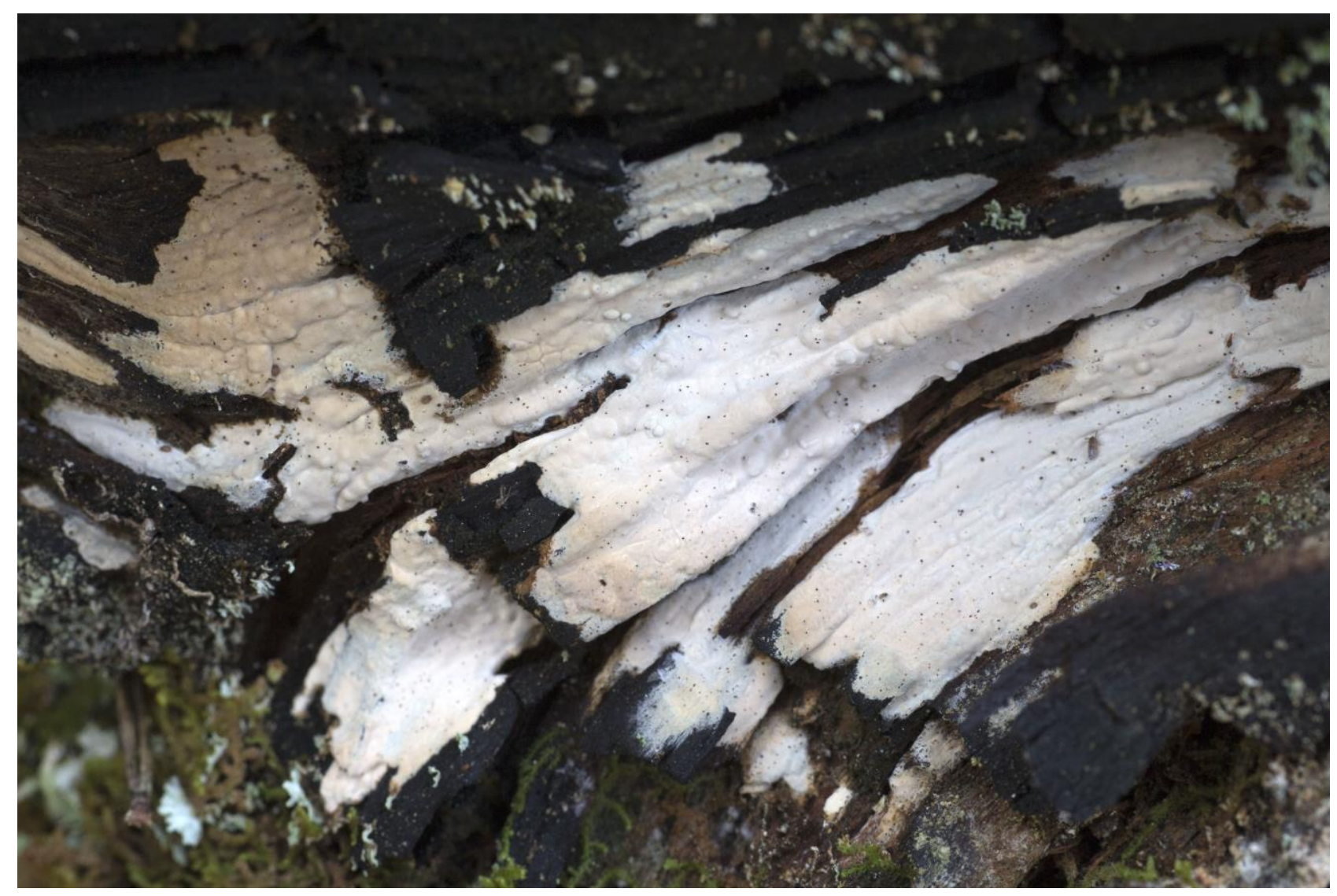

Figure 12 - Hyphoderma crassescens in Paltamo. Photo: Teppo Helo 
on uprooted Populus tremula (diam. $65 \mathrm{~cm}$, decay stage 1) in near natural herb-rich forest, 30 Aug 2007, leg. KJ 1034; Tavastia borealis, Rautalampi, Etelä-Konnevesi National Park, UCS 6941695:3484778, on fallen trunk of Populus tremula (diam. $35 \mathrm{~cm}$, decay stage 5) in old-growth mesic heath forest, 16 Sep 2017, leg. \& det. MK 48/17 (OULU), conf. HK.

New to Southern boreal, Lake District $(2 b)$. These are the $2^{\text {nd }}-4^{\text {th }}$ records from Finland. The first record is from Inari (4c) where it grew also on Populus tremula (Kotiranta et al. 2009). Data Deficient.

\section{Hyphoderma medioburiense (Burt) Donk}

Specimen examined - Tavastia australis, Jyväskylä, Korpilahti, Oittila, UCS 6870823:3433880, on unidentified hardwood (diam. $3 \mathrm{~cm}$, decay stage 3) in near natural herb-rich forest, 24 Aug 2007, leg. KJ 604 (K.J.); Luhanka, Moiskala, UCS 6854030:3430852, on fallen Betula (diam. 2 cm, decay stage 2) in birch-dominated wood-pasture, 27 Sep 2013, leg. KJ 5794 (K.J.).

New to Southern boreal, Lake District (2b).

\section{Hyphoderma nemorale K.H. Larss.}

Specimen examined - Tavastia borealis, Viitasaari, Niinilahti, Pitkämäki, UCS 6981071:3443904, on two fallen Betula (diam. 2 and $2.5 \mathrm{~cm}$, decay stage 2) in young birchdominated afforested field, 11 Oct 2012, leg. KJ 6115, 6116 (K.J.).

New to Southern boreal, Lake District (2b).

Hyphoderma occidentale (D.B. Rogers) Boidin \& Gilles

Specimen examined - Tavastia australis, Jyväskylä, Korpilahti, Oittila, UCS 6870823:3433880, on unidentified hardwood (diam. $3 \mathrm{~cm}$, decay stage 2) in near natural herb-rich forest, 24 Aug 2007, leg KJ 615 (K.J.).

New to Southern boreal, Lake District (2b).

\section{Hyphoderma roseocremeum (Bres.) Donk}

Specimen examined - Tavastia borealis, Viitasaari, Niinilahti, Pitkämäki, UCS 6981071:3443904, on fallen Betula sp. (diam. 2 cm, decay stage 2) in young birch-dominated afforested field, 10 Oct 2012, leg. KJ 5983 (K.J.); Ostrobottnia kajanensis, Kajaani, Teppana, UCS 71263:35362, on fallen trunk of deciduous tree (diam. $6 \mathrm{~cm}$, decay stage 3) in small thicket forest area in spruce-dominated mesic heath forest with high amount of dead wood, 26 Sep 2017, leg. TH 20170032 (T.H., OULU), det. MK. $(3 b)$.

New to Southern boreal, Lake District (2b) and Middle boreal, Northern Carelia - Kainuu

\section{Hyphodontiella hauerslevii K.H. Larss. \& Hjortstam}

Specimen examined - Tavastia borealis, Jyväskylä, Tourujoki, UCS 6905621:3435418, on twig of Sorbus aucuparia (diam. $0.9 \mathrm{~cm}$ ) in near natural herb-rich forest, 18 Oct 2007, leg. KJ 2745 (K.J.); Petäjävesi, Suolahti, UCS 6911151:3405740, on twig of Salix sp. (diam. $0.4 \mathrm{~cm}$ ) in young birch-dominated afforested field, 26 Sep 2012, leg. KJ 5597 (K.J.).

New to Finland and hence new to Southern boreal, Lake District (2b).

\section{Hypochnicium geogenium (Bres.) J. Erikss}

Specimen examined - Ostrobottnia kajanensis, Kajaani, Ilmarata, UCS 71268:35337, on fallen trunk of Salix caprea (diam. $4 \mathrm{~cm}$, decay stage 3), in riverside thicket forest with high amount of dead wood, 9 Oct 2016, leg. \& det. TH (OULU GAJ.5437), conf. MK.

New to Middle boreal, Northern Carelia - Kainuu (3b). There are several collections from the Kajaani area after this by the author TH. 
Hypochnicium lundellii (Bourdot) J. Erikss.

Specimen examined - Ostrobottnia kajanensis, Kajaani, Paltaniemi, Kirkkoniemi, UCS 71323:35300, on fallen top of Larix sp. (diam. $3 \mathrm{~cm}$, decay stage 2, thinning waste) in herbrich larch forest with cultural impact, 23 Oct 2016, leg. \& det. TH (OULU GAJ.5473), conf. MK.

New to Middle boreal, Northern Carelia - Kainuu (3b). There are several collections from the Kajaani area after this by the author TH.

Hypochnicium punctulatum (W.B. Cooke) J. Erikss.

Specimen examined - Tavastia australis, Jyväskylä, Korpilahti, Särkijärvi, UCS 6893755:3414170, on log of Pinus sylvestris (diam. $32 \mathrm{~cm}$, decay stage 2) in old-growth near natural spruce-dominated forest, 10 Sep 2007, leg KJ 1593 (K.J.); Tavastia borealis, Petäjävesi, Suolahti, UCS 6911023:3405715, on two Betula twigs (diam. 1 and $0.4 \mathrm{~cm}$ ) in young birchdominated afforested field, 21 Sep 2012, leg KJ 5347, KJ 5370 (K.J.).

New to Southern boreal, Lake District (2b).

Kneiffiella alienata (S. Lundell) Jülich \& Stalpers

Specimen examined - Tavastia australis, Muurame, Kuusimäki, UCS 6902060:3421978, on downed Betula sp. (diam. $25 \mathrm{~cm}$, decay stage unknown) in near natural old-growth sprucedominated forest, 29 Aug 2007, leg KJ 961 (K.J.).

New to Southern boreal, Lake District $(2 b)$. This is the $6^{\text {th }}$ observation from Finland. The previous ones are from Kullaa (2a), Siikainen (2a), Suomussalmi (3b), Kittilä (4b), and Muonio (4c) (Kotiranta et al. 2009, Kunttu et al. 2014). Vulnerable.

\section{Lentaria byssiseda (Pers.: Fr.) Corner}

Specimens examined - Ostrobottnia kajanensis, Puolanka, Paljakka, Mustakumpu, UCS 71723:35508, on trunk of Sorbus aucuparia (diam. $8 \mathrm{~cm}$, decay stage 3), in old-growth sprucedominated mesic heath forest with high amount of dead wood, 13 Oct 2017, leg. TH 2017007 \& MK (T.H., OULU), det. TH; Lapponia kittilensis Muonio, Pallastunturi, Pyhäjoki, UCS 7551483:3380928, on twigs in mesic Picea abies dominated forest, 5 Aug 2016, leg. Päivi Paalamo \& TK 2303, det. TK (OULU).

New to Middle boreal, Northern Carelia - Kainuu (3b) and Northern boreal, Forest Lapland (4c).

\section{Lentaria dendroidea (Fr.) J.H. Petersen}

Specimen examined - Lapponia kittilensis, Muonio, Pallastunturi, Pyhäjoki, UCS 755148:338092, on twigs in mesic Picea abies dominated forest, 5 Aug 2016, leg. Päivi Paalamo \& TK 2304 (OULU), det. TK

New to Northern boreal, Forest Lapland (4c).

\section{Leptosporomyces montanus (Jülich) Ginns \& M.N.L Lefebvre}

Specimens examined - Tavastia australis, Luhanka, Molikko Nature Reserve, UCS 6850082:3431504, on twigs of Betula sp. (diam. 1-1.5 cm, decay stage 2) in grass-herb forest, 12 Oct 2007, leg. KJ 2578, 2579, 2580 (JYV), det. KJ, HK; Tavastia borealis, Viitasaari, UCS 6981071:3443904, on twigs of Betula sp. (diam. 0.8, 0.9, 1, $1.2 \mathrm{~cm}$, decay stage 1) in afforested former field, 10 Oct 2012, leg. KJ 5956, 5974, 5973, 5982 (JYV), det. KJ, HK.

New to Finland, and hence new to Southern boreal, Lake District (2b).

\section{Leucogyrophana sororia (Burt) Ginns}

Specimen examined - Ostrobottnia kajanensis, Suomussalmi, Hossa, Valkeisenkangas, UCS 7268:3610, on fallen trunk of Pinus sylvestris (diam. $45 \mathrm{~cm}$, decay stage 3) in old-growth xeric heath forest with high amount of dead wood, 18 Oct 2015, leg. \& det. TH 20150102 (T.H.).

New to Northern boreal, Kuusamo District (4a). 
Litschauerella clematitis (Bourdot \& Galzin) J. Erikss. \& Ryvarden

Specimen examined - Tavastia borealis, Jyväskylä, Ylistönrinne, UCS 6903388:3434987, on unidentified hardwood twig (diam. $0.7 \mathrm{~cm}$ ) in near natural herb-rich forest, 26 Sep 2007, leg. KJ 2309 (K.J.).

New to Southern boreal, Lake District $(2 b)$. This is the $3^{\text {rd }}$ record in Finland. The previous ones are from Tammisaari (1b) and Helsinki (1b) (Kotiranta et al. 2009).

\section{Luellia recondita (H.S. Jacks) K.H. Larss. \& Hjortstam}

Specimen examined - Tavastia borealis, Jyväskylä, Saarenmaa, UCS 6915570:3427898, on twig of Picea abies (diam. $0.4 \mathrm{~cm}$ ) in mature managed spruce-dominated forest, 14 Sep 2007, leg. KJ $1733 b$ (K.J.).

New to Southern boreal, Lake District $(2 b)$. This is the $7^{\text {th }}$ record in Finland. The previous ones are from Eckerö (1a), Helsinki (1b), Tammisaari (1b), Kemiönsaari (1b), Hamina (2a), and Rovaniemi (3c) (Kotiranta et al. 2009, Kunttu et al. 2012, 2015, 2016a).

\section{Lyomyces erastii Saaren. \& Kotir.}

Specimens examined - Altogether 13 observations from four localities in Tavastia borealis (two herb-rich forests, Ylistönrinne and Tourujoki, in Jyväskylä, and two birch-dominated afforested field sites, Petäjävesi and Viitasaari). The main substrata were unidentified hardwood or Betula twig/branch (diam. 0.2-2.5 cm). One record was from log of Salix caprea (diam. $11 \mathrm{~cm}$, decay stage 2). All specimens are in the personal collection of K.J.

New to Southern boreal, Lake District (2b).

\section{Mucronella bresadolae (Quél.) Corner}

Specimen examined - Ostrobottnia kajanensis, Suomussalmi, Hossa, Pahamaailma, UCS 7263:3621, on charred fallen trunk of Pinus sylvestris (diam. $35 \mathrm{~cm}$, decay stage 4) in xeric heath forest with high amount of dead wood, 16 Oct 2015, leg. Pekka Helo 2922 (P.H.), det. TH.

New to Northern boreal, Kuusamo District (4a).

\section{Oliveonia fibrillosa (Burt) Donk}

Specimens examined - Regio aboënsis, Kemiönsaari, Morgonlandet UCS 6635:3258, on 25 Oct 2010, on five broken fallen trunks of Populus tremula (diam. $13 \mathrm{~cm}$, decay stage 3, diam. 17 $\mathrm{cm}$, decay stage 2, diam. $16 \mathrm{~cm}$, decay stage 2, diam. 17, decay stage 4, diam. $19 \mathrm{~cm}$, decay stage 3) leg. PK 7517a, 7518f, 7519a, 7524a, 7528a, det. MK; Kemiönsaari, Gärskär, UCS 6646057: 3222267, on broken fallen trunk of Betula sp. (diam. 21 cm, decay stage 4) 24 Aug 2010, leg. PK 6889a, det. MK, conf. HK and on the same island: Gärskär UCS 6645:3222, on broken fallen trunk of Sorbus aucuparia (diam. $12 \mathrm{~cm}$, decay stage 2), PK 6899a, det. MK, conf. HK; Tavastia borealis, Äänekoski, Aatula, UCS 6938645:3439579, on downed Betula sp. (diam. 2.5 cm, decay stage 2) in birch-dominated wood-pasture, 14 Sep 2013, leg. KJ 5225 (K.J.); Ostrobottnia kajanensis, Kajaani, Suvantola, UCS 71268:35342, on fallen trunk of deciduous tree (diam $10 \mathrm{~cm}$, decay stage 3) in riverside thicket forest with high amount of dead wood, 8 Oct 2016, leg. \& det. TH (OULU GAJ.5454), conf. HK.

New to Middle boreal, Northern Carelia - Kainuu (3b). These are the $3^{\text {rd }}-6^{\text {th }}$ records in Finland. The previous records are from Helsinki (1b) and Karjalohja (1b) (Kotiranta et al. 2009).

\section{Oliveonia pauxilla (H.S. Jacks) Donk}

Specimen examined - Tavastia borealis, Toivakka, Lappila, UCS 6902242:3460412, on branch of Betula sp. (diam. $1 \mathrm{~cm}$ ) in young birch-dominated afforested field, 13 Sep 2013, leg. KJ 6677 (K.J.).

This is the $4^{\text {th }}$ record in Finland. The previous ones are from Jomala (1a), Lammi (2a), and Jyväskylä (2b) (Kotiranta et al. 2009). 
Specimen examined - Regio aboënsis, Parainen, Archipelago Sea National Park, Boskär (Storlandet), UCS 6669:3209, on ground next to big Pinus sylvestris trees in mixed heath/herb-rich forest, 11 Jul 2017, leg. Maritta Laukkanen (H, OULU, TUR), det. M. Laukkanen, MK \& TH, conf. Tuomo Niemelä.

New to Finland, and hence new to $1 \mathrm{~b}$. The species is also new to Northern Europe.

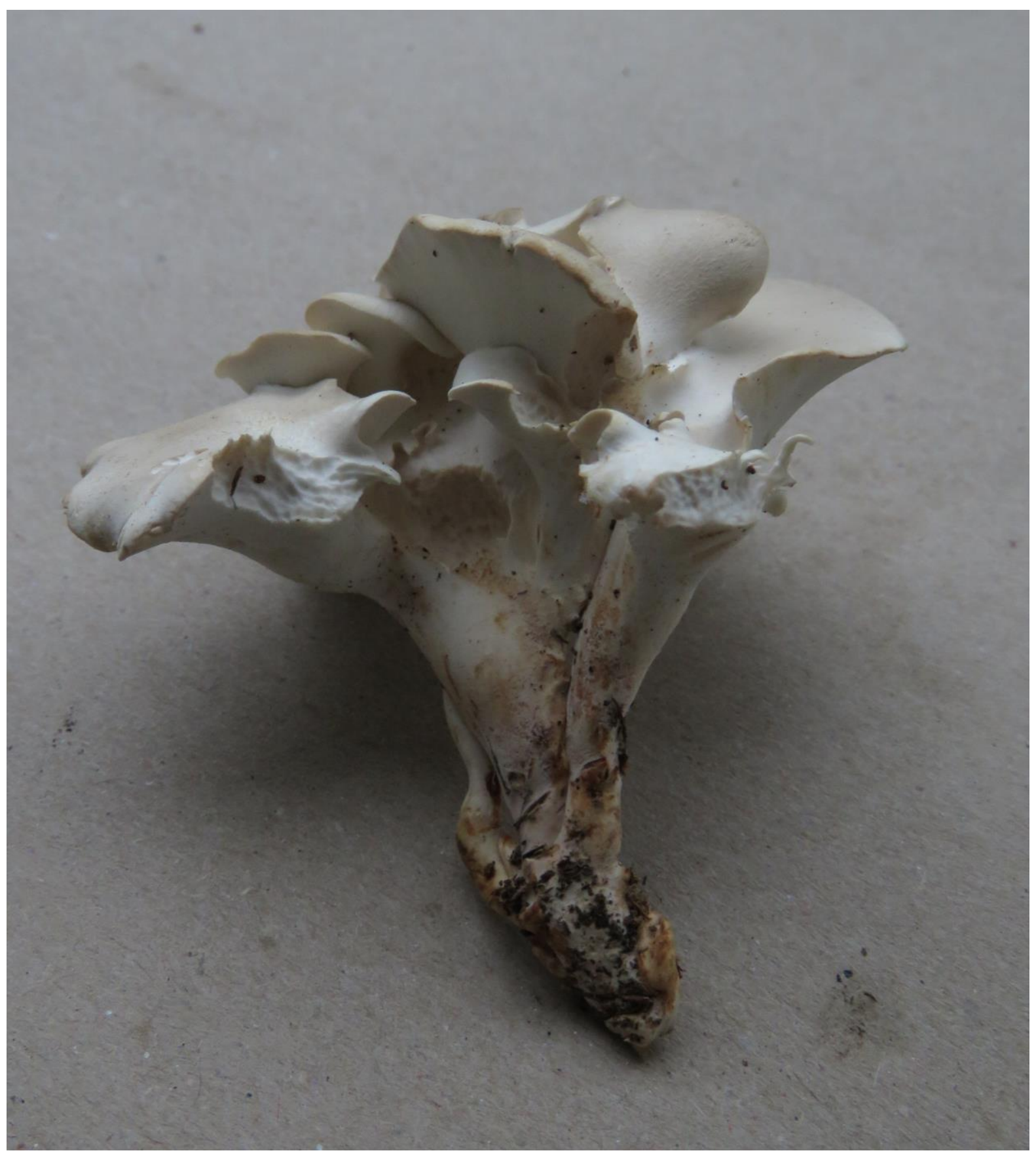

Figure 13 - Osteina obducta in Parainen, ex situ. Photo: Maritta Laukkanen

Phanerochaete deflectens (P. Karst.) Hjortstam

Fig. 14

Specimens examined - Tavastia borealis, Äänekoski, Aatula, UCS 6938588:3439737, on two fallen Betula (both diam. $2.5 \mathrm{~cm}$, decay stage 2) in birch-dominated wood-pasture, 13 Sep 2013, leg. KJ 5168, KJ 5171 (K.J.); Ostrobottnia kajanensis, Kajaani, Pöllyvaara, UCS 7126:3535, on fallen trunk of Betula sp. (diam. $4 \mathrm{~cm}$, decay stage 3-4) in spruce-dominated mesic heath forest, 11 Sep 2017, leg. \& det. TH 20170035 (T.H., OULU), conf. MK, HK. 
New to Southern boreal, Lake District (2b) and Middle boreal, Northern Carelia - Kainuu (3b). Near Threatened.

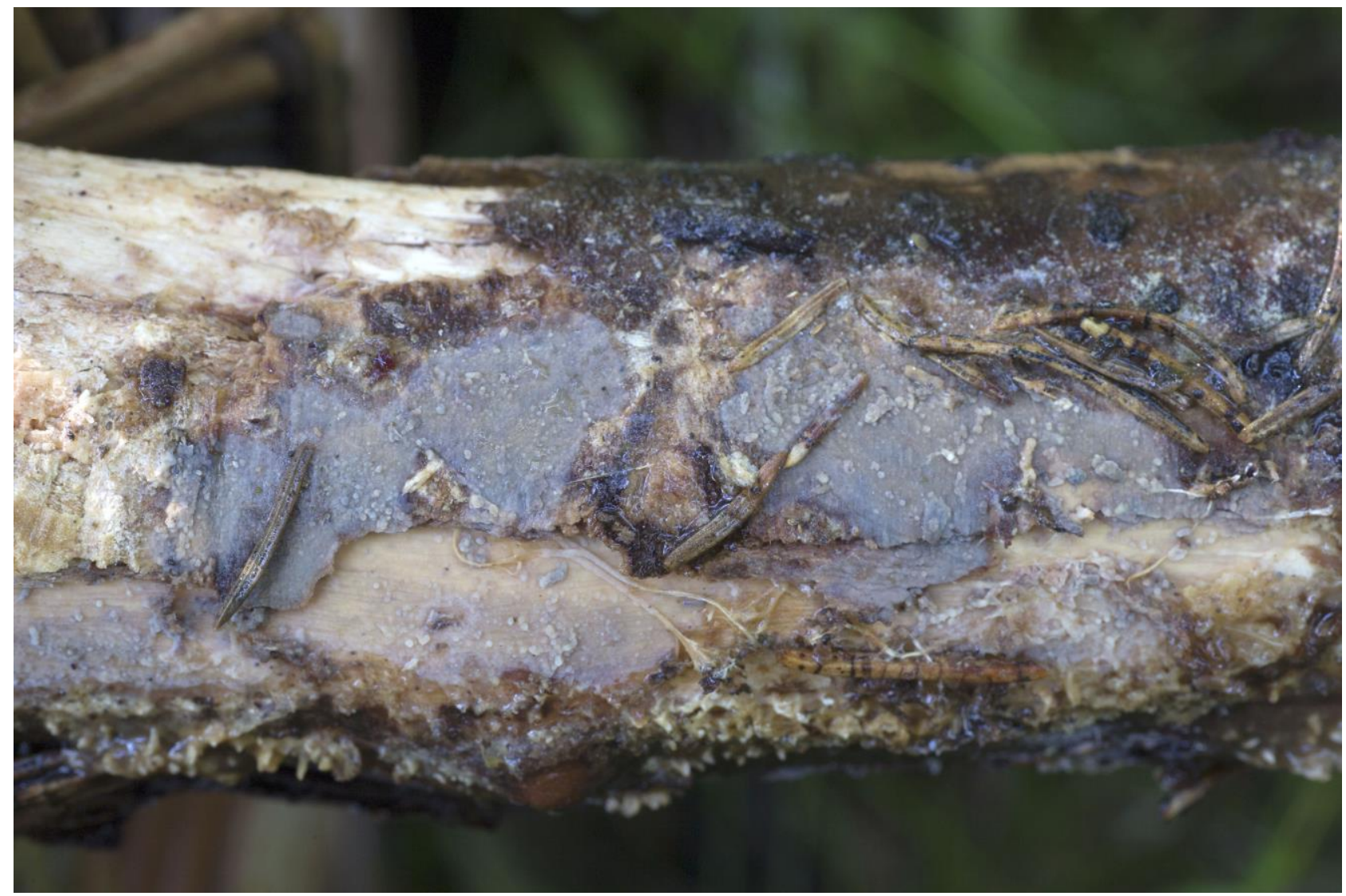

Figure 14 - Phanerochaete deflectens in Kajaani (TH 20170035). Photo: Teppo Helo.

Peniophorella pubera (Fr.) P. Karst.

Ostrobottnia kajanensis, Kajaani, Teppana, Ämmänkoski, UCS 71258:35357, on fallen trunk of Betula sp. (diam. $45 \mathrm{~cm}$, decay stage 3) in small spruce-dominated mesic heath forest area, 4 Nov 2014, leg. \& det. TH (OULU GAJ.5461), conf. MK.

New to Middle boreal, Northern Carelia - Kainuu (3b). There are several collections from the Kajaani area after this by the author TH.

Phlebia femsioeensis (Litsch. \& Lund.) J. Erikss. \& Hjortstam Fig. 15

Specimens examined - Ostrobottnia kajanensis, Suomussalmi, Koisti, UCS 71775:35999, on fallen kelo trunk of Pinus sylvestris (diam. $45 \mathrm{~cm}$, decay stage 3) in very old pine-dominated mesic heath forest with very high amount of dead wood, 17 Sep 2017, leg. \& det. TH 20170008 (T.H., OULU), conf. MK.; Kajaani, Pirunvaara, UCS 71270:35307, on fallen kelo trunk of Pinus sylvestris (diam. $8 \mathrm{~cm}$, decay stage 3 ) in old xeric heath pine forests, 3 Oct 2016, leg. \& det. TH 20160105 (T.H., OULU), conf. MK.

These are the $5^{\text {th }}-6^{\text {th }}$ records in Finland, both found in subzone $3 b$. Previous records are from Koski (2a), Hämeenlinna (2a), Pudasjärvi (3b), and Kuhmo (3b) (Kotiranta et al. 2009, Kunttu et al. 2013, 2015).

Phlebia firma J. Erikss. \& Hjortstam

Specimen examined - Tavastia australis, Muurame, Kuusimäki, UCS 6901032:3424348, on log of Sorbus aucuparia (diam. $6 \mathrm{~cm}$, decay stage unknown) in mature managed spruce-dominated forest, 22 Aug. 2007, leg KJ 446a (K.J.).

New to Southern boreal, Lake District (2b). Near Threatened. 


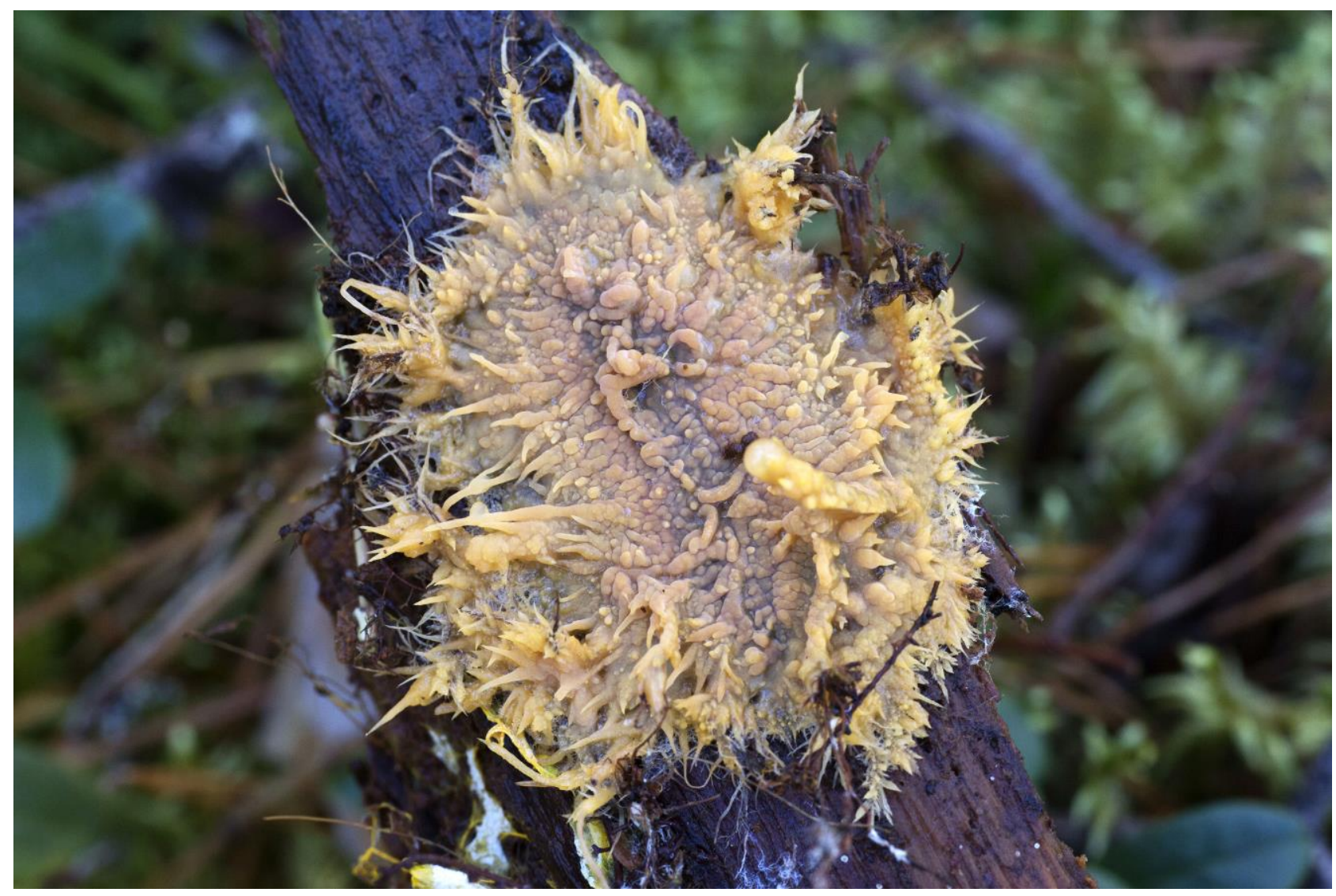

Figure 15 - Phlebia femsioeensis in Kajaani (TH 20160105). Photo: Teppo Helo

Phlebia lilascens coll. (Bourdot) J. Erikss. \& Hjortstam

Specimen examined - Ostrobottnia kajanensis, Paltamo, Kuuskanlahti, Teerivaara, UCS 71467:35140, on fallen trunk of Pinus sylvestris (diam. $12 \mathrm{~cm}$, decay stage 3 ) in old-growth xeric heath forest with high amount of dead wood, 12 Oct 2015, leg. \& det. TH (OULU GAJ.5485), conf. HK.

New to Middle boreal, Ostrobothnia (3a).

Phlebia subcretacea (Litsch.) M.P. Christ.

Fig. 16

Specimens examined - Ostrobottnia kajanensis, Paltamo, Kuuskanlahti, Teerivaara, UCS 71467:35140, on fallen trunk of Pinus sylvestris (diam. $15 \mathrm{~cm}$, decay stage 2) in old-growth xeric heath forest with high amount of dead wood, 12 Oct 2015, leg. \& det. TH (OULU GAJ.5483), conf. MK; Suomussalmi, Hossa, Valkeisenkangas, UCS 7268:3610, on fallen trunk of Pinus sylvestris (diam. $30 \mathrm{~cm}$, decay stage 3) in old-growth xeric heath forest with high amount of dead wood, 18 Oct 2015, leg. \& det. TH (OULU GAJ.5484), conf. MK.

New to Middle boreal, Ostrobothnia (3a). These are the $10^{\text {th }}-11^{\text {th }}$ records in Finland. The previous records derive throughout Finland (Kotiranta et al. 2009, Kunttu et al. 2015, 2016a). The species is found mainly on large trunks of Pinus sylvestris.

Physodontia lundellii Ryvarden \& Solheim

Specimen examined - Ostrobottnia kajanensis, Paltamo, Kuuskanlahti, Teerivaara, UCS 7146762:3514105, on charred root plate of Pinus sylvestris (diam. $30 \mathrm{~cm}$, decay stage 4) in oldgrowth xeric heath forest with high amount of dead wood, 12 Oct 2015, leg. Pekka Helo 2841 (P.H.), det. TH.

New to Middle boreal, Ostrobothnia (3a). Near Threatened. 


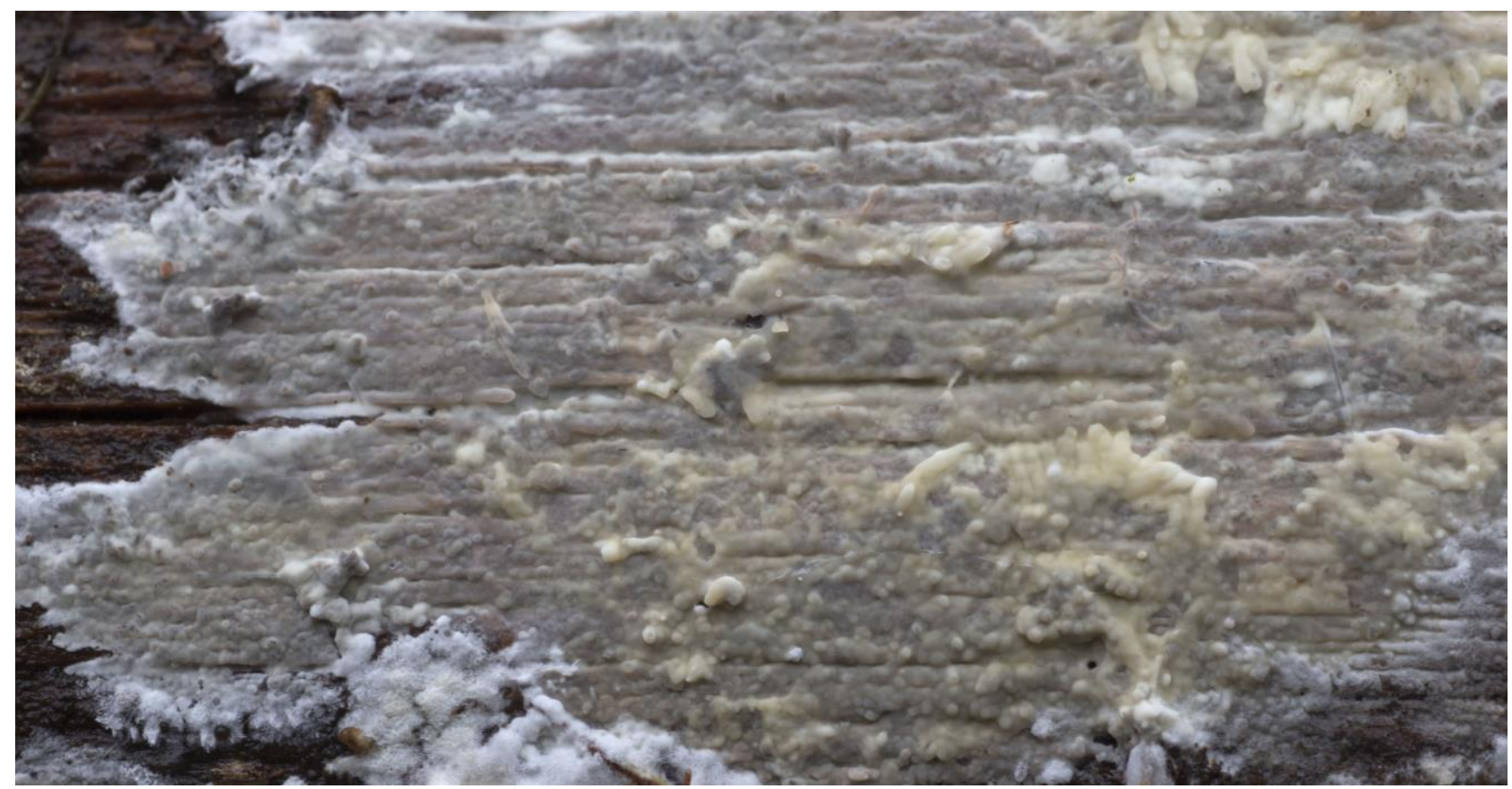

Figure 16 - Phlebia subcretacea in Suomussalmi. Photo: Teppo Helo

Postia persicina Niemelä \& Y.C. Dai

Fig. 17

Specimen examined - Regio kuusamoensis, Kuusamo, Oulanka National Park, Juuma, Hautaniitynvuoma, UCS 7354595:3610124, on fallen and unbarked trunk of Picea abies (diam. 25 $\mathrm{cm}$ ) in herb-rich forest, 7 Sep 2017, Pekka Halonen 7 (OULU, H), det. MK \& P. Halonen, conf. Viacheslav Spirin.

New to Northern boreal, Kuusamo district (4a). This is the $3^{\text {rd }}$ record in Finland. The previous records are from Puolanka (3b) and Kolari (4b) (Niemelä 2016). Critically Endangered.

\section{Pseudotomentella tristis (P. Karst.) M.J. Larsen}

Specimens examined - Ostrobottnia kajanensis, Puolanka, Paljakka, Latvavaara, UCS 7178:3546, on fallen trunk of Picea abies (diam. $15 \mathrm{~cm}$, decay stage 3) in very old-growth sprucedominated mesic heath forests with high amount of dead wood, 2 Oct 2016, leg. \& det. TH 20160102 (T.H.); Kajaani, Pöllyvaara, UCS 71263:353566, on fallen trunk of Pinus sylvestris (diam. $12 \mathrm{~cm}$, decay stage 4) in spruce-dominated mesic heath forest, 11 Sep 2017, leg. \& det. TH 20170129, conf. MK; Kajaani, Teppana, UCS 71262:353632, on fallen branch of Picea abies (diam. $3 \mathrm{~cm}$, decay stage 3) in small spruce-dominated mesic heath forest area, 26 Sep 2017, leg. TH 20170030 (OULU), det. MK.

New to Middle boreal, Northern Carelia - Kainuu (3b). This seems to be quite common species in Kainuu region and several collections have been made in addition to these records by the author TH.

Pterula multifida (Chevall.) Fr.

Specimen examined - Ostrobottnia kajanensis, Paltamo, Saviranta, Antinmäki, UCS 71389:35486, in mesic eutrophic herb-rich forest with aspen and spruce, 8 Sep 2014, leg. \& det. TH 20140101 (T.H., OULU).

New to Middle boreal, Northern Carelia - Kainuu (3b).

Ramaricium alboochraceum (Bres.) Jülich

Specimen examined: Tavastia borealis, Toivakka, Lappila, UCS 6902349:3460415, on six Betula twigs (diam. 0.1-1.2 cm) in young birch-dominated afforested field, 10 Sep 2013, leg. KJ 6539-41, 6548, 6561-62 (K.J.). 
This is the $3^{\text {rd }}$ record in Finland. The previous ones are from Jämsä (2b) and Kuusamo (4a) (Kotiranta et al. 2009). Vulnerable.

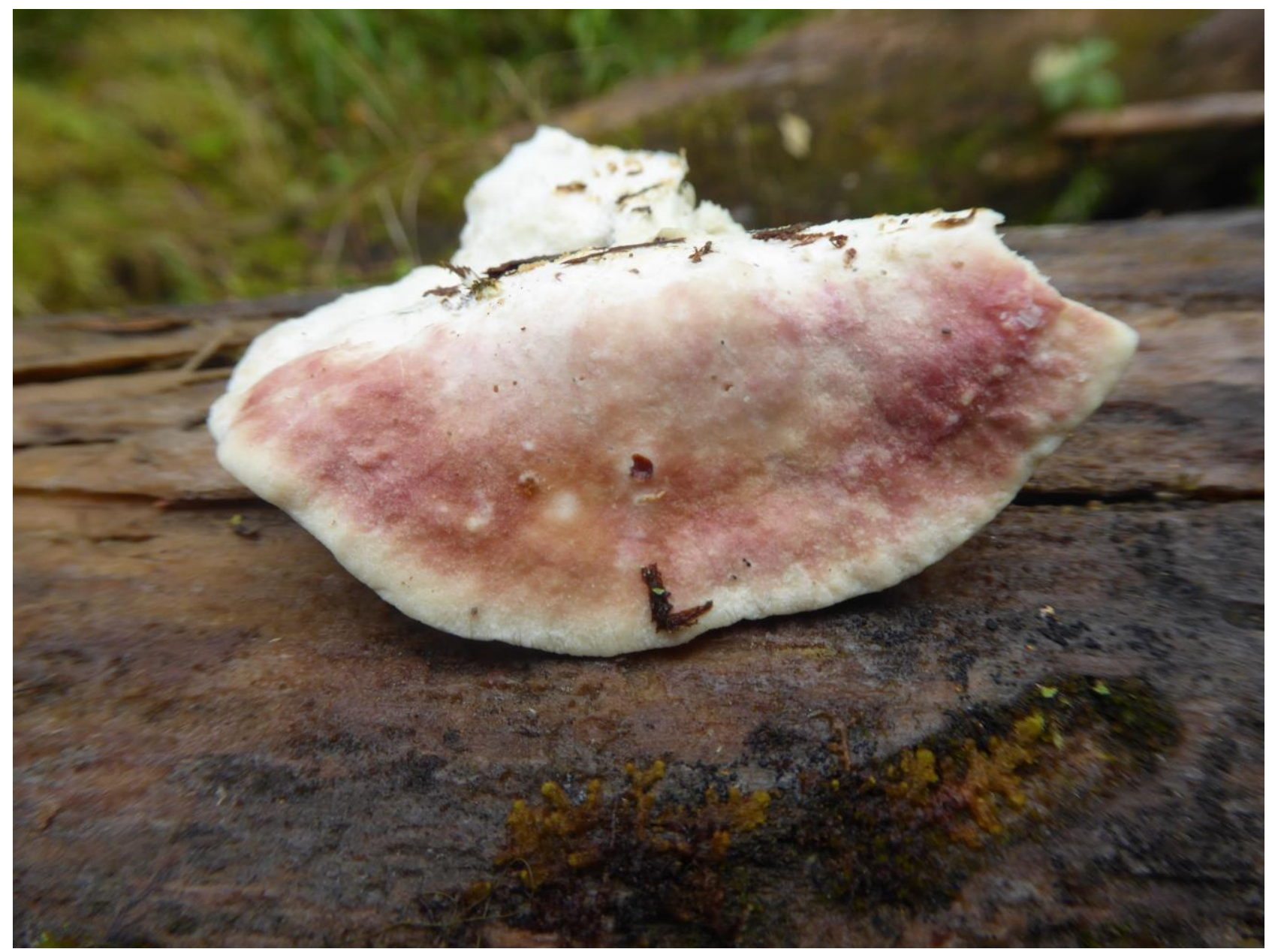

Figure 17 - Postia persicina in Kuusamo. Photo: Pekka Halonen

Sarcodon lundellii Maas Geest. \& Nannf.

Specimen examined - Lapponia sompiensis, Pelkosenniemi, Suvanto, Kalkkivaara, UCS 7455307:3503916, south facing calcareous rocky slopes with Picea abies near river bank, 28 Aug 2016, leg. \& det. TK 2448 (H 6064776).

New to Northern boreal, North Ostrobothnia (4b). This is the $5^{\text {th }}$ record in Finland. The previous records are from Lohja (1b), Porvoo (2a), Hämeenlinna (2a) and Kälviä (3a) (Kotiranta et al. 2009). Vulnerable.

\section{Scytinostroma praestans (H.S. Jacks) Donk}

Specimen examined - Tavastia australis, Jyväskylä, Korpilahti, Särkijärvi, UCS 6893806:3414262, on four Picea abies, two Pinus sylvestris and two Betula sp. twigs/branches (diam. 0.2-1.5 cm) in old-growth near natural spruce-dominated forest, 9 Sep 2007, leg. KJ 1516$17,-19,-26,-33,-35,-37$ (K.J.).

New to Southern boreal, Lake District (2b).

Sebacina epigaea (Berk. \& Broome) Neuhoff

Specimen examined - Tavastia australis, Luhanka, Onkisalo island, Molikko, UCS 6850044:3431528, on fallen Betula sp. (diam. $5 \mathrm{~cm}$, decay stage 3) in near natural herb-rich forest, 24 Sep 2007, leg. KJ 2217b (K.J.). 
New to Southern boreal, Lake District $(2 b)$. This is the $3^{\text {rd }}$ observation from Finland. The previous ones are from Kankaanpää (3a) and Kuusamo (4a) (Kotiranta et al. 2009).

Sebacina helvelloides (Schwein.) Burt

Specimen examined - Tavastia australis, Luhanka, Onkisalo island, Molikko, UCS 6850023:3431556, on Populus tremula twig (diam. $0.4 \mathrm{~cm}$ ) in near natural herb-rich forest, 12 Oct 2007, leg. KJ 2553 (K.J.).

New to Finland and hence new to Southern boreal, Lake District (2b).

Sistotrema autumnale Ryvarden \& Solheim

Fig. 18

Specimens examined - Tavastia borealis, Viitasaari, Niinilahti, Pitkämäki, UCS 6981203:3443835, on Betula twig (diam. $0.4 \mathrm{~cm}$ ) in young birch-dominated afforested field, 25 Oct 2012, leg. KJ 6272 (K.J.); Ostrobottnia kajanensis, Puolanka, Paljakka, Latvavaara, UCS 7178:3546, on fallen trunk of Populus tremula (diam. $30 \mathrm{~cm}$, decay stage 3 ) in very old sprucedominated mesic heath forests, 2 Oct 2016, leg. \& det. TH (GAJ.5419 OULU), TH, conf. MK; Puolanka, Latvavaara, UCS 7178880:3546834, on fallen trunk of Populus tremula (diam. 25 cm, decay stage 1) in very old spruce-dominated mesic heath forests with high amount of dead wood, 15 Oct 2017, leg. \& det. MK 123/17, (OULU); Puolanka, Latvavaara, UCS 7178:3546, on fallen trunk of Populus tremula (diam. $35 \mathrm{~cm}$, decay stage 3 ) in very old spruce-dominated mesic heath forests with high amount of dead wood, 15 Oct 2017, leg. \& det. TH 20170016, (T.H.); Puolanka, Kettukallio, UCS 7185376:3525476, on fallen trunk of Betula sp. (diam. $22 \mathrm{~cm}$, decay stage 3) in very old pine-dominated mesic heath forests with high amount of dead wood, 14 Oct 2017, leg. \& det. MK 118/17 (OULU); Puolanka, Mustakumpu, UCS 7172331:3551073, on fallen trunk of Betula sp. (diam. $20 \mathrm{~cm}$, decay stage 4) in very old spruce-dominated mesic heath forests with high amount of dead wood, 13 Oct 2017, leg. \& det. MK 107/17 (OULU); Puolanka, Mustakumpu, UCS 7172:3551, on fallen trunk of Betula sp. (diam. $30 \mathrm{~cm}$, decay stage 3) in very old spruce-dominated mesic heath forests with high amount of dead wood, 13 Oct 2017, leg. \& det. TH 20170017 (T.H.); Kajaani, Pyykönpuro, UCS 71250:35333, on fallen trunk of Salix caprea (diam. $2 \mathrm{~cm}$, decay stage 2) in deciduous thicket forest with high amount of dead wood, 3 Oct 2017, leg. \& det. TH 20170018 (T.H.); Kajaani, Ensilä, Maitoniemi, UCS 71264:35344, on the fallen trunk of deciduous tree (diam. $4 \mathrm{~cm}$, decay stage 2) in deciduous riparian thicket forest with high amount of dead wood, 17 Oct 2017, leg. \& det. TH 20170019 (T.H.).

New to Southern boreal, Lake District $(2 b)$. These are the $3^{\text {rd }}-8^{\text {th }}$ records from Finland. The previous records are from Padasjoki (2a) and Kajaani (3b) (Kotiranta et al. 2009, Kunttu et al. 2016a).

Sistotrema confluens Pers.: Fr.

Specimen examined - Ostrobottnia ultima, Kemi, Ajos, Kalasatama, UCS 7288881:3386345, on ground in Populus tremula dominated deciduous forest, 23 Sep 2016, leg \& det. TK 2758 (H 6064705).

New to Middle boreal, Southwestern Lapland (3c).

Sistotrema coroniferum (Höhn. \& Litsch.) Donk

Specimen examined - Tavastia borealis, Toivakka, Soimamäki, UCS 6887650:3441087, on three Pinus sylvestris twigs/branches (diam. $0.4-2.3 \mathrm{~cm}$ ) in old-growth near natural pinedominated forest, 4 Sep 2007, leg. KJ 1268, 1275, 1276 (K.J.).

New to Southern boreal, Lake District (2b).

\section{Sistotrema diademiferum (Bourdot \& Galzin) Donk}

Specimens examined - Tavastia australis, Muurame, Muuratharju, UCS 68905:34297, on two twigs of Pinus sylvestris (diam. 0.2 and $0.7 \mathrm{~cm}$ ) in mature managed pine-dominated forest, 23/27 Aug 2007, leg. KJ 472, KJ 598 (K.J.); Jyväskylä, Korpilahti, Vaaru, UCS 6870493:3432769, on 
twig of Pinus sylvestris (diam. $0.3 \mathrm{~cm}$ ) in mature managed spruce-dominated forest, 31 Aug 2007, leg. KJ 1134 (K.J.); Joutsa, Leivonmäki National Park, Ahvenlampi, UCS 6872458:3448823, on twig of Pinus sylvestris (diam. $0.5 \mathrm{~cm}$ ) in mature managed pine-dominated forest, 15 Oct 2007, leg. KJ 2634 (K.J.); Joutsa, Leivonmäki National Park, Keskisenkangas, UCS 6870162:3448414, on twig of Picea abies (diam. $0.9 \mathrm{~cm}$ ) in mature managed spruce-dominated forest, 16 Oct 2007, leg. KJ 2680b (K.J.); Jämsä, Riutanmäki, UCS 6882756:3410666, on two Picea abies twigs (diam. 0.2 and $0.4 \mathrm{~cm}$ ) in old-growth near natural spruce-dominated forest, 29 Oct 2007, leg. KJ 3018, -19 (K.J.); Kuhmoinen, Isojärvi National Park, Lortikka, UCS 6845370:3394181, on Pinus sylvestris twig (diam. $0.5 \mathrm{~cm}$ ) in old-growth near natural pine-dominated forest, 18 Sep 2007, leg. KJ 1861 (K.J.); Mänttä-Vilppula, Huhtijärvi, UCS 6886037:3366580, on twig of Betula sp. (diam. 0,5 cm) in young birch-dominated afforested field, 4 Oct 2013, leg. KJ 7479 (K.J.); Tavastia borealis, Toivakka, Soimamäki, UCS 6887705:3441106, on branch of Pinus sylvestris (diam. $0.8 \mathrm{~cm}$ ) in oldgrowth near natural pine-dominated forest, 6 Sep 2007, leg. KJ 1415(2) (K.J.); Jyväskylä, Tourujoki, UCS 6905628:3435436, on Salix caprea log/crown (diam. $14 \mathrm{~cm}$, decay stage 2) in near natural herb-rich forest, 11 Oct 2007, leg. KJ 2499 (K.J.); Petäjävesi, Suolahti, UCS 6911151:3405740, on twig of Betula sp. (diam. $0.4 \mathrm{~cm}$ ) in young birch-dominated afforested field, 26 Sep 2012, leg KJ 5593 (K.J.); Toivakka, Lappila, UCS 6902242:3460412, on fallen Betula (diam. 4 cm, decay stage 2) in young birch-dominated afforested field, 13 Sep 2013, leg KJ 6693 (K.J.); Toivakka, Haukanmaa, UCS 68868:34389, on four twigs of Pinus sylvestris (diam. 0.2-0.5 $\mathrm{cm}$ ) in old growth near natural pine-dominated forest, 17/25 Sep 2007, leg KJ 1774, 1806, 2251, 2286 (K.J.).

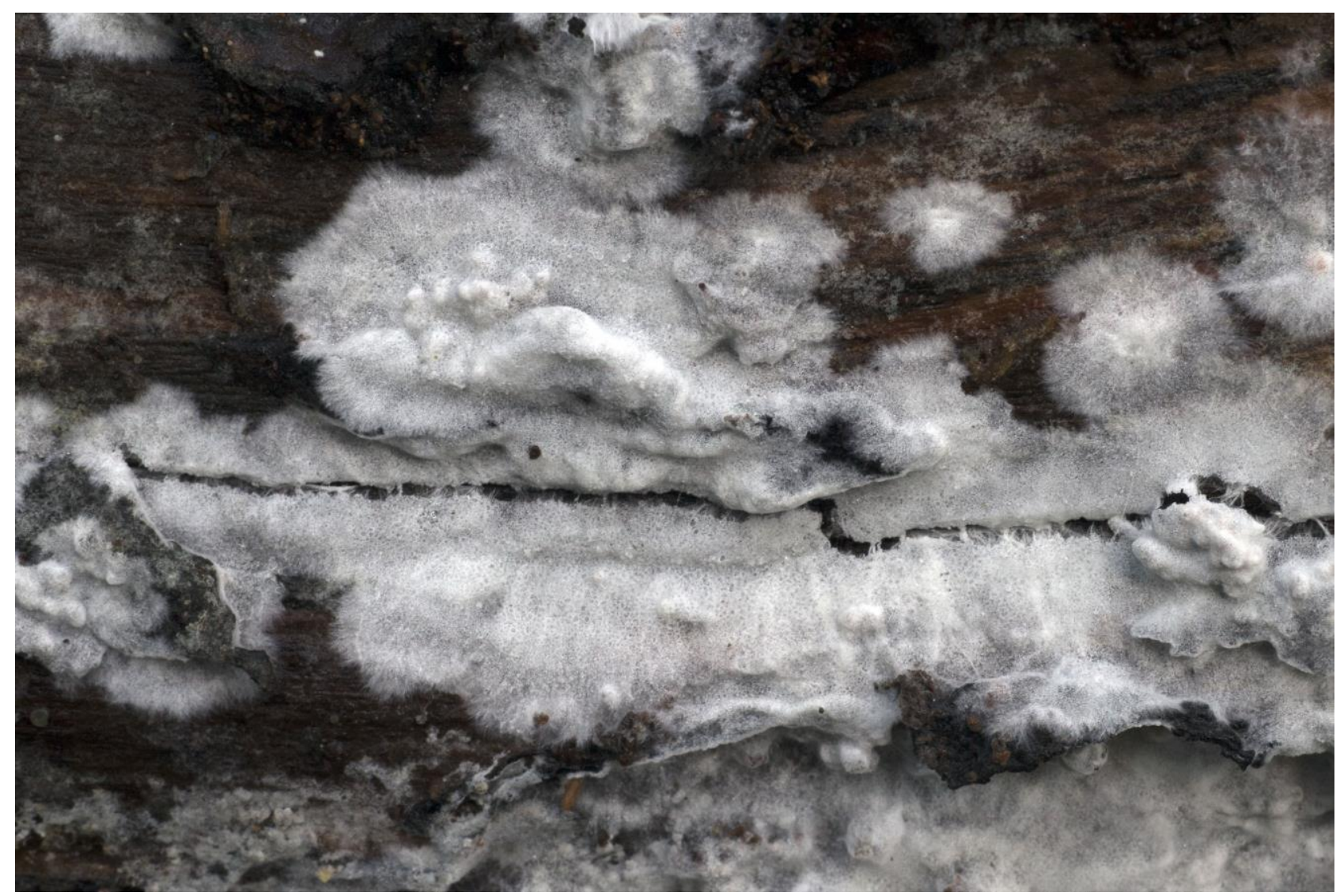

Figure 18 - Sistotrema autumnale in Puolanka. Photo: Teppo Helo

These are the $7^{\text {th }}-18^{\text {th }}$ record in Finland. The previous ones are from Helsinki (1b), Lammi (2a), Padasjoki (2a), Kesälahti (2b), Suomussalmi (3b), and Rovaniemi (3c) (Kotiranta et al. 2009, Kunttu et al. 2011). 
Sistotrema efibulatum (J. Erikss.) Hjortstam

Specimen examined - Regio aboënsis, Salo, Orjanperä, Korkianiemenkallio, UCS 66842:33220, on corticated branches of Picea abies (diam. $1.5 \mathrm{~cm}$, decay stage 1) in clear cut area, 10 May 2010, leg. \& det. HK 22661 (H, H.K.); Tavastia australis, Luhanka, Moiskala, UCS 6854056:3430810, on four Pinus sylvestris and two Betula sp. twigs (diam. 0.2-0.4 cm) in birchdominated wood-pasture, 5 Oct 2013, leg. KJ 5858-63 (K.J.); Tampere, Multisilta, UCS 68193:33267, on fallen trunk of Picea abies, 28 Apr 2017, leg. \& det. Unto Söderholm 5056 (OULU), conf. MK.

New to Southern boreal, SW Finland and Southern Ostrobothnia (2a) and Southern boreal, lake district $(2 \mathrm{~b})$. These are the $3^{\text {rd }}-5^{\text {th }}$ records from Finland. The previous records are from Finström (1a) where it grew on Picea abies and Utsjoki (4d) where it grew on Juniperus communis (Kotiranta et al. 2009, Kotiranta \& Shiryaev 2013).

Sistotremastrum niveocremeum (Höhn. \& Litsch.) J. Erikss.

Specimens examined - Ostrobottnia kajanensis, Kajaani, Ensilä, UCS 71264:35344, on fallen trunk of deciduous tree (diam. $4 \mathrm{~cm}$, decay stage 3), in deciduous riparian thicket forest with high amount of dead wood, 17 Oct 2017, leg. TH 20170025 (OULU), det. MK; Kajaani, Teppana, UCS 71262:353632, on fallen branch of Picea abies (diam $5 \mathrm{~cm}$, decay stage 2), in small sprucedominated mesic heath forest area, 26 Sep 2017, leg. \& det. TH 20170027 (OULU), conf. MK; Sotkamo, Parkua, Kivimäki, UCS 71056:35470, on fallen trunk of deciduous tree (diam. 4, decay stage 2), in small deciduous thicket forest area in spruce-dominated mesic heath forest, overgrown old house yard, 29 Sep 2017, leg. \& det. TH 20170026 (OULU), conf. MK.

New to Middle boreal, Northern Carelia - Kainuu (3b).

Skeletocutis delicata Miettinen \& Niemelä

Specimen examined - Ostrobottnia ultima, Tervola, Pisavaara Strict Nature Reserve, UCS 7353575:3415497, on fallen trunk of Picea abies (diam. $20 \mathrm{~cm}$ ) in spruce mire, 23 Sep 2000, leg. \& det. MK 241/00 (OULU);

New to Middle boreal, Southwestern Lapland (3c). This species is lately described, separated from other Skeletocutis-species (Niemelä 2016). According to Finnish herbaria's collection management system Kotka (Luonnontieteellinen keskusmuseo 2018), Niemelä (2016), there are at least ca. 25 records all over Finland, from subzones 1b, 2a, 2b, 3b, 4a and 4b.

Sparassis crispa (Wulfen) Fr.

Specimen examined - Ostrobottnia ultima, Rovaniemi, Pisavaara Strict Nature Reserve, Teeripäri, UCS 7357991:3415042, on fallen trunk of Pinus sylvestris (diam. $30 \mathrm{~cm}$ ) in mesic heath forest, 19 Sep 2016, leg. \& det. Saija Ahonen \& MK 27/16 (OULU).

New to Middle boreal, Southwestern Lapland (3c).

Stereopsis vitellina (Plowr.) D.A. Reid

Specimen examined - Ostrobottnia kajanensis, Suomussalmi, Hossa, Pahamaailma, UCS 7263080:3622452, under fallen kelo trunk of Pinus sylvestris (diam $15 \mathrm{~cm}$, decay stage 4) in very old pine-dominated xeric heath forest with high amount of dead wood, 17 Oct 2015, leg. \& det. TH 20150103 (T.H.).

New to Northern boreal, Kuusamo District (4a).

Stypella subgelatinosa (P. Karst.) P. Roberts

Specimens examined - Tavastia borealis, Petäjävesi, Suolahti, UCS 6911023:3405715, on fallen Betula (diam. 4cm, decay stage 3) in young birch-dominated afforested field, 21 Sep 2012, leg KJ 5413 (K.J.) and later on the same site: UCS 6911151:3405740, on Betula branch (diam. 2.5 cm, decay stage 3) in young birch-dominated afforested field, 2 Oct 2012, leg. KJ 5796 (K.J.). 
This is the $5^{\text {th }}$ observation from Finland. The previous ones are from Kangasala (2a), Luhanka (2a), Tammela (2b), and Oulu (3a) (Kotiranta et al. 2009, Kunttu et al. 2012). Near Threatened.

Stypella vermiformis (Berk. \& Broome) D. A. Reid

Fig. 19

Specimen examined - Ostrobottnia kajanensis, Suomussalmi, Koisti, UCS 71777:35999, on fallen kelo trunk of Pinus sylvestris (diam. $45 \mathrm{~cm}$, decay stage 3) in old pine-dominated mesic heath forest with very high amount of dead wood, 17 Sep 2017, leg. \& det. TH 20170014 (T.H., OULU).

This is the $5^{\text {th }}$ record in Finland. The previous records are from Kemiönsaari (1b), Lieksa (two sites, 3b), and Inari (4c) (Kotiranta et al. 2009, Kunttu et al. 2016a).

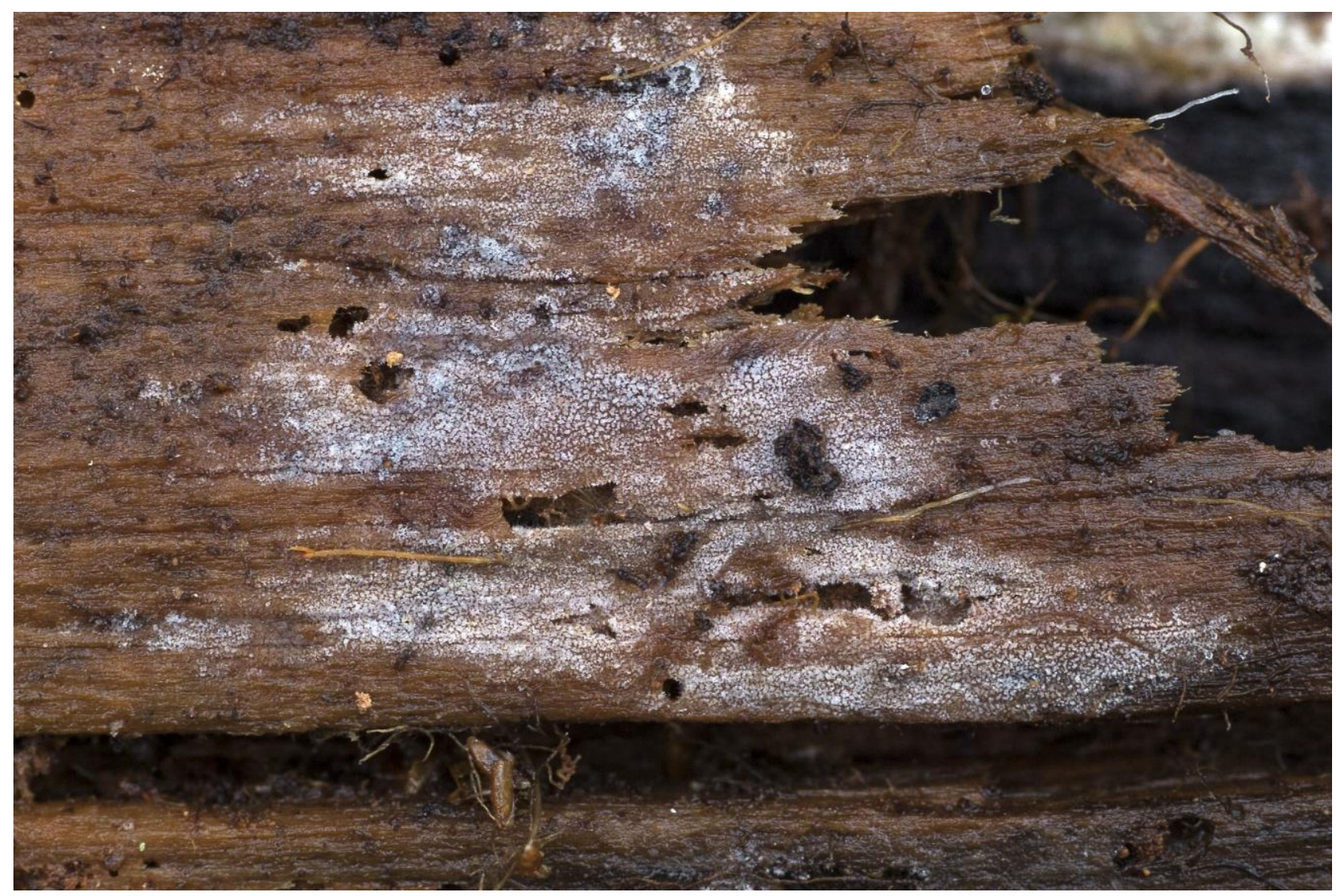

Figure 19 - Stypella vermiformis in Suomussalmi (TH 20170014). Photo: Teppo Helo

Suillosporium cystidiatum (D.P. Rogers) Pouzar

Fig. 20

Specimen examined - Ostrobottnia kajanensis, Puolanka, Kettukallio, UCS 71855:35255, on fallen kelo trunk of Pinus sylvestris with Tylospora fibrillosa (diam. $50 \mathrm{~cm}$, decay stage 4) in very old pine-dominated mesic heath forest with high amount of dead wood, 14 Oct 2017, leg. \& det. TH 20170004 (H.K., OULU), conf. HK.

New to Middle boreal, Northern Carelia - Kainuu (3b). This is the $3^{\text {rd }}$ record in Finland. The previous records are from Lammi (2a) and Korpilahti (2b) (Kotiranta et al. 2009). Data Deficient.

Thanatephorus fusisporus (J. Schröt.) P. Roberts \& Hauerslev

Specimens examined - Ostrobottnia kajanensis, Kajaani, Suvantola, UCS 71269:35343, on fallen trunk of Salix caprea (diam. $12 \mathrm{~cm}$, decay stage 3), in riparian thicket forest with high amount of dead wood, 8 Oct 2016, leg. \& det. TH (OULU GAJ.5463), conf. MK; Suomussalmi, Hossa, UCS 71630:36237, on fallen trunk of Populus tremula (diam. $13 \mathrm{~cm}$, decay stage 4), in oldgrowth forest with high amount of dead wood, 17 Oct 2015, leg. Pekka Helo 2948 (OULU, H.K.), 
det. HK. This latter record has previously reported from false subzone (3b) (Kunttu et al. 2016a), but it should be 4 a.

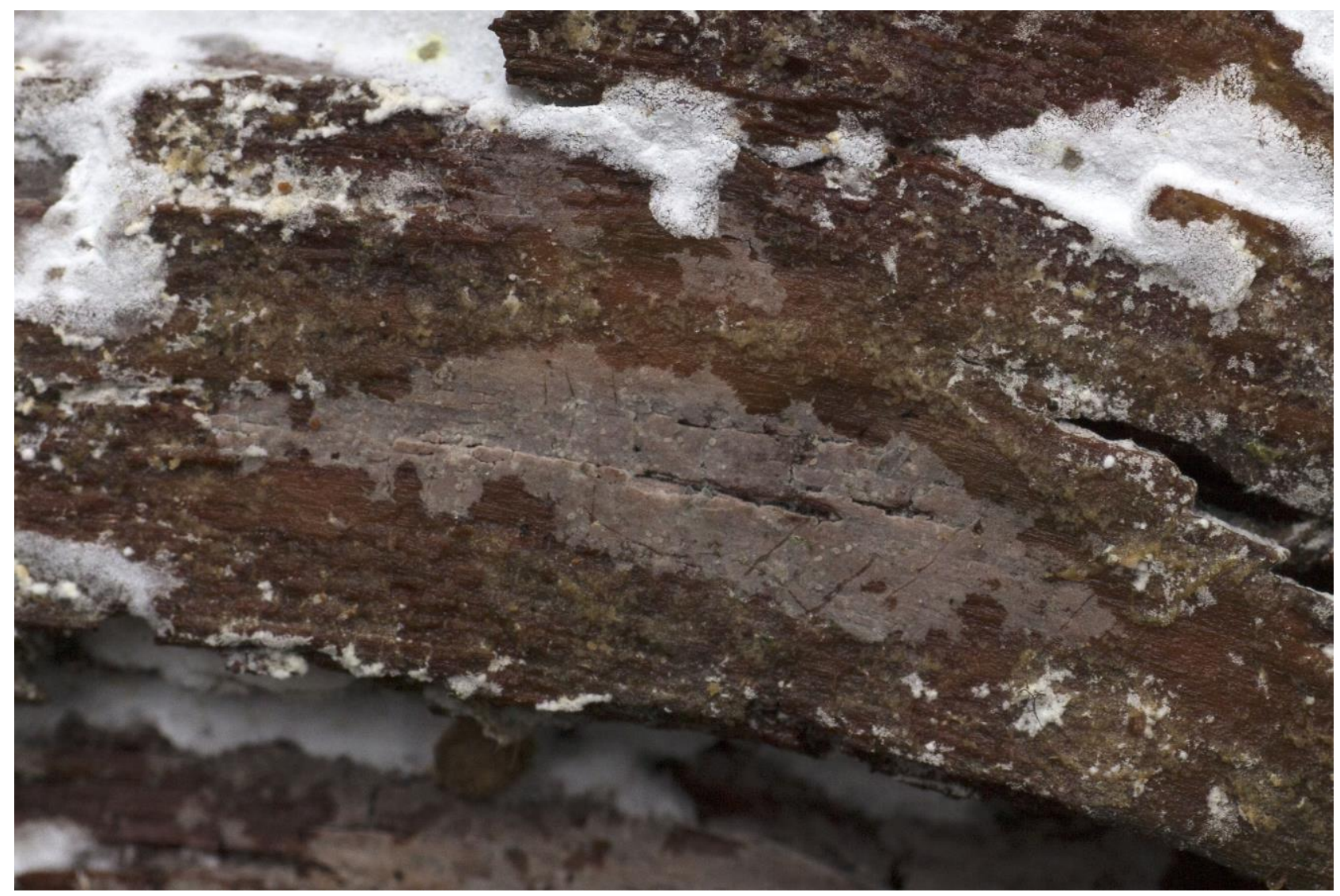

Figure 20 - Suillosporium cystidiatum in Puolanka (TH 20170004) with Tylosporium fibrillosum. Photo: Teppo Helo

New to Middle boreal, Northern Carelia - Kainuu (3b) and Northern boreal, Kuusamo district (4a). There are several collections from the Kajaani area after this by the author TH.

Thelephora caryophyllea Schaeff.: Fr.

Specimen examined - Ostrobottnia kajanensis, Paltamo, Melalahti, UCS 714718:353281, in grassland at sandy road shoulder, 28 Aug 2017, leg. \& det. TH 20170009 (T.H.).

New to Middle boreal, Northern Carelia - Kainuu (3b).

Thelephora palmata Scop.: Fr.

Specimen examined - Ostrobottnia kajanensis, Paltamo, Melalahti, Myllymäki, UCS 71450:35324, in spruce-dominated mesic eutrophic herb-rich forest, 4 Aug 2015, leg. \& det. TH 20150104 (T.H.).

New to Middle boreal, Northern Carelia - Kainuu (3b).

Tomentella bryophila (Pers.) M.J. Larsen

Specimen examined - Ostrobottnia kajanensis, Paltamo, Teerivaara, UCS 71460:35142, on fallen trunk of Betula sp. (diam. 25, decay stage 3) in old spruce-dominated mesic heath forest, 6 Oct 2016, leg. \& det. TH 20160103 (T.H.), conf. MK.

New to Middle boreal, Ostrobothnia (3a).

Tomentella coerulea (Bres.) Höhn. \& Litsch

Fig. 21

Specimens examined - Ostrobottnia kajanensis, Kajaani, Teppana, UCS 71262:35363, on 
fallen trunk of Picea abies (diam. $3 \mathrm{~cm}$, decay stage 3) in spruce-dominated mesic heath forest, 26 Sep 2017, leg. TH 20170010 (T.H., OULU), det. MK; Kajaani, Pöllyvaara, UCS 7126:3535, on fallen branch of deciduous tree (diam. 3) in spruce-dominated mesic heath forest, 12 Sep 2017, leg. TH 20170031 (T.H., OULU), det. MK.

New to Middle boreal, Northern Carelia - Kainuu (3b). This is the $7^{\text {th }}$ record in Finland. The previous records are from Parainen (1b), Kemiönsaari (two sites, 1b), Rautalampi (2b), Rovaniemi (3c), and Enontekiö (4c) (Kotiranta et al. 2009, Kunttu et al. 2012, 2013, 2014)

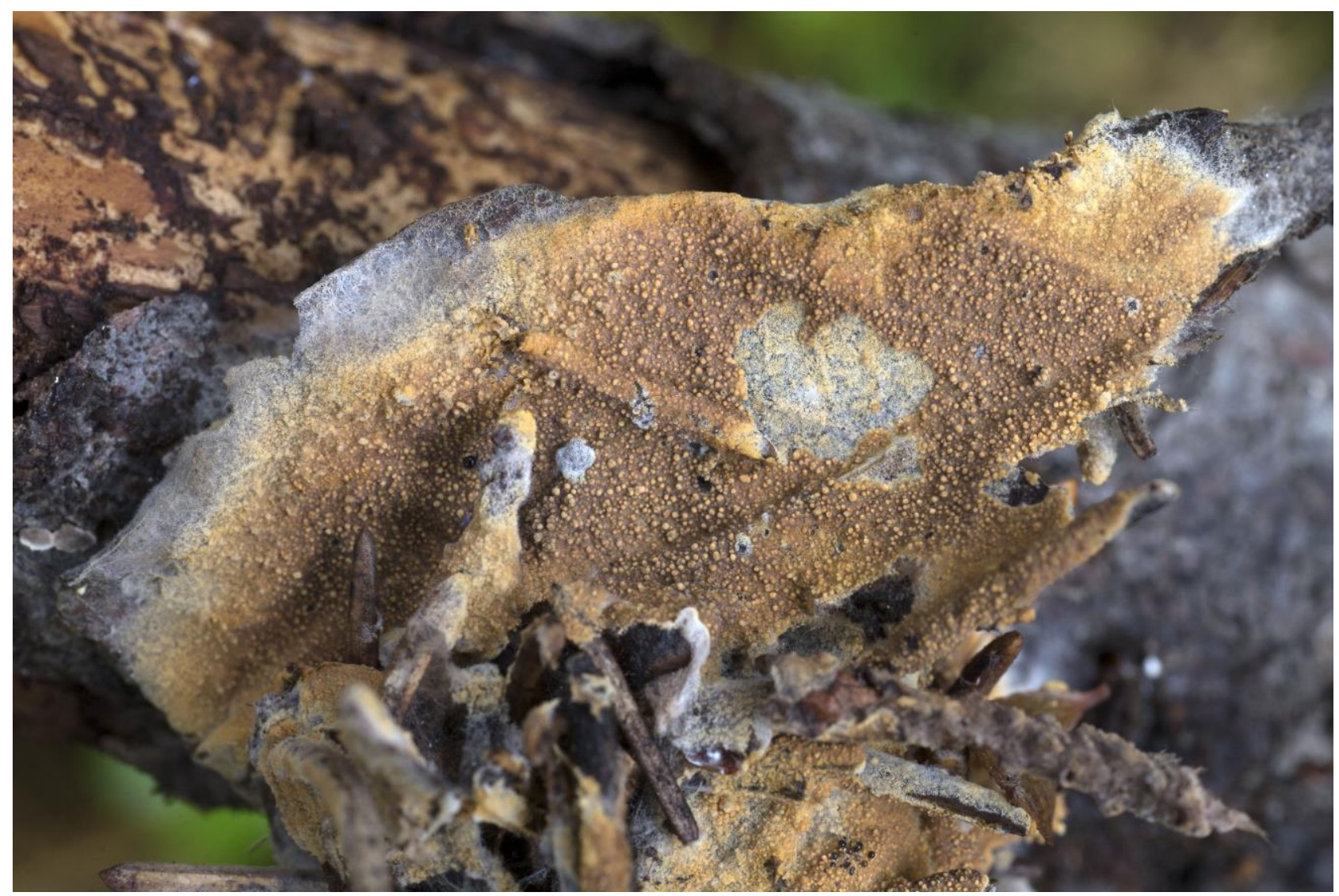

Figure 21 - Tomentella coerulea in Kajaani (TH 20170010). Photo: Teppo Helo

Tomentella crinalis (Fr.) M.J. Larsen

Specimens examined - Tavastia autralis, Jyväskylä., Korpilahti, Oittila, UCS 6870823:3433880, on four unidentified hardwood (diam. 2.5-10 cm, decay stage 2-3) and Alnus incana log (diam. $18 \mathrm{~cm}$, decay stage 4) in near natural herb-rich forest, 30 Aug 2007, leg. KJ $1080,-82,79,-78,-35$ (K.J.).

New to Southern boreal, Lake District (2b).

Tomentella radiosa (P. Karst.) Rick

Specimens examined - Ostrobottnia kajanensis, Paltamo, Kuuskanlahti, Teerivaara, UCS 7146671:3513985, on charred root plate of Pinus sylvestris (diam. $35 \mathrm{~cm}$, decay stage 3-4) in oldgrowth dry heath forest, 2 Sep 2012, leg. Pekka Helo 2305 (OULU), det. MK; Puolanka, Kettukallio, UCS 7185464:3525490, on charred root plate of Pinus sylvestris (diam. $33 \mathrm{~cm}$, decay stage 1) in old-growth mesic heath forest, 14 Oct 2017, leg. \& det. MK 114/17 (OULU).

New to Middle boreal, Northern Carelia - Kainuu (3b).

Tomentella stuposa (Link) Stalpers

Specimen examined - Ostrobottnia kajanensis, Kajaani, Pöllyvaara, UCS 71263:35356, on 
fallen trunk of Picea abies (diam. $8 \mathrm{~cm}$, decay stage 2) in spruce-dominated mesic heath forest, 11 Sep 2017, leg. \& det. TH 20170020 (T.H.), conf. MK.

New to Middle boreal, Northern Carelia - Kainuu (3b).

Tomentella subclavigera Litsch.

Fig. 22

Specimens examined - Tavastia australis, Mänttä-Vilppula, Huhtijärvi, UCS 6886037:3366580, on three Betula twigs (diam. 0.2-0.6 cm) in young birch-dominated afforested field, 18/29 Sep 2013, leg. KJ 7008b, KJ 7055b, KJ 7371 (K.J.); Ostrobottnia kajanensis, Sotkamo, Parkua, Kivimäki, UCS 71056:35470, on fallen trunk of Salix caprea (diam. $20 \mathrm{~cm}$, decay stage 3) in spruce-dominated mesic heath forests, 29 Sep 2017, leg. \& det. TH 20170011 (T.H., OULU); Kajaani, Pyykönpuro, UCS 71250:35333, on fallen trunk of Salix caprea (diam. 4 cm, decay stage 3 ) in deciduous riparian thicket forest with high amount of dead wood, 1 Oct 2017, leg. TH 20170012 (T.H., OULU), det. MK.

New to Middle boreal, Northern Carelia - Kainuu (3b). These are the $7^{\text {th }}-9^{\text {th }}$ records in Finland. The previous records are from Helsinki (three sites, 1a), Tammela (2a), Savonranta (2b), and Rovaniemi (3c) (Kotiranta et al. 2009, Kunttu et al. 2016a).

Tomentella sublilacina coll. (Ellis \& Holw.) Wakef.

Specimen examined - Ostrobottnia kajanensis, Puolanka, Latvavaara, UCS 7178880:3546834, on fallen trunk of Populus tremula (diam. $25 \mathrm{~cm}$, decay stage 1) in sprucedominated mesic heath forests with high amount of dead wood, 15 Oct 2017, leg. \& det. MK 122/17 (OULU).

New to Middle boreal, Northern Carelia - Kainuu (3b).

Tomentellopsis echinospora (Ellis) Hjortstam

Specimen examined - Ostrobottnia kajanensis, Paltamo, Kuuskanlahti, Teerivaara, UCS 71467:35140, on charred piece of fallen trunk of Pinus sylvestris (decay stage 4) in old-growth xeric heath forest with high amount of dead wood, 12 Oct 2015, leg. \& det. TH (OULU GAJ.5480), conf. MK.

New to Middle boreal, Ostrobothnia (3a). There are several collections from the same area after this record by the author $\mathrm{TH}$.

Trechispora cohaerens (Schwein.) Jülich \& Stalpers

Specimen examined - Ostrobottnia ouluensis, Oulu, Oinaansuo, UCS 7221013:3431986, on snag of Betula sp. (diam. $10 \mathrm{~cm}$, decay stage 3) in spruce mire, 6 Sep 2017, MK 88/17 \& Iita Tiusanen (OULU), det. MK.

New to Middle boreal, Ostrobothnia (3a).

\section{Trechispora praefocata (Bourdot \& Galzin) Liberta}

Specimen examined - Tavastia borealis, Jyväskylä, Ylistönrinne, UCS 6903388:3434987, on nine unidentified hardwood twigs (diam. 0.2-0.7 cm), one hardwood and one Betula branch (diam. 1.4 and $1.9 \mathrm{~cm}$ ), and one fallen hardwood (diam. $3 \mathrm{~cm}$, decay stage 3 ) in near natural herb-rich forest, 21 Sep 2007, leg. KJ (K.J.).

New to Southern boreal, Lake District (2b).

Trechispora stellulata (Bourdot \& Galzin) Liberta

Specimens examined - Tavastia autralis, Joutsa, Leivonmäki National Park, Keskisenkangas, UCS 6870162:3448414, on two Picea abies twigs (diam. 0.2 and $0.3 \mathrm{~cm}$ ) in mature managed spruce-dominated forest, 16 Oct 2007, leg. KJ 2702, -01 (K.J.); Tavastia borealis, Viitasaari, Niinilahti, Pitkämäki, UCS 6981203:3443835, on Betula twig (diam. $0.6 \mathrm{~cm}$ ) in young birchdominated afforested field, 25 Oct 2012, leg. KJ 6184 (K.J.); Ostrobottnia kajanensis, Kajaani, Ensilä, Maitoniemi, UCS 71265:35345, on fallen branch of old Pinus sylvestris (diam. $5 \mathrm{~cm}$, decay 
stage 3) in area between hayfield and deciduous riparian thicket forest, 21 Oct 2016, leg. \& det. TH (OULU GAJ.5469), conf. MK.

New to Southern boreal, Lake District (2b) and Middle boreal, Northern Carelia - Kainuu (3b).

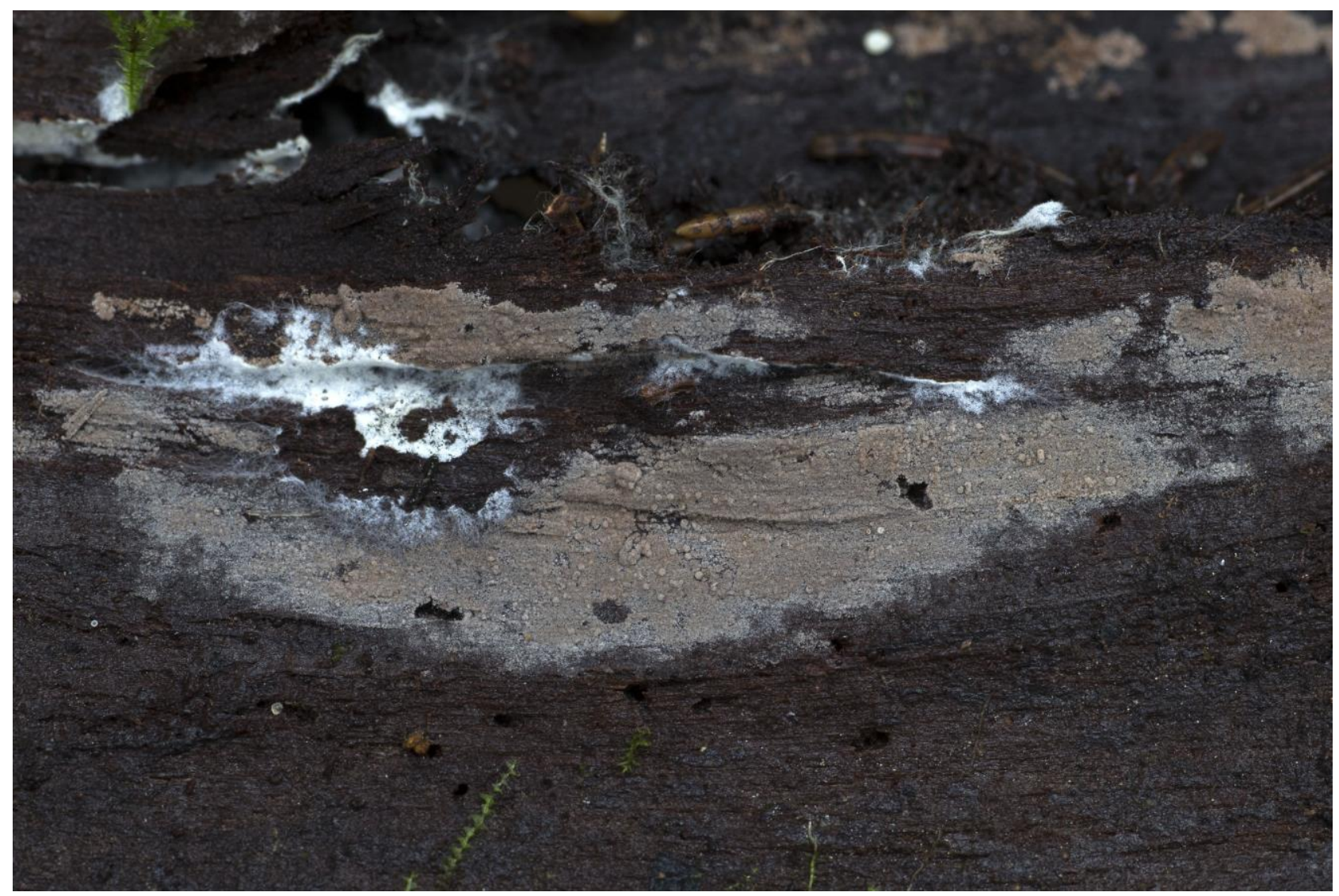

Figure 22 - Tomentella subclavigera in Sotkamo (TH 20170011). Photo: Teppo Helo

Trechispora stevensonii (Berk. \& Broome) K.H. Larss.

Specimen examined - Tavastia borealis, Jyväskylä, Ylistönrinne, UCS 6903388:3434987, on unidentified hardwood branch (diam. $2 \mathrm{~cm}$, decay stage 2) in near natural herb-rich forest, 26 Sep 2007, leg KJ 2328 (K.J.).

New to Southern boreal, Lake District (2b).

Trechispora verruculosa (G. Cunn.) K.H. Larss.

Specimen examined - Ostrobottnia kajanensis, Sotkamo, Laakajärvi, Viltonvaara, UCS 7083879:3561330, on fallen trunk of Picea abies (decay stage 2) in old-growth dry heath forest, 25 Oct 2011, leg. Pekka Helo 2133 (OULU), det. MK, conf. HK.

New to Middle boreal, Northern Carelia - Kainuu (3b).

Tremella indecorata Sommerf.

Specimen examined - Ostrobottnia ultima, Rovaniemi, Pullinranta, UCS 73801:34448, on Diatrype bullata on deciduous thicket of Salix sp., 27 May 2015, leg. \& det. TK 1744 (TUR).

New to Northern boreal, North Ostrobothnia (4b). This is the $5^{\text {th }}$ record in Finland. The previous records are from Asikkala (2a), Lempäälä (2a), Tammela (2a), and Oulu (3a) (Kotiranta et al. 2009).

Tretomyces microsporus Kotir. \& Saaren. \& K.H. Larss.

Fig. 23

Specimens examined - Ostrobottnia ouluensis, Oulu, Pikkarala, Hangaskangas, UCS 
7201508:3441746, on fallen trunk of Pinus sylvestris (diam. $5 \mathrm{~cm}$, decay stage 3) in dry heath forest, 9 Oct 2016, leg. \& det. MK 68/16 \& Tiiu Tenno (OULU), conf. HK; Ostrobottnia kajanensis, Suomussalmi, Hossa, Valkeisenkangas, UCS 7268:3610, on fallen branch of Pinus sylvestris (diam. $4 \mathrm{~cm}$, decay stage 3) in old-growth xeric heath forest with high amount of dead wood, 18 Oct 2015, leg. TH (OULU GAJ.5047), det. MK.

Northern boreal, Kuusamo district (4a). These are the $3^{\text {rd }}-4^{\text {th }}$ records in Finland. The previous records are from Paltamo (3a) and Lieksa (3b) (Kotiranta et al. 2009, Kunttu et al. 2015).

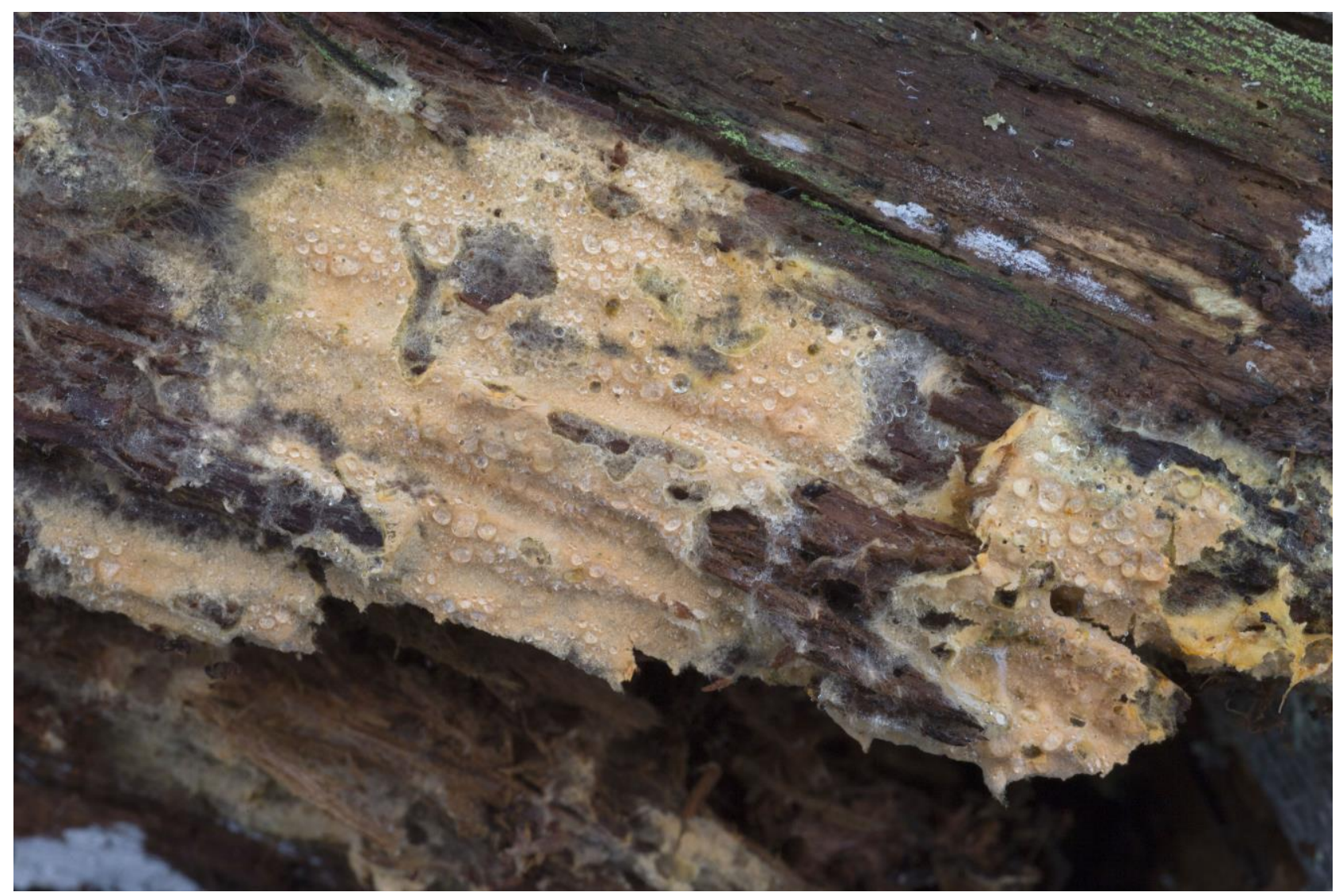

Figure 23 - Tretomyces microsporus in Suomussalmi. Photo: Teppo Helo

Tubulicrinis accedens (Bourdot \& Galzin) Donk

Specimens examined - Tavastia australis, Kuhmoinen, Isojärvi National Park, Lortikka, UCS 6845370:3394181, on log of Pinus sylvestris (diam. $15 \mathrm{~cm}$, decay stage 3) in old-growth near natural pine-dominated forest, 18 Sep 2007, leg. KJ 1831 (K.J.); Ostrobottnia kajanensis, Paltamo, Kuuskanlahti, Teerivaara, UCS 71461:35142, on charred fallen trunk of Pinus sylvestris (diam. 30 $\mathrm{cm}$, decay stage 4) with Leptosporomyces galzinii, in old-growth xeric heath forest with high amount of dead wood, 6 Oct 2016, leg. TH (OULU GAJ.5425), det. TH, conf. MK.

New to Southern boreal, Lake District (2b) and Middle boreal, Ostrobothnia (3a).

Tubulicrinis hirtellus (Bourdot \& Galzin) J. Erikss.

Specimen examined - Ostrobottnia ultima, Rovaniemi, Pisavaara Strict Nature Reserve, Teeripäri, UCS 7357857:3414538, on fallen trunk of Pinus sylvestris (diam. $25 \mathrm{~cm}$, decay stage 4) in dry and rocky heath forest, 19 Sep 2016, leg. \& det. MK 23/16 (OULU).

This is the $4^{\text {th }}$ record from Finland. The previous are from Lammi (2a), Kuhmo (3b), and Tervola (3c) (Kotiranta et al. 2009, Kunttu et al. 2016a).

Tubulicrinis sororius (Bourdot \& Galzin) Oberw.

Specimen examined - Ostrobottnia kajanensis, Kajaani, Pöllyvaara, UCS 7126:3535, on 
fallen branch of Picea abies (diam. $2 \mathrm{~cm}$, decay stage 3) in spruce-dominated mesic heath forest, 26 Sep 2017, leg. \& det. TH 20170013 (T.H., OULU), conf. MK.

New to Middle boreal, Northern Carelia - Kainuu (3b). There are several collections from the same area after this. All the findings are from the thin spruce branches that are under the big trees.

Tulasnella albida Bourdot \& Galzin

Fig. 24

Specimens examined - Tavastia australis, Kuhmoinen, Isojärvi National Park, Lortikka, UCS 68453:339418, on three Pinus sylvestris twigs (diam. 0.2-0.6 cm) in old-growth near natural pinedominated forest, 18/19 Sep 2007, leg. KJ 1839b, 1859, 1962 (K.J.); Jyväskylä, Korpilahti, Haapajoki, UCS 6874863:3446345, on Betula branch (diam. $1.8 \mathrm{~cm}$, decay stage 2) in birchdominated wood-pasture, 9 Oct 2012, leg. KJ 5926 (K.J.); Tavastia australis, Joutsa, Kivijärvi, UCS 6874653:3454712, on Betula branch (diam. 2,5 cm, decay stage 3) in birch-dominated woodpasture, 19 Oct 2012, leg. KJ 5294 (K.J.); Mänttä-Vilppula, Huhtijärvi, UCS 6886037:3366580, on Betula twig (diam. $0.7 \mathrm{~cm}$ ) in young birch-dominated afforested field, 20 Sep 2013, leg. KJ 7147 (K.J.); Luhanka, Moiskala, UCS 6854030:3430852, on Alnus incana stump (diam. 3.5 cm, decay stage 3) in birch-dominated wood-pasture, 27 Sep 2013, leg KJ 5671 (K.J.); Tavastia borealis, Jyväskylä, Ylistönrinne, UCS 6903364:3434987, on unidentified hardwood (diam. $2.5 \mathrm{~cm}$, decay stage 3) in near natural herb-rich forest, 21 Sep 2007, leg. KJ 2125 (K.J.); Toivakka, Haukanmaa, UCS 6886886:3438974, on Pinus twig (diam. $0.4 \mathrm{~cm}$ ) in old growth near natural pine-dominated forest, 25 Sep 2007, leg. KJ 2287 (K.J.); Jyväskylä, Tourujoki, UCS 6905621:3435418, on unidentified hardwood (diam. $4.5 \mathrm{~cm}$, decay stage 2) in near natural herb-rich forest, 18 Oct 2007, leg KJ 2771b (K.J.); Viitasaari, Niinilahti, Pitkämäki, UCS 6981071:3443904/6981203:3443835, on four Betula branches (diam. 1-1.3 cm) and one $\log$ (diam. $7 \mathrm{~cm}$, decay stage 2) in young birchdominated afforested field, 11/25 Oct 2012, leg. KJ 6072-74, 6105, 6235 (K.J.); Petäjävesi, Suolahti, UCS 6911151:3405740, on two Betula twigs (diam. 0.3 and $0.6 \mathrm{~cm}$ ) and five branches (diam. 1-2.5 cm) in young birch-dominated afforested field, 26 Oct 2012, leg. KJ 5518, -34b, -73, 94, 5637-38, -53a (K.J.); Ostrobottnia kajanensis, Kajaani, Suvantola, UCS 71268:35343, on Fomes fomentarius which grew on fallen trunk of Betula sp. (diam. $35 \mathrm{~cm}$, decay stage 4) in riparian thicket forest with high amount of dead wood, 4 Nov 2015, leg. TH (OULU GAJ.5457), det. MK, conf. HK.

New to Middle boreal, Northern Carelia - Kainuu (3b) These are the $6^{\text {th }}-16^{\text {th }}$ records in Finland. The previous records are from Sipoo (2a), Padasjoki (2a), Pieksänmaa (2b), Oulu (3a), Inari (4c), and Utsjoki (4d) (Kotiranta et al. 2009, Kotiranta \& Shiryaev 2013, Kunttu et al. 2015, 2016a).

Tulasnella allantospora Wakef. \& A. Pearson

Fig. 25

Specimen examined - Tavastia australis, Muurame, Muuratharju, UCS 6890515:3429763, on twig of Pinus sylvestris (diam. $0.7 \mathrm{~cm}$ ) in mature managed pine-dominated forest, 23 Aug 2007, leg. KJ 455(2)b (K.J.); Ostrobottnia kajanensis, Suomussalmi, Koisti, UCS 71777:35997, on fallen trunk of Pinus sylvestris (diam. $20 \mathrm{~cm}$, decay stage 4, kelo tree) in old pine-dominated mesic heath forests with very high amount of dead wood, 15 Sep 2017, leg. \& det. TH 20170015 (T.H., OULU).

New to Southern boreal, Lake District (2b) and Middle boreal, Northern Carelia - Kainuu (3b). These are the $4^{\text {th }}-5$ th records in Finland. The previous records are from Lohja (1b), Kirkkonummi (1b), and Porvoo (2a) (Kotiranta et al. 2009).

Tulasnella brinkmannii s.l. Bres.

Fig. 26

Specimen examined - Savonia borealis, Suonenjoki, Viippero, Ilmakkamäki, UCS 6934168:3497418, inside Steccherinum/Betula (diam. $23 \mathrm{~cm}$, decay stage 3) in managed mixed forest, 3 Jul 2016, leg. Jenna Purhonen 4018 (JYV), det. Viacheslav Spirin; Ostrobottnia kajanensis, Suomussalmi, Koisti, UCS 71777:5998, on saw top of Pinus sylvestris (diam. $35 \mathrm{~cm}$, 
decay stage 4) which has been left on the ground, in very old pine-dominated mesic heath forest with high amount of dead wood, 15 Sep 2017, leg. TH 20170002 (H, H.K.), det. HK.

New to Finland, and hence new to Southern boreal, lake district (2b) and Middle boreal, Northern Carelia - Kainuu (3b).

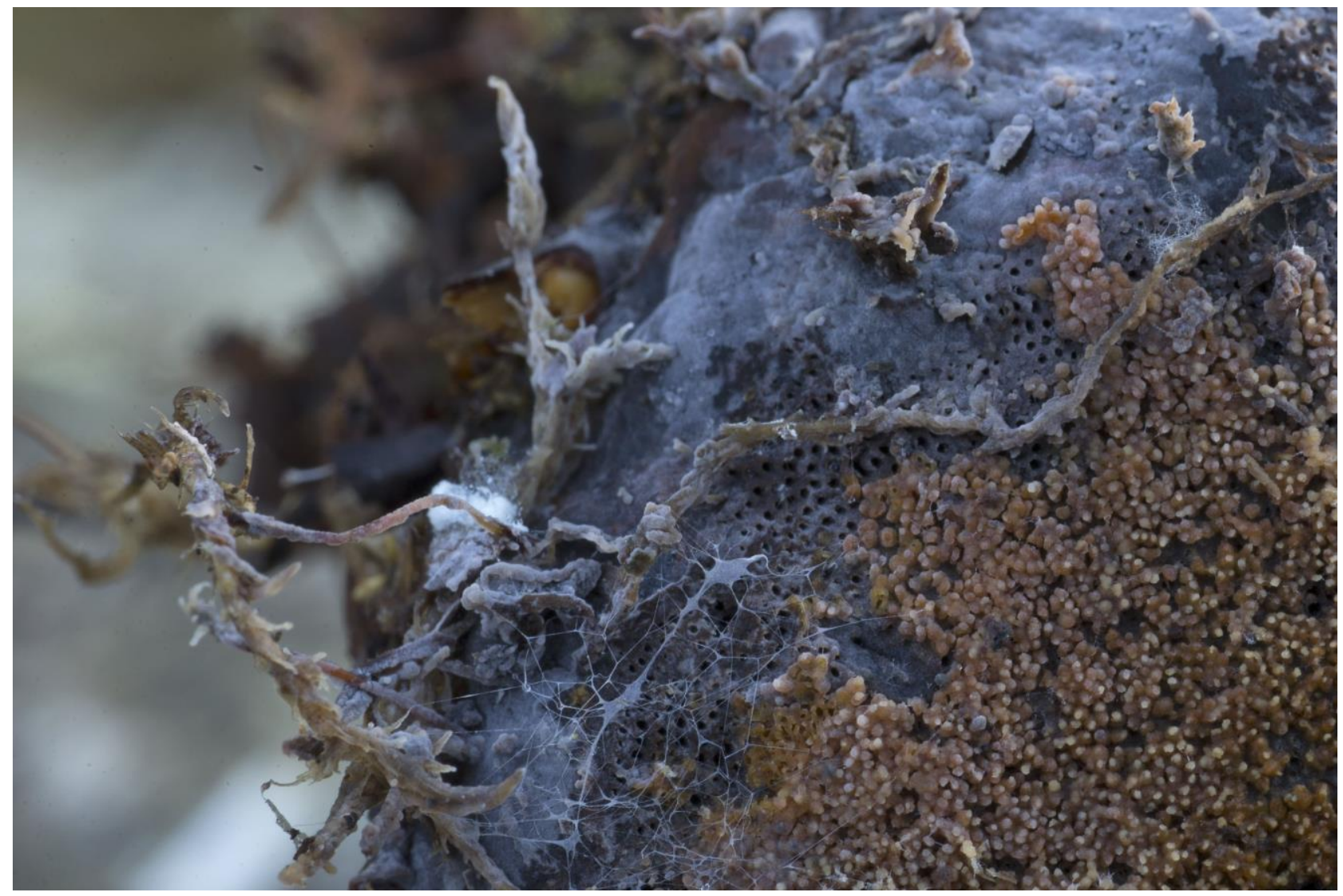

Figure 24 - Tulasnella albida in Kajaani. Photo: Teppo Helo

Tulasnella deliquescens (Juel) Juel

Fig. 27

Specimen examined - Tavastia australis, Jyväskylä, Korpilahti, Särkijärvi, UCS 6893755:3414170, on branch of Pinus sylvestris (diam. $1.3 \mathrm{~cm}$ ) in old-growth near natural spruce-dominated forest, 10 Sep 2007, leg. KJ 1569b (K.J.); Ostrobottnia kajanensis, Puolanka, Kettukallio, UCS 7185:3525, on fallen kelo branch of Pinus sylvestris (diam. 5cm, decay stage 3-4) in very old pine-dominated mesic heath forest with high amount of dead wood, 14 Oct 2017, leg. \& det. TH 20170040 (T.H., OULU); Suomussalmi, Koisti, UCS 71777:35997, on fallen top of Pinus sylvestris (diam. $12 \mathrm{~cm}$, decay stage 4 , thinning waste, kelo tree) in very old pine-dominated mesic heath forest with high amount of dead wood, 15 Sep 2017, leg. \& det. TH 20170003 (H, H.K.), conf. HK.

New to Southern boreal, Lake District (2b) and Middle boreal, Northern Carelia - Kainuu (3b). These are the $2^{\text {nd }}-4^{\text {th }}$ records in Finland. The previous record is from Helsinki (1b) (Kotiranta et al. 2009).

\section{Tulasnella eichleriana Bres.}

Specimens examined - Tavastia borealis, Äänekoski, Aatula, UCS 6938588:3439737, on fallen Juniperus communis (diam. $4.5 \mathrm{~cm}$, decay stage 1) in birch-dominated wood-pasture, 13 Sep 2013, leg. KJ 5175 (K.J.); Toivakka, Lappila, UCS 6902242:3460412, on Betula sp. branch (diam. $1.4 \mathrm{~cm}$ ) in young birch-dominated afforested field, 24 Sep 2013, leg KJ 7185 (K.J.); Ostrobottnia ultima, Rovaniemi, Pisavaara Strict Nature Reserve, UCS 7357848:3414554, on fallen trunk of Pinus sylvestris (diam. 9 cm, decay stage 3) in dry and rocky heath forest, 19 Sep 2016, leg. \& det. MK 24/16, (OULU), conf. HK. 
New to Southern boreal, Lake District (2b) and Middle boreal, Southwestern Lapland (3c).

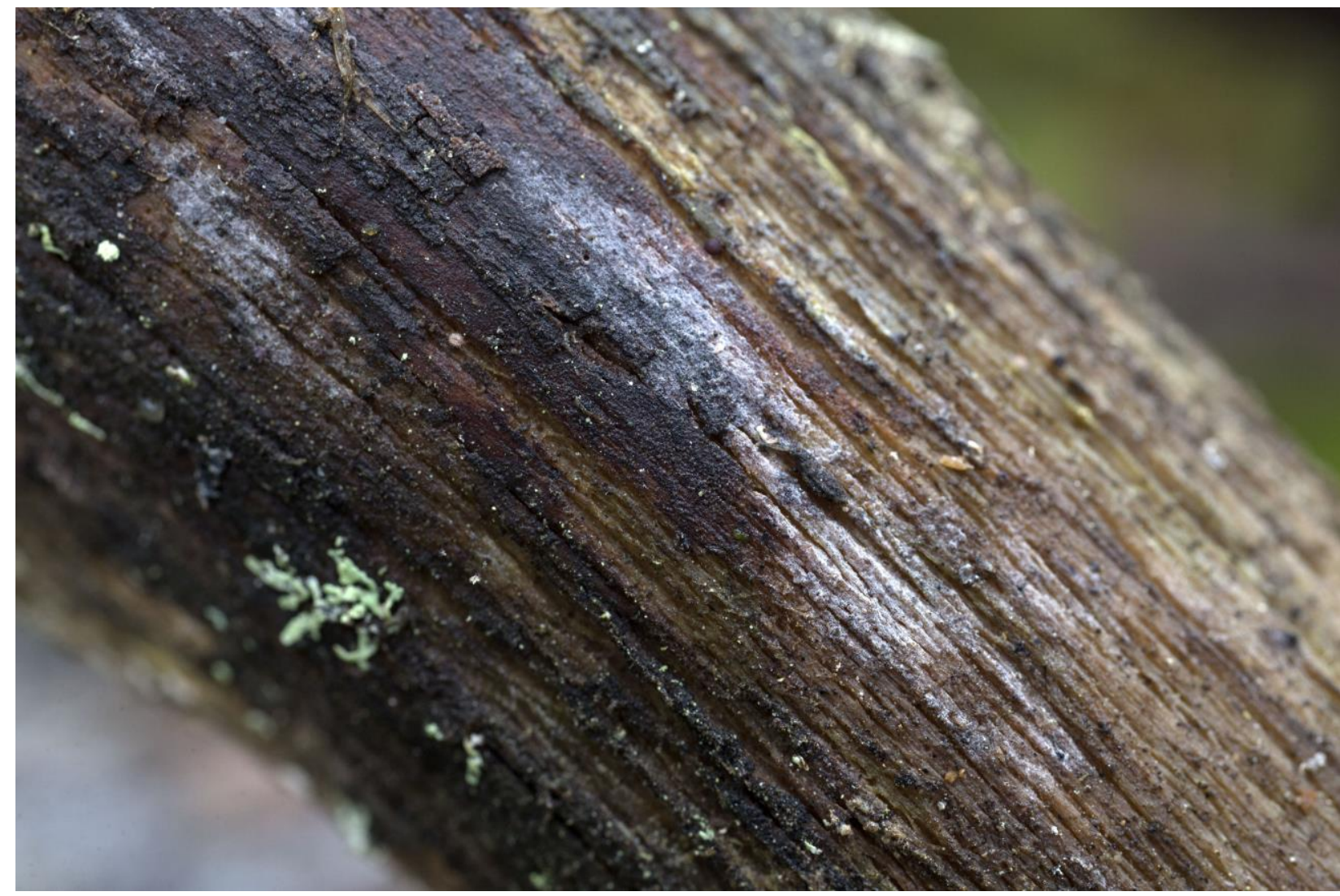

Figure 25 - Tulasnella allantospora in Suomussalmi (TH 20170015). Photo: Teppo Helo

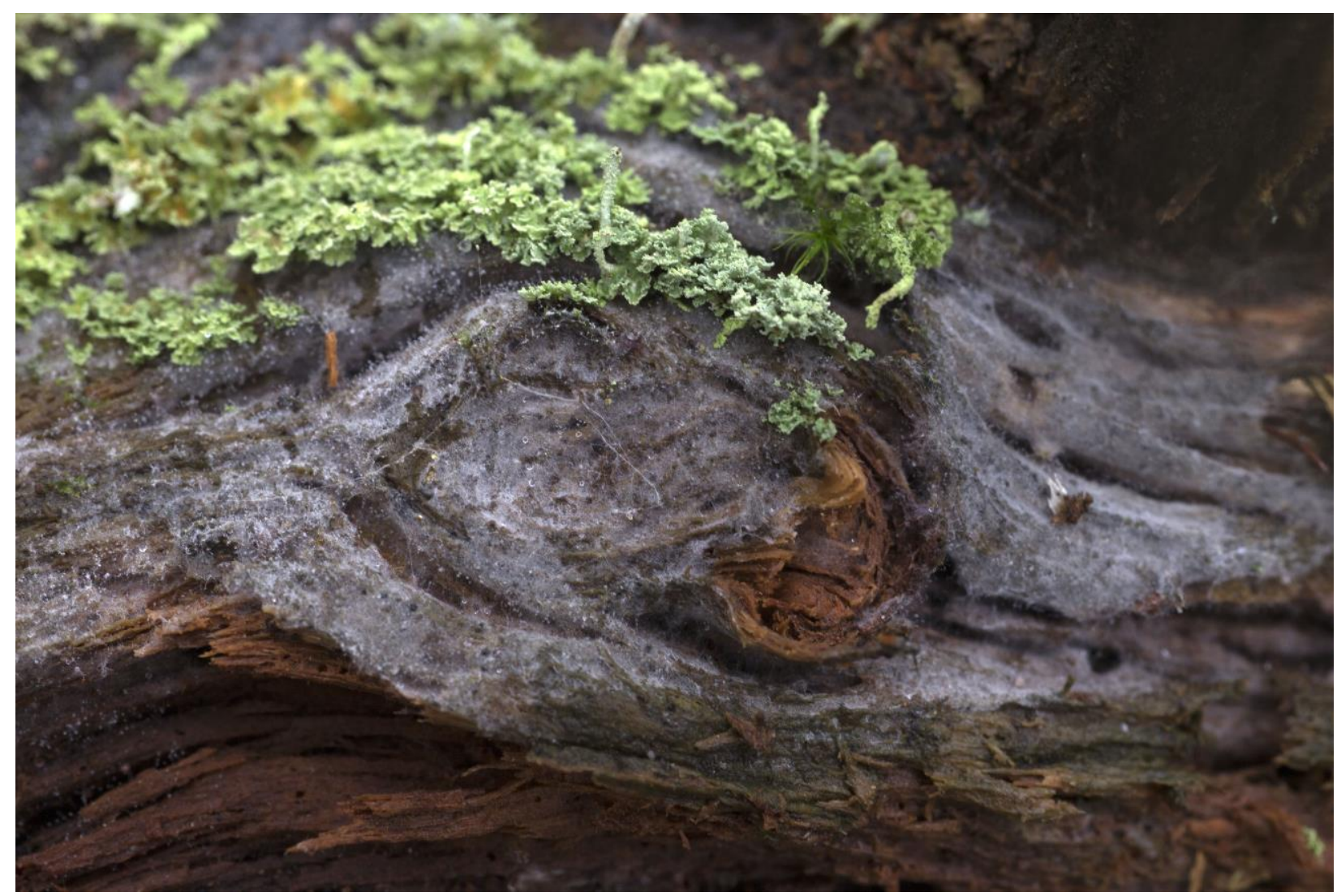

Figure 26 - Tulasnella brinkmannii s.l. in Suomussalmi (TH 20170002). Photo: Teppo Helo 




Figure 27 - Tulasnella deliquescens in Puolanka (TH 20170040). Photo: Teppo Helo

\section{Tulasnella fuscoviolacea Bres.}

Specimens examined - Tavastia australis, Jyväskylä, Korpilahti, Särkijärvi, UCS 6893806:3414262, on one Picea abies, one Pinus sylvestris and two Betula sp. twigs (diam. 0, 3-2, $2 \mathrm{~cm}$ ) in old-growth near natural spruce-dominated forest, 9 Sep 2007, leg. KJ 1524-25, KJ 1531, KJ 1540 (K.J.).

New to Southern boreal, Lake District (2b). This is the $2^{\text {nd }}$ record in Finland. The first one is from Tammela (2a) (Kotiranta et al. 2009).

Tulasnella permacra $\mathrm{P}$. Roberts

Specimen examined - Ostrobottnia kajanensis, Puolanka, Paljakka, Mustakumpu, UCS 71724:35506, on fallen trunk of Picea abies (diam. $7 \mathrm{~cm}$, decay stage 2) with Botryobasidium ellipsosporum, in old-growth spruce-dominated forest with high amount of dead wood, 13 Oct 2017, leg. \& det. TH 20170001 (H, H.K.), conf. HK.

New to Middle boreal, Northern Carelia - Kainuu (3b). This is the $3^{\text {rd }}$ record in Finland. The previous records are from Helsinki (1b) and Tammisaari (1b) (Kotiranta et al. 2009).

\section{Tulasnella thelephorea (Juel) Juel}

Specimen examined - Ostrobottnia kajanensis, Kajaani, Ilmarata, UCS 71342:35201, on fallen trunk of Alnus incana (diam. $10 \mathrm{~cm}$, decay stage 3) in riparian thicket forest with high amount of dead wood, 9 Oct 2016, leg. \& det. TH (OULU GAJ.5431), conf. MK and HK.

This is the $5^{\text {th }}$ record in Finland. The previous records are from Lohja (1b), Inkoo (1b), Lieksa (3b), and Utsjoki (4d) (Kotiranta et al. 2009).

Tulasnella tomaculum P. Roberts

Fig. 28

Specimens examined - Ostrobottnia kajanensis, Kajaani, Suvantola, UCS 71268:35342, on fallen trunk of deciduous tree (diam. $5 \mathrm{~cm}$, decay stage 4) in riparian thicket forest with high amount of dead wood, 8 Oct 2016, leg. \& det. TH (OULU GAJ.5432), conf. MK; Kajaani, Ensilä, 
UCS 71235:35343, on fallen trunk of Alnus incana (diam. $8 \mathrm{~cm}$, decay stage 3) in mesic heath forest, 21 Oct 2016, leg. \& det. TH (OULU), conf. MK; Kajaani, Kirkkoniemi, UCS 7132:3529, on fallen branch of Pinus sylvestris (diam. $5 \mathrm{~cm}$, decay stage 3) in old-growth dry heath forest, 23 Oct 2016, leg. TH (OULU), det. MK, conf. HK.

New to Middle boreal, Northern Carelia - Kainuu (3b). This seems to be quite common species in Kainuu region. The author TH has collected several specimens during autumns 2016 and 2017. These are the $6^{\text {th- }} 8^{\text {th }}$ records in Finland. The previous records are from Lemland (1a), Helsinki (1b), Padasjoki (2a), Luhanka (2b), Kuusamo (4a), and Inari (4c) (Kotiranta et al. 2009, Miettinen 2012).

Tylospora asterophora (Bonord.) Donk

Specimen examined - Ostrobottnia media, Raahe, Savolahti, Peiso, UCS 7169:3381, on fallen trunk of Picea abies (diam. $20 \mathrm{~cm}$ ), 1 Oct 2003, leg. Jari Särkkä \& Stefan Jakobsson (OULU), det. MK.

New to Middle boreal, Ostrobothnia (3a).

\section{Vuilleminia erastii Ghob.-Nejh.}

Specimen examined - Tavastia australis, Jyväskylä, Korpilahti, Haapajoki, UCS 6874897:3446231, on Betula branch (diam. $1 \mathrm{~cm}$ ) in birch-dominated wood-pasture, 1 Oct 2012, leg. KJ 5778 (K.J.).

This is the $3^{\text {rd }}$ record in Finland. The previous ones are from Kangaslampi (2b) and Sodankylä (4b) (Kunttu et al. 2012).

Xenasma pruinosum (Pat.) Donk

Fig. 29

Specimens examined - Tavastia autralis, Jyväskylä, Korpilahti, Oittila, UCS 6870823:3433880, on unidentified hardwood branch (diam. $1.6 \mathrm{~cm}$ ) in near natural herb-rich forest, 24 Aug 2007, leg. KJ 490 (K.J.); two more collections from the same site as the first Finnish record (Kotiranta et al. 2009): Luhanka, Onkisalo Island, Molikko, UCS 6850044:3431528, on downed Betula (diam. 5 $\mathrm{cm}$, decay stage 3) and on two unidentified hardwood branches (diam. 1, 2 and 1, $3 \mathrm{~cm}$ ) in near natural herb-rich forest, 24 Sep 2007, leg. KJ 2180-81 (K.J.); Ostrobottnia kajanensis, Kajaani, Suvantola, UCS 7126900:3534333, on dead branch of Sorbus aucuparia (diam. $4 \mathrm{~cm}$, decay stage 1) in riparian thicket forest with high amount of dead wood, 26 Oct 2015, leg. Pekka Helo 3055 \& TH (H, H.K.), det TH, conf. HK, and in the same place on fallen dead branch of deciduous tree (diam. 4 cm, decay stage 3), 11 Oct 2016, leg. \& det. TH (OULU GAJ.5430), conf. MK.

New to Middle boreal, Northern Carelia - Kainuu (3b). These are the $2^{\text {nd }}-3^{\text {rd }}$ records in Finland. The previous record is from Luhanka (2b) (Kotiranta et al. 2009).

Xenasmatella borealis (K.H. Larss. \& Hjortstam) Duhem (syn. Phlebiella borealis)

Fig. 30

Specimens examined - Tavastia australis, Kuhmoinen, Isojärvi National Park, Lortikka, UCS 6845322:3394215, on twigs of Betula sp. and Pinus sylvestris (diam. 0.4-1 cm) in near natural oldgrowth pine-dominated forest, 19 Sep 2007, leg. KJ 1956, KJ 1931 (K.J.); Tavastia borealis, Petäjävesi, Suolahti, UCS 6911023:3405715, on Betula branch (diam. $1.3 \mathrm{~cm}$ ) in young birchdominated afforested field, 21 Sep 2012, leg. KJ 5340 (K.J.); Ostrobottnia kajanensis, Kajaani, Paltaniemi, Kirkkoniemi, UCS 71323:35299, on fallen dead branch of Pinus sylvestris (diam. $5 \mathrm{~cm}$, decay stage 4 , kelo tree) and on fallen top of Pinus sylvestris (diam. $9 \mathrm{~cm}$, decay stage 3 , kelo tree) in old cemetery with pine-dominated xeric heath forests, 23 Oct 2016, leg. TH (OULU GAJ.5460, GAJ.5462), det. TH, conf. MK and HK.

New to Southern boreal, Lake District $(2 \mathrm{~b})$. These are the $4^{\text {th }}-7$ th records in Finland. The previous records are from Helsinki (1b), Lieksa (3b), and Salla (4c) (Kotiranta et al. 2009). 


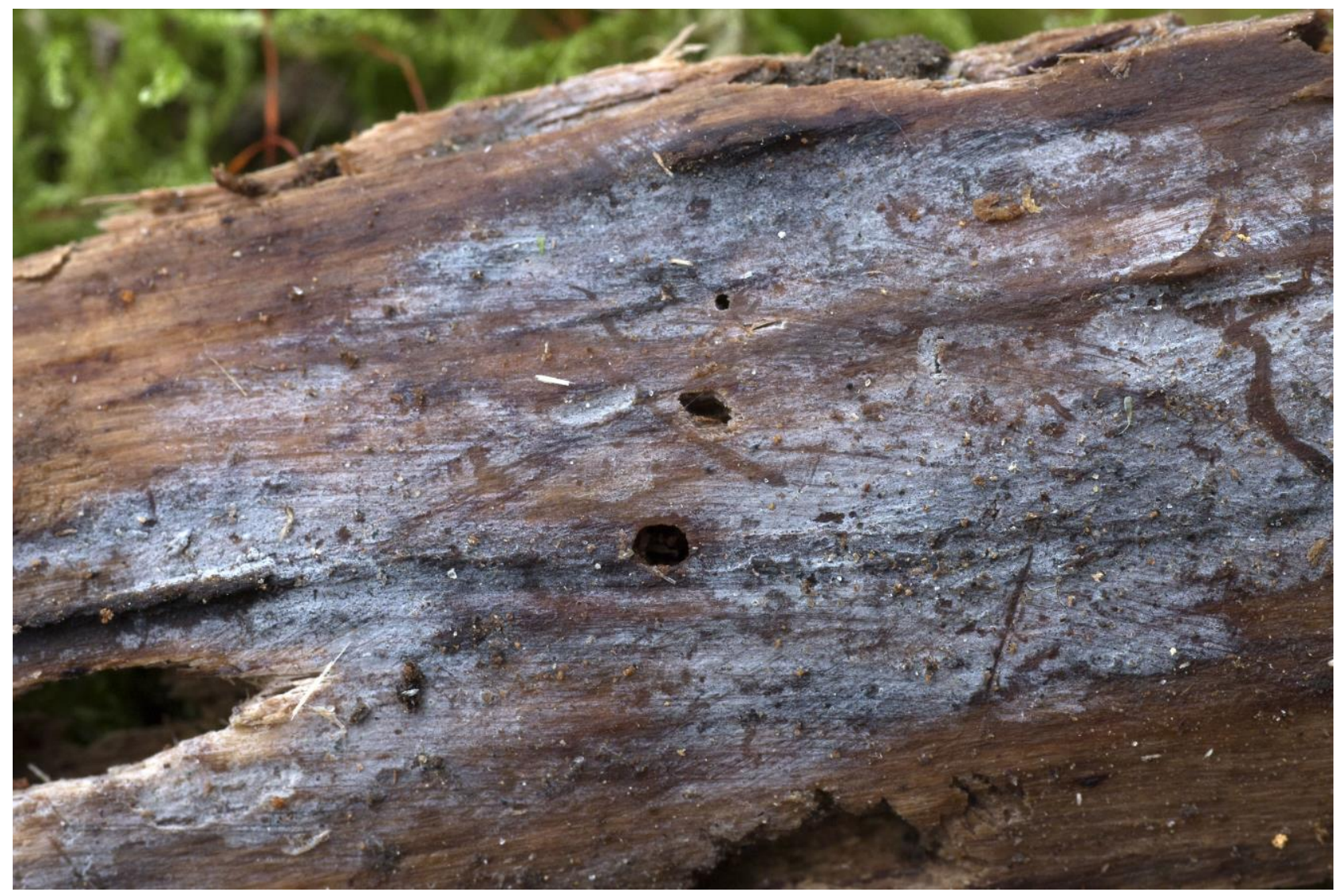

Figure 28 - Tulasnella tomaculum in Kajaani. Photo: Teppo Helo

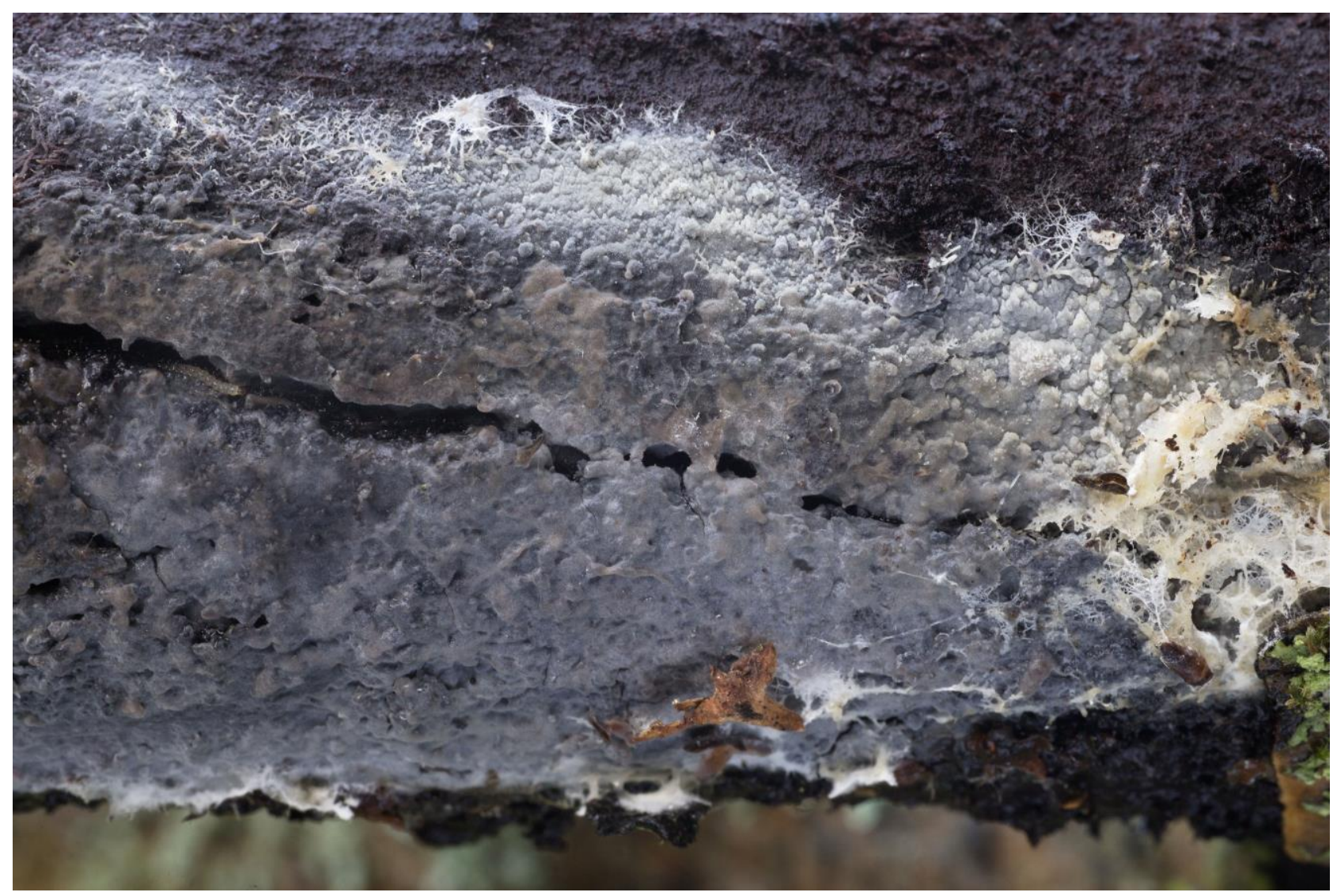

Figure 29 - Xenasma pruinosum in Kajaani. Photo: Teppo Helo 


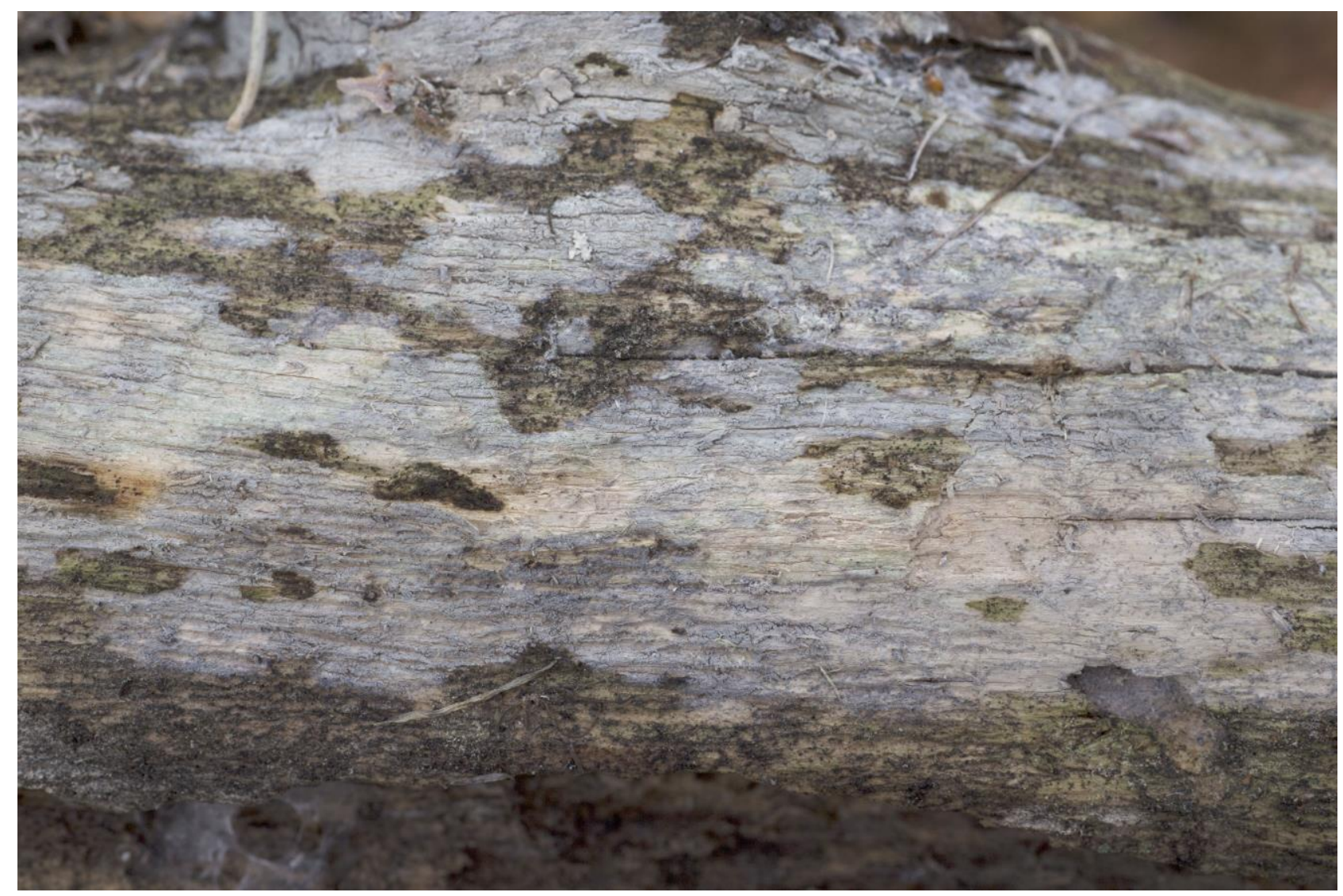

Figure 30 - Xenasmatella borealis in Kajaani. Photo: Teppo Helo

Xenasmatella insperata (H.S. Jacks.) Jülich (syn. Phlebiella insperata)

Fig. 31

Specimens examined - Tavastia borealis, Jyväskylä, Ylistönrinne, UCS 6903388:3434987, on fallen Alnus incana (diam. $3 \mathrm{~cm}$, decay stage 2) in near natural herb-rich forest, 26 Sep 2007, leg. KJ 2326 (K.J.); Ostrobottnia kajanensis, Kajaani, Ensilä, Maitoniemi, UCS 71264:35344, on dead trunk of Alnus incana (diam. $2 \mathrm{~cm}$, decay stage 3) in deciduous riverside thicket forest with high amount of dead wood, 17 Oct 2017, leg. \& det. TH 20170034 (T.H., OULU), conf. MK, HK.

New to Southern boreal, Lake District (2b) and Middle boreal, Northern Carelia - Kainuu (3b). These are the $2^{\text {nd }}-3^{\text {rd }}$ records in Finland. The first record is from Tuusula (2a) (Kotiranta et al. 2009). Endangered.

Xenasmatella tulasnelloidea (Höhn. \& Litsch.) Oberw. ex. Jülich (syn. Phlebiella tulasnelloidea)

Specimens examined - Tavastia borealis, Jyväskylä, Tourujoki, UCS 6905621:3435418, on two fallen Alnus incana (diam. $3 / 3.5 \mathrm{~cm}$, decay stage 2 both) and one unidentified hardwood (diam. $2 \mathrm{~cm}$, decay stage 3) in near natural herb-rich forest, 25 Oct 2007, leg. KJ 2944, -48, -64 (K.J.); Ostrobottnia kajanensis, Kajaani, Suvantola, UCS 7126:3534, on fallen trunk of Salix caprea (diam. 5 cm, decay stage 3), 4 Nov 2015, leg. \& det. TH (OULU), conf. MK; Kajaani, Suvantola, UCS 71269:35343, on dead branch of deciduous tree (diam. $7 \mathrm{~cm}$, decay stage 3) in riparian thicket forest with high amount of dead wood, 8 Oct 2016, leg. \& det. TH (OULU GAJ.5424), conf. MK;

New to Southern boreal, Lake District (2b) and Middle boreal, Northern Carelia - Kainuu (3b). This seems to be quite a common species in the thicket forests of the Kajaani area. The author TH has collected several specimens during autumns 2016 and 2017. 


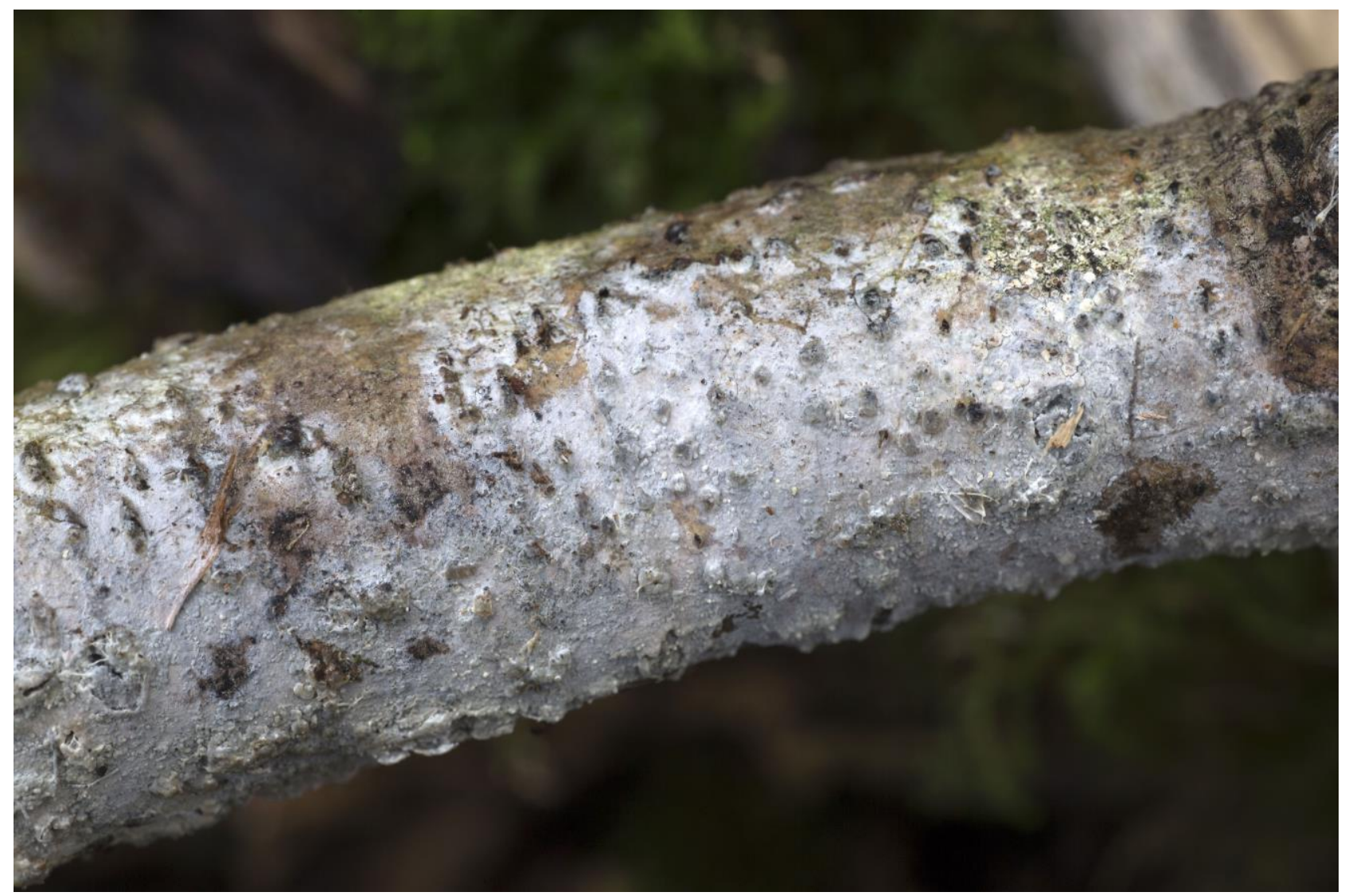

Figure 31 - Xenasmatella insperata in Kajaani (TH 20170034). Photo: Teppo Helo

\section{Discussion}

\section{Species new to Finland}

We report here six species new to Finland. The most surprising species is Osteina obducta, which has not been found before from Northern Europe. Osteina obducta has a wide distribution in Central Europe mostly on dead gymnosperm, especially on Larix (Ryvarden \& Gilbertson 1994). It is common on Pseudotsuga menziesii in North America (Gilbertson \& Ryvarden 1987) and relatively common in natural forests of China, mainly in old-growth forests of Larix, sometimes also on e.g. Picea and Pinus, but rarely on angiosperm wood (Dai 2012). The fungus has been reported also on Tsuga in Japan (Aoshima \& Furukawa 1963) and on Larix in Siberia (e.g. Kotiranta \& Shiryaev 2016, Kotiranta et al. 2016) and Russian Far East (Lyubarsky \& Vasilyeva 1975). The fungus mostly grows on roots or decayed buried wood (Cui et al. 2014).

Cristinia rhenana was described from Germany (Hjortstam \& Grosse-Brauckmann 1993), and after that it has been reported from France, Italy, the Netherlands and United Kingdom (Bernicchia \& Gorjón 2010). Our specimen does not fit exactly with the protologue and therefore we are not fully convinced of its identity. In outer appearance, it fits well with the description, and turns violet in $\mathrm{KOH}$. The monomitic hyphal system consists mostly of clamped hyphae, and many hyphae in subiculum lack clamps. Also the basidia fit to the concept of $C$. rhenana, even if some of them are very long (even over $50 \mu \mathrm{m}$ ). The differences are in the shape and size of spores. Our specimen has broadly ellipsoid to subglobose spores, and the shape is somewhere between $C$. eichleri (Bres.) Nakasone and $C$. helvetica (Pers.) Parm. The thick-walled spores are cyanophilous, (4.2-)4.6-6(-6.8) X 3.7-4.4(-4.8) $\mu \mathrm{m}, \mathrm{L}=5.1 \mu \mathrm{m}, \mathrm{W}=4.2 \mu \mathrm{m}, \mathrm{Q}=1.2(\mathrm{n}=30)$, sometimes with a prominent apiculus. According to Grosse-Brauckmann (Hjortstam \& Grosse-Brauckmann 1993) the spores are globose to ovoid, $(4-) 5-6.5(-7) \mu \mathrm{m}$, thus differing somewhat in size and shape of our specimen. 
The basidiomes of Hyphodontiella hauerslevii are very tiny, but it is still surprising that the first Finnish specimens were not collected before the year 2007. The two hitherto identified specimens grew on small twigs and were collected in a large ecological study (Juutilainen et al. 2016). Hyphodontiella hauerslevii is widely distributed in Europe (Bernicchia \& Gorjón 2010), and probably not very rare, but easily overlooked.

Leptosporomyces montanus is a poorly known species and we have not seen any reference specimens of it. However, the description of Jülich (1972; as Confertobasidium olivaceo-album var. montanum Jülich var. nova) fits fairly well with our specimens, which all grew on small twigs. According to Jülich (1972), Bernicchia \& Górjon (2010) L. montanus has been collected from France, the Netherlands, Russia and United States.

Sebacina helvelloides, like three previous species above, was found in an extensive ecological study where even the smallest woody particles were studied (Juutilainen et al. 2016). These small twigs are often overlooked by the corticologists and therefore it is not very surprising that this is the first record from Finland. Sebacina helvelloides seems, however, to be rarely collected also elsewhere, but it has been reported at least from Denmark, Russia, North America and India (Burt 1915, Wojewoda 1977).

Tulasnella brinkmannii, like other Tulasnellas, is often invisible or almost invisible to the naked eye. The first Finnish collection grew inside Steccherinum sp., but the second was visible. The Finnish finds are probably new to the Nordic countries (Jülich 1984, Roberts \& Hauerslev 1997, The Norwegian Mycological Database (NMD) 27 Jan 2017, Herbarium Catalogue (S) 25 Jan 2018). According Roberts (1994) T. brinkmannii has been collected from Germany (holotype), Switzerland and United Kingdom, where it appears to be uncommon. There are some differences in the shape of spores between the collections, but because of the small number of specimens, Roberts (1994) was not sure if the variation is intraspecific, or if they represent some other taxon. The collection J. Purhonen 4018 is relatively poor, but the other one ( $T H$ 20170002) is in good condition and shows spores similar to those of in Roberts 400 (see Roberts 1994, p. 1239).

\section{Significant extensions of known distribution}

Many of the regionally new records derived far away from their previously known localities. This is largely explained by the fact that little studied areas, habitats and substrates were now surveyed. For example, the author KJ studied fine and very fine woody debris in Central Finland, the author TH studied overlooked habitats, like thickets, in Kainuu region, the author PK studied driftwood logs on the shores of the Baltic Sea, and the author TK studied calcareous slopes in Northern Finland.

Hyphoderma incrustatum was found now from three localities (2b) in Central Finland, but the first Finnish record is from Inari (4c) in Northern Finland. The distance is roughly $700 \mathrm{~km}$. Colacogloea peniophorae was found now from Jyväskylä (2b), Oulu (3a), and Kajaani (3b), but all previous records are from the southwestern archipelago or the south coast subzones $1 \mathrm{a}$ and $1 \mathrm{~b}$ (Kotiranta et al. 2009, Kunttu et al. 2009, 2012, 2015, 2016a, Miettinen 2012).

The following species with small or inconspicuous basidioma were found now 200-400 km north from their previous known localities: Basidiodendron radians, Botryobasidium ellipsosporum, Colacogloea peniophorae, Oliveonia fibrillosa, Trechispora stellulata, Tulasnella

allantospora, Tulasnella deliquescens, Tulasnella permacra, Xenasmatella insperata, and Xenasmatella tulasnelloidea. Furthermore, the known distribution extended 200-400 km north for these commonly overlooked species with rather easily detectable basidioma: Clavaria amoenoides, Clavaria incarnata, Helicogloea farinacea, Hyphoderma roseocremeum, Phlebia deflectens, Suillosporium cystidiatum, and Xenasma pruinosum

Autumn 2016 was a good year for mycorrhizal fungi in Northern Finland, which showed as many collections of e.g. rare Cortinarius-species. This relates also to mycorrhizal polypores and hydnaceous fungi. The new record of Boletopsis leucomelaena was $300 \mathrm{~km}$, Sarcodon lundellii 400 $\mathrm{km}$ and Hydnellum auratile $700 \mathrm{~km}$ north of the old ones. The habitats were south facing calcareous rocky or sandy slopes near big rivers, which make circumstances ideal for thermophilic 
or southern species. The habitats in Kolari and Pelkosenniemi have been quite frequently visited by mycologists, so it seems evident that these species produce basidiomata very seldom in North Finland.

One obvious explanation of the "expansion" of southern species to the north is increasing collecting activity in Northern and Eastern Finland. However, we cannot fully exclude the possibility that the climate change has also affected this phenomenon.

\section{Little collected species, but probably not so rare as thought}

Craterocolla cerasi has been collected from Finland only a few times, and mainly from Betula. Earlier collections on Picea abies are by P. Karsten in 1866 (as C. insignis, www.laji.fi). These names are probably synonyms as $C$. cerasi grows also on P. abies (Oberwinkler et al. 2014). From Middle and Northern parts of Sweden there are quite many observations with the names $C$. cerasi from deciduous trees and $C$. insignis from coniferous trees (www.artportalen.se). C. cerasi is probably merely overlooked but not truly rare species in Finland.

Hyphoderma crassescens was reported by Bernicchia \& Górjon (2010) from Finland, Norway, Sweden, Italy and Russia (see also Shiryaev \& Kotiranta 2015, p. 47). In Finland there are tens of collections, and most of them grew on burned or charred pines in primeval forests. $H$. crassescens can locally be very common in burned boreal forests, but it is apparently rare in southern parts of Europe and in managed forests.

According to our records presented here and some so far unpublished findings we suspect that the following species, which have been considered as nationally rare, are not so rare in reality. They have been rarely collected, because their basidiomata are small and inconspicuous, and they are difficult to find or identify: Colacogloea peniophorae, Oliveonia fibrillosa, Sistotrema autumnale, Sistotrema diademiferum, Tomentella coerulea, and Tulasnella tomaculum.

Additionally, the following species new to Kainuu region (3b) are not so rare as previously thought, because their habitats and substrates have been neglected and, therefore, the collecting activity has been low: Basidiodendron eyrei, Galzinia incrustans, Sistotremastrum niveocremeum, Thanatephorus fusisporus, and Xenasmatella tulasnelloidea.

The distribution of many groups of aphyllophoroid fungi, like corticioids, clavarioids and tremelloids, is still inadequately known in many regions in Finland, especially in Northern and Eastern Finland. It is obvious that dozens of species - found now elsewhere in Finland - can still be found in these areas. Therefore, the little collected species' range may be less fragmented than what is now displayed in the distribution maps (Kotiranta et al. 2009). Furthermore, the fungal communities occupying the smallest fractions of woody debris seems to be poorly known. Species inhabiting this substrate have commonly been overlooked due to their minuscule size and the need of a huge amount of work both in the field and in the laboratory (Juutilainen et al. 2011, 2014, 2016). In order to establish which species are truly rare, more effort should be allocated into inventories. Of course, a certain portion of aphyllophoroid fungal species are truly rare or geographically restricted, for example because of their specialisation in a certain habitat type or substrate.

\section{Acknowledgements}

We are grateful to following persons who provided photographs, made collections, identified specimens or helped in fieldwork: Saija Ahonen, Pekka Halonen, Pekka Helo, Karoliina Huusko, Stefan Jakobsson, Jari Julkunen, Kaisa Junninen, Lassi Kalleinen, Sanna-Mari Kunttu, Hilkka Lahti, Mauri Lahti, Maritta Laukkanen, Tuomo Niemelä, Esteri Ohenoja, Päivi Paalamo, AnnaLiisa Ruotsalainen, Viacheslav Spirin, Jari Särkkä, Unto Söderholm, Tiiu Tenno, and Iita Tiusanen.

\section{References}

Anonymous 2014 - Eliömaakunnat [Biogeographical provinces of Finland]. Finnish Museum of Natural History. http://www.luomus.fi/fi/eliomaakunnat. (Accessed 6 Jan 2018) 
Aoshima K, Furukawa H. 1963 - A note on Grifola obducta (Berk.) Aoshima et Furukawa, comb. nov. Transactions of the Mycological Society of Japan 4, 91-93.

Bernicchia A, Gorjón SP. 2010 - Corticiaceae s. 1. Fungi Europaei. Vol. 12, Edizioni Candusso, Alassio. $1008 \mathrm{p}$.

Boddy L, Frankland JC, van West P. 2008 - Ecology of saprotrophic basidiomycetes. Elsevier Academic Press, London. 386 p.

Burt EA. 1915 -The Thelephoraceae of North America. V. Tremellodendron, Eichleriella, and Sebacina. Annals of the Missouri Botanical Garden 2(4), 731-770. http://www.jstor.org/stable/2989955

Cui BK, Vlasák J, Dai YC. 2014 - The phylogenetic position of Osteina obducta (Polyporales, Basidiomycota) based on samples from Northern Hemisphere. Chiang Mai Journal of Science. 41 (4), 838-845.

Dai YC. 2012 - Polypore diversity in China with an annotated checklist of Chinese polypores. Mycoscience 53, 49-80. DOI: 10.1007/s10267-011-0134-3

Dudka IO, Romanenko KO. 2006 - Co-existence and interaction between myxomycetes and other organisms in shared niches. Acta Mycologica 41, 99-112.

Gilbertson RL, Ryvarden L. 1987 - North American polypores 2. Megasporoporia - Wrightoporia. Fungiflora, Oslo.

Hansen L, Knudsen H. 1997 - Nordic macromycetes 3, 1-444.

Heikinheimo O, Raatikainen M. 1981 - Grid references and names of localities in the recording of biological finds in Finland. Notulae Entomologicae 61, 133-154. (In Finnish with English summary)

Hibbett DS, Bauer R, Binder M, Giachini AJ et al. 2014 - 14 Agaricomycetes. In: Systematics and Evolution, 2nd Edition. Springer-Verlag, Berlin Heidelberg. Pp. 373-429.

Hjortstam K, Grosse-Brauckmann H. 1993 - Two new species of Cristinia (Basidiomycotina, Aphyllophorales) and a survey of the genus. Mycotaxon 47, 405-410.

Hjortstam K, Ryvarden L. 2009. - A checklist of names in Hyphodontia sensu stricto - sensu lato and Schizopora with new combinations in Lagarobasidium, Lyomyces, Kneiffiella, Schizopora and Xylodon. Synopsis Fungorum 26, 33-55.

Jonsell M, Nordlander G, Ehnström B. 2001 - Substrate preferences of insects breeding in wood decaying fungi. Ecological Bulletins 49, 173-194.

Jülich W. 1972 - Monographie der Athelieae (Corticiaceae, Basidiomycetes). Willdenowia 7 (Beiheft), 1-283.

Jülich W. 1984 - Kleine Kryptogamenflora. Die Nichtblätterpilze, Gallertpilze und Bauchpilze. Gustav Fischer Verlag, Stuttgart, New York. 626 p.

Juutilainen K. 2016 - Ecology, environmental requirements and conservation of corticioid fungi occupying small diameter dead wood. Jyväskylä Studies in Biological and Environmental Science 313, 1-55.

Juutilainen K, Halme P, Kotiranta H, Mönkkönen M. 2011 - Size matters in studies of dead wood and wood-inhabiting fungi. Fungal Ecology 4: 342-349. DOI: 10.1016/j.funeco.2011.05.004.

Juutilainen K, Mönkkönen M, Kotiranta H, Halme P. 2014 - The effects of forest management on wood-inhabiting fungi occupying dead wood of different diameter fractions. Forest Ecology and Management 313, 283-291. DOI: 10.1016/j.foreco.2013.11.019

Juutilainen K, Mönkkönen M, Kotiranta H, Halme P. 2016 -The role of novel forest ecosystems in the conservation of wood-inhabiting fungi in boreal broadleaved forests. Ecology and Evolution 6, 6943-6954. DOI: 10.1002/ece3.2384

Kotiranta H, Junninen K, Saarenoksa R, Kinnunen J, Kytövuori I. 2010 - Aphyllophorales \& Heterobasidiomycetes. - In: Rassi P, Hyvärinen E, Juslén A, Mannerkoski I. (eds.), The 2010 Red List of Finnish Species. Ministry of the Environment \& Finnish Environment Institute, Helsinki. Pp. 249-263.

Kotiranta H., Niemelä T. 1996 - Threatened polypores in Finland. 2nd revised edition. Finnish Environment Institute \& Edita, Helsinki. 184 p. (in Finnish with English summary) 
Kotiranta H, Saarenoksa R, Kytövuori I. 2009 - Aphyllophoroid fungi of Finland. A check-list with ecology, distribution, and threat categories. Norrlinia 19, 1-223.

Kotiranta H, Shiryaev A. 2013 - Notes on aphyllophoroid fungi (Basidiomycota) in Kevo, collected in 2009. Kevo Notes 14, 1-22.

Kotiranta H, Shiryaev A. 2016. - Aphyllophoroid fungi (Basidiomycota) in Tunguska River basin, central East Siberia, Russia. Karstenia 55, 25-42.

Kotiranta H, Shiryaev A, Spirin V. 2016. - Aphyllophoroid fungi (Basidiomycota) of Tuva Republic, southern Siberia, Russia. Folia Cryptogamica Estonica 53, 51-64.

Knudsen H, Vesterholt J. (eds.) 2008 - Funga Nordica. Agaricoid, boletoid and cyphelloid genera. Nordsvamp, Copenhagen.

Kunttu P. 2016 - Dead-wood-associated aphyllophoroid fungi: perspectives on the diversity, ecology and conservation biology of species and their habitats. Dissertationes Forestales 225. 66 p. DOI: $10.14214 /$ df.225

Kunttu P, Kosonen T, Kulju M, Kotiranta H. 2009 - Phlebia cremeoalutacea new to Finland and new records of rare corticioid fungi (Basidiomycota). Karstenia 49, 69-71.

Kunttu P, Kulju M, Kekki T, Pennanen J et al. 2016a - Extensions of known geographic distribution of aphyllophoroid fungi (Basidiomycota) in Finland. Mycosphere 7(3), 333-357. DOI: $10.5943 /$ mycosphere/7/3/7

Kunttu P, Kulju M, Kotiranta H. 2016b - Athelia singularis and Leptosporomyces mundus (Basidiomycota) new to Finland. Mycobiota 6, 29-37. DOI:10.12664/mycobiota.2016.06.03

Kunttu P, Kulju M, Kotiranta H. 2012 - New national and regional biological records for Finland 2. Contributions to the Finnish aphyllophoroid funga (Basidiomycota). Memoranda Societas Fauna Flora Fennica, 88, 61-66.

Kunttu P, Kulju M, Kotiranta H. 2015. - Contributions to the Finnish aphyllophoroid funga (Basidiomycota): new and rare species. Czech Mycology 67, 137-156.

Kunttu P, Kulju M, Pennanen J, Kotiranta H, Halme P. 2011 - Additions to the Finnish aphyllophoroid fungi. Folia Cryptogamica Estonica 48, 25-30.

Kunttu P, Pennanen J, Helo T, Kulju M, Söderholm U. 2013 - New national and regional biological records for Finland 4. Additions to the knowledge of Finnish aphyllophoroid funga (Basidiomycota). Memoranda Societas Fauna Flora Fennica 89, 119-124.

Kunttu P, Pennanen J, Kulju M, Kekki T, Suominen M. 2014 - Noteworthy records of aphyllophoroid fungi in Finland (Basidiomycota). Acta Mycologica 49, 221-235. DOI: 10.5586/am.2014.017.

Leikola M. 1969 - On the termination of diameter growth of Scots pine in old age in northernmost Finnish Lapland. Silva Fennica 3, 50-61. (In Finnish with English summary)

Luonnontieteellinen keskusmuseo 2018 - Finnish herbaria's collection management system Kotka. Accessed at https://wiki.helsinki.fi/display/digit/Manual+for+Kotka (accessed 21 Jan 2018)

Lyubarsky LV, Vasilyeva LN. 1975 - Derevorazrushayushchie griby Dal'nego Vostoka, Nauka, Novosibirsk.

Miettinen O. 2012 - The Corticiaceae survey of the forests in Veräjämäki, Patola and Tali 2011. Publications by City of Helsinki Environment Centre 6/2012. 24 p. (in Finnish) https://www.hel.fi/static/ymk/julkaisut/julkaisu-06-12.pdf

Niemelä T. 2016. - The polypores of Finland. Norrlinia 31, 1-430. (In Finnish with English summary)

Niemelä T, Wallenius T, Kotiranta H. 2002 - The kelo tree, a vanishing substrate of specified wood-inhabiting fungi. Polish Botanical Journal 47, 91-101

Nitare J. 2000 - Indicator species for assesing the nature conservation value of woodland sites - a flora of selected cryptogams. Skogstyrelsens förlag, Karlshamn. (In Swedish with English summary)

Oberwinkler F, Riess K, Bauer R, Garnica S. 2014 - Morphology and molecules: the Sebacinales, a case study. Mycological Progress 13, 445-470. 
Rassi P, Hyvärinen E, Juslén A, Mannerkoski I. (eds.) 2010 - The 2010 Red List of Finnish Species. Ministry of the Environment \& Finnish Environment Institute, Helsinki. 685 p.

Renvall P. 1995 - Community structure and dynamics of wood-rotting Basidiomycetes on decomposing conifer trunks in Northern Finland. Karstenia 35, 1-51.

Roberts P. 1994 - Long-spored Tulasnella species from Devon, with additional notes on allantoidspored species. Mycological Research 98, 1235-1244.

Roberts P, Hauerslev K. 1997 - Tulasnellales. - In: Hansen L, Knudsen H. Nordic Macromycetes $3,1-444$.

Ryvarden L, Gilbertson RL. 1994 - European polypores 2, Synopsis Fungorum 7, 394-743.

Schigel DS. 2009 - Polypore assemblages in boreal old-growth forests, and associated Coleoptera. Academic dissertation. Publications in Botany from the University of Helsinki, $44 \mathrm{p}$.

Shiryaev A, Kotiranta H. 2015 - Aphyllophoroid fungi (Basidiomycota) of the middle part of Yenisei River basin, East Siberia, Russia. Karstenia 55, 43-59.

Stokland J, Sippola AL. 2004 - Monitoring protocol for wood-inhabiting fungi in the Alberta Biodiversity Monitoring Program. Alberta Biodiversity Monitoring Program. 58 p.

Wojewoda W. 1977 - Flora Polska. Grzyby (Mycota) VIII. Polska Akademia Nauk, Warszawa \& Krakơw. 332 p. 